\title{
Cardiac Aging: From Molecular Mechanisms to Significance in Human Health and Disease
}

\author{
Dao-Fu Dai, ${ }^{1}$ Tony Chen, Simon C. Johnson,, Hazel Szeto, ${ }^{1}$ and Peter S. Rabinovitch ${ }^{1}$
}

\section{Abstract}

Cardiovascular diseases (CVDs) are the major causes of death in the western world. The incidence of cardiovascular disease as well as the rate of cardiovascular mortality and morbidity increase exponentially in the elderly population, suggesting that age per se is a major risk factor of CVDs. The physiologic changes of human cardiac aging mainly include left ventricular hypertrophy, diastolic dysfunction, valvular degeneration, increased cardiac fibrosis, increased prevalence of atrial fibrillation, and decreased maximal exercise capacity. Many of these changes are closely recapitulated in animal models commonly used in an aging study, including rodents, flies, and monkeys. The application of genetically modified aged mice has provided direct evidence of several critical molecular mechanisms involved in cardiac aging, such as mitochondrial oxidative stress, insulin/ insulin-like growth factor/PI3K pathway, adrenergic and renin angiotensin II signaling, and nutrient signaling pathways. This article also reviews the central role of mitochondrial oxidative stress in CVDs and the plausible mechanisms underlying the progression toward heart failure in the susceptible aging hearts. Finally, the understanding of the molecular mechanisms of cardiac aging may support the potential clinical application of several "anti-aging" strategies that treat CVDs and improve healthy cardiac aging.

I. Introduction

II. Aging and Epidemiology of CVDs

III. Physiology of Cardiac Aging

A. Ventricular changes

B. Valvular changes

IV. Animal Models of Cardiac Aging

A. Rodents

B. Drosophila

C. Canines

D. Nonhuman primates

V. Mitochondria and the Free Radical Theory of Aging 1498

A. ROS and aging

B. Pleiotropy of ROS

C. Mitochondrial hormesis in aging

D. Mitochondrial turnover in aging

$\begin{array}{ll}\text { A. Mitochondrial oxidative stress in cardiac aging } & 1501 \\ \text { B. Neurohormonal regulation of cardiac aging } & 1502\end{array}$

1. Renin-angiotensin system in cardiac aging 1502

2. B-adrenergic signaling 1502

3. Insulin/insulin-like growth factor 1/PI3K signaling 1502

4. Natriuretic peptides signaling 1503

C. Nutrient signaling in cardiac aging 1503

D. Cardiac stem cell aging and telomeres 1504

Reviewing Editors: Andrew J. Boyle, Issei Komuro, Junichi Sadoshima, Jeson Sangaralingham, Vladimir P. Skulachev and Anielle C. Takahashi

${ }^{1}$ Department of Pathology, University of Washington, Seattle, Washington.

${ }^{2}$ Department of Pharmacology, Weill Cornell Medical College, New York, New York. 
VII. Aging, Oxidative Stress, and CVDs 1505

A. Oxidative stress and mitochondria in CVDs 1505

1. The central role of mitochondrial oxidative stress and redox status in hypertension and heart failure 1505

2. The role of mitochondria and oxidative stress in IR injury 1507

B. Mechanisms of progression to heart failure in the aged hypertrophic heart 1508

1. Increased cardiomyocyte death 1508

2. ECM remodeling 1508

3. Alteration of calcium handling proteins 1508

4. Hypoxic response and angiogenesis 1509

5. Mitochondrial dysfunction and abnormalities in energetics 1509

VIII. Exercise, Cardiovascular Risks, and Cardiac Aging 1509

IX. Emerging "Anti-Aging" Interventional Strategies for Cardiac Aging and CVDs 1510

A. Dietary restriction 1510

B. Antioxidant interventions 1510

$\begin{array}{ll}\text { 1. Nontargeted antioxidants } & 1510\end{array}$

2. Mitochondrial-targeted antioxidants 1511

$\begin{array}{lr}\text { a. } \mathrm{TPP}^{+} \text {conjugated antioxidants } & 1512\end{array}$

$\begin{array}{lr}\text { b. Szeto-schiller peptides } & 1512\end{array}$

C. Resveratrol and SIRTs activators 1513

X. Conclusion and Future Directions 1514

\section{Introduction}

C ARdiovascular Diseases (CVDs) are the leading cause of death, especially in the elderly population. Old age is a major risk factor for cardiovascular disease, which prolongs exposure to hypertension, diabetes, hypercholesterolemia, smoking, and other cardiovascular risk factors. In addition, intrinsic aging of the heart also makes the heart more susceptible to stress and contributes to increased cardiovascular mortality and morbidity in the elderly. Intrinsic cardiac aging is defined as the slowly progressive structural changes and functional declines with age, in the absence of major cardiovascular risks. Intrinsic cardiac aging is evident in rodents and flies, even though the risk factors common in humans are generally absent in these species, making these model organisms valuable for the study of the pathophysiology and genetics of intrinsic cardiac aging.

\section{Aging and Epidemiology of CVDs}

CVDs are highly prevalent in the western hemisphere. It was estimated that 82.6 million adults in the United States have one or more types of CVD (273). An estimated 75.4 million adults are living with high blood pressure. Coronary heart disease affects 16.3 million adults today, including 7.9 million presenting with acute coronary syndrome (myocardial infarction) and 9 million manifesting as stable angina pectoris. Heart failure accounts for 5.7 million cases per year in the United States (2006), and stroke accounts for 7 million cases (273). The 2010 update of American Heart Association's Heart Disease and Stroke Statistics, based on the data from National Center for Health Statistics (NCHS) and National Heart Lung and Blood Institute, showed that the prevalence of high blood pressure, stroke, coronary heart diseases, and heart failure increase dramatically with age in both men and women (Fig. 1A-D). Furthermore, the elderly (>60 years old) account for more than $80 \%$ of patients with coronary heart disease, more than $75 \%$ of patients with congestive heart failure, and more than $70 \%$ of patients with atrial fibrillation.
The 10th revision of the International Classification of Diseases (ICD-10) mortality data shows that $33.6 \%$ ( $~ 814,000$ people) of all deaths in 2007 have CVD as the underlying cause of death (273). In the same year for both older men and women (65 years of age or older), CVD are the number one leading causes of death (273). According to the original and offspring cohort data from the Framingham Heart Study (1980 to 2003), the average incidence of first cardiovascular events in men and women increases progressively with age; from 3 per 1000 men at the age ranging from 35 to 44 years old, to 74 per 1000 men at the age ranging from 85 to 94 years old, and comparable proportions are observed in women 10 years later in life. According to the data from the NCHS, the CVDs mortality rate increases exponentially with age (exponential curve $R^{2}=0.9895$, Fig. 1E), and mean life expectancy would increase by almost 7 years if all forms of cardiovascular disease were abolished (273). These exponential increases in both the incidence of cardiovascular events and CVD mortality in the elderly population suggest that aging per se is a major risk factor for CVDs. With these stark statistics, further research into the effect of aging on the structure and function of the cardiovascular system is imperative.

\section{Physiology of Cardiac Aging}

\section{A. Ventricular changes}

According to Framingham Heart Study and Baltimore Longitudinal Study on Aging, based on the data from apparently healthy adults, there was an age-dependent increase in left ventricular wall thickness measured by echocardiography in both men and women (Fig. 2A), indicating increased prevalence of left ventricular hypertrophy (LVH) with age, even in the absence of clinical hypertension, which is the most common causative risk factor of LVH. Left ventricular (LV) filling in early diastole, measured as peak E wave by Doppler echocardiography, is gradually compromised with increasing age in both genders (Fig. 2B), with possible causes due to fibrosis and 
A

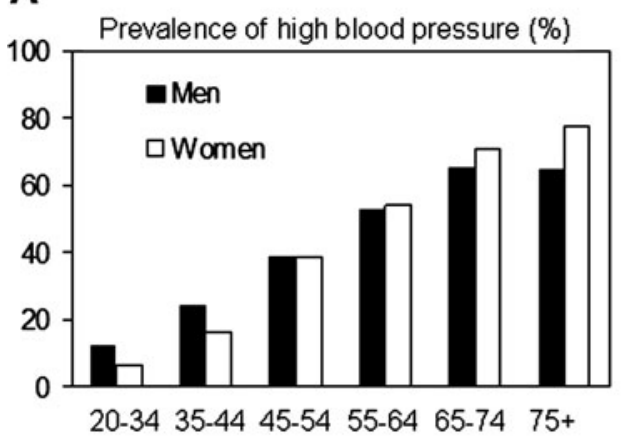

C Prevalence of coronary heart diseases (\%)

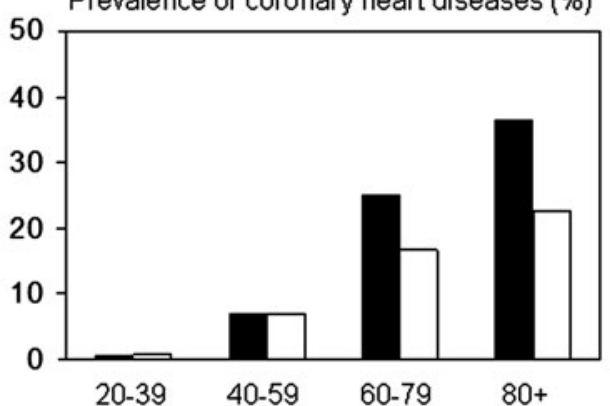

B

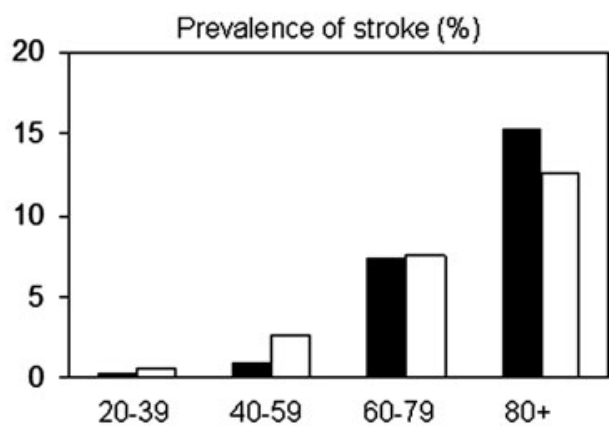

D Prevalence of heart failure (\%)

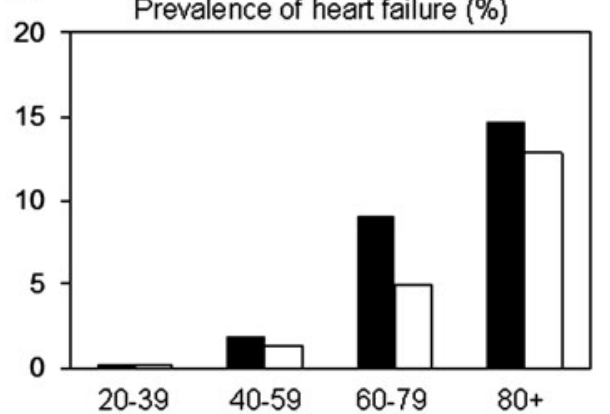

FIG. 1. The prevalence of various CVDS with age. The prevalence of high blood pressure (A), stroke (B), coronary heart diseases (C), and heart failure (D) significantly increase with age in both men and women. There is an exponential increase in CVD mortality in the elderly population (E). Data source: NCHS and NHLBI (273). CVD, cardiovascular disease; NCHS, National Center for Health Statistics; NHLBI, National Heart Lung and Blood Institute.

E Cardiovascular diseases mortality vs. cancer mortality (in thousands)

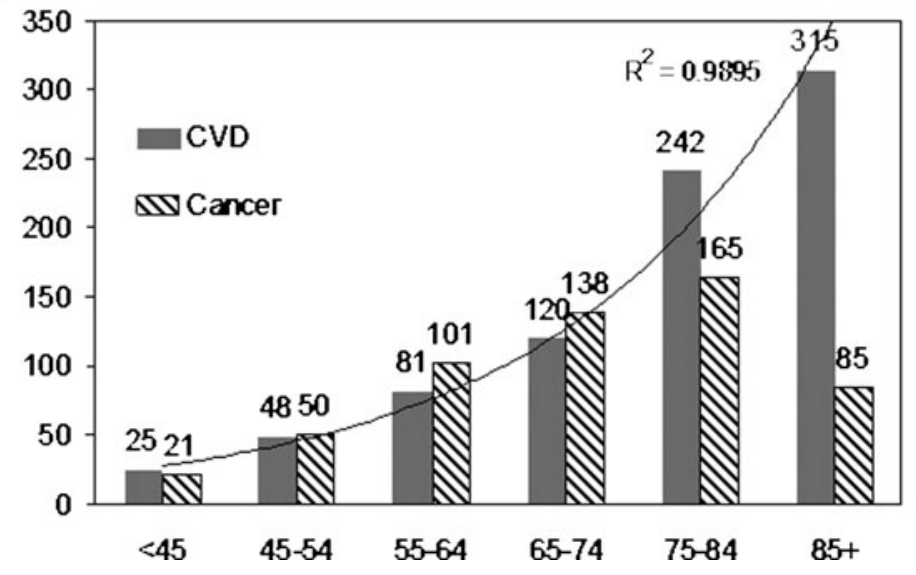

decreased elasticity of the ventricle as well as a delay in active ventricular relaxation. Reduced rates of calcium reuptake by myocardial sarcoplasmic reticulum calcium ATPase (SERCA2a) will delay ventricular relaxation, thus further exacerbating compromised LV filling in early diastole. To maintain LV filling, atrial contraction (A wave) is gradually increased in aging, which also increases atrial pressure and adversely contributes to atrial hypertrophy and an increased risk of atrial fibrillation. The prevalence of atrial fibrillation increases as well with aging (172-174). Doppler echocardiographic measurement of the E/A ratio, the ratio between early (E) and late (A) diastolic LV filling, declines dramatically with age (Fig. 2C) (70,71). This decline in the $\mathrm{E} / \mathrm{A}$ ratio suggests that a greater portion of blood filling in the LV results from late diastolic filling as opposed to early diastolic filling, which is clinically interpreted as an indication of diastolic dysfunction. Diastolic dysfunction is highly prevalent in older adults (43), and it adversely affects exercise capacity in the geriatric population. It also predisposes to the development of diastolic heart failure, which is defined as heart failure with preserved ejection fraction (systolic function). Diastolic heart failure accounts for more than half of the heart failure cases in patients older than 75 years.

Aging also contributes to the decline of the maximal heart rate during exhaustive exercise, but does not appear to affect the resting heart rate when in the supine position (87). While systolic function determined from ejection fraction is relatively preserved at rest, exercise capacity significantly declines with age, as does cardiovascular reserve after prolonged exercise (63). This is attributed to a modest decrease in ejection fraction after maximal exercise (Fig. 2D) and a prominent decline in maximal heart rate at peak exercise (Fig. 2E). The cardiac index is another measure of systolic function calculated as the cardiac output normalized to the body surface area. Healthy adults exhibit a reduction in maximum 
FIG. 2. Age-dependent changes in cardiac structure and function. (A). Posterior wall thickness $\left(\mathrm{cm} / \mathrm{m}^{2}\right)$ by M-mode echocardiography significantly increases with age in both men and women, (B). Peak E wave (early diastolic filling) declines with age. (C). Doppler E/A ratio of mitral inflow, an indicator of diastolic function, decreased with age in apparently healthy participants in both the Baltimore Longitudinal Study on Aging and the Framingham Heart Study. Ejection fraction (D) and heart rate (E) after maximal exercise decrease with age in both genders. (F). Cardiac index (Cardiac output normalized to body surface area) decreases with age. [Reproduced with permission from Lakatta and Levy (2003)].
A
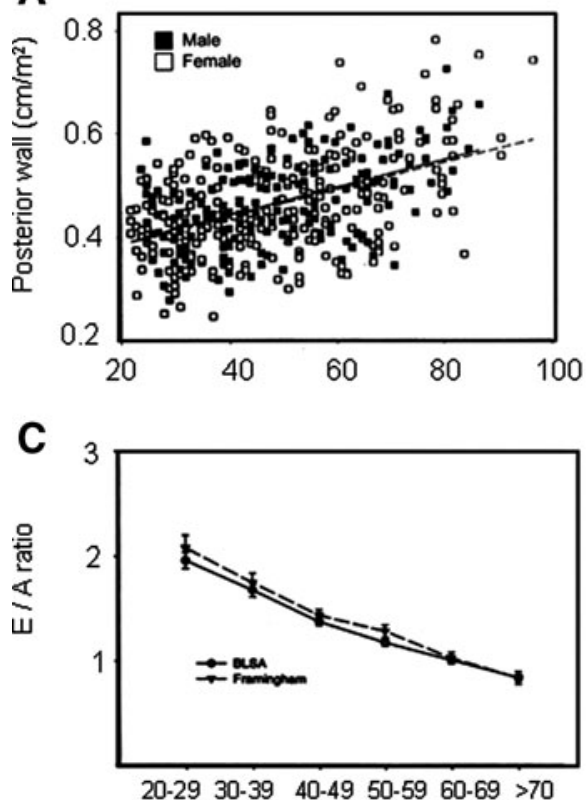

E

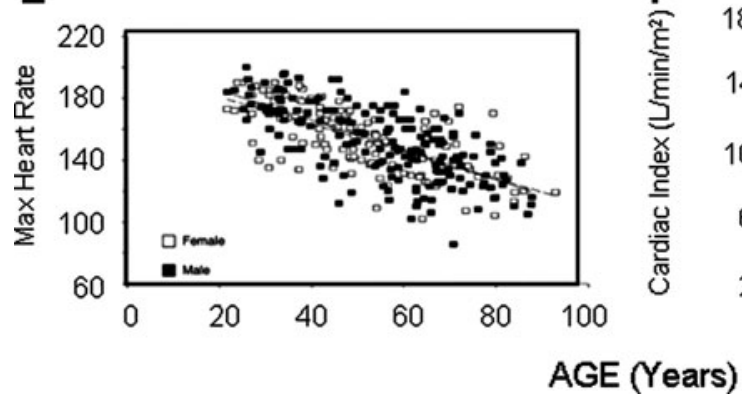

B
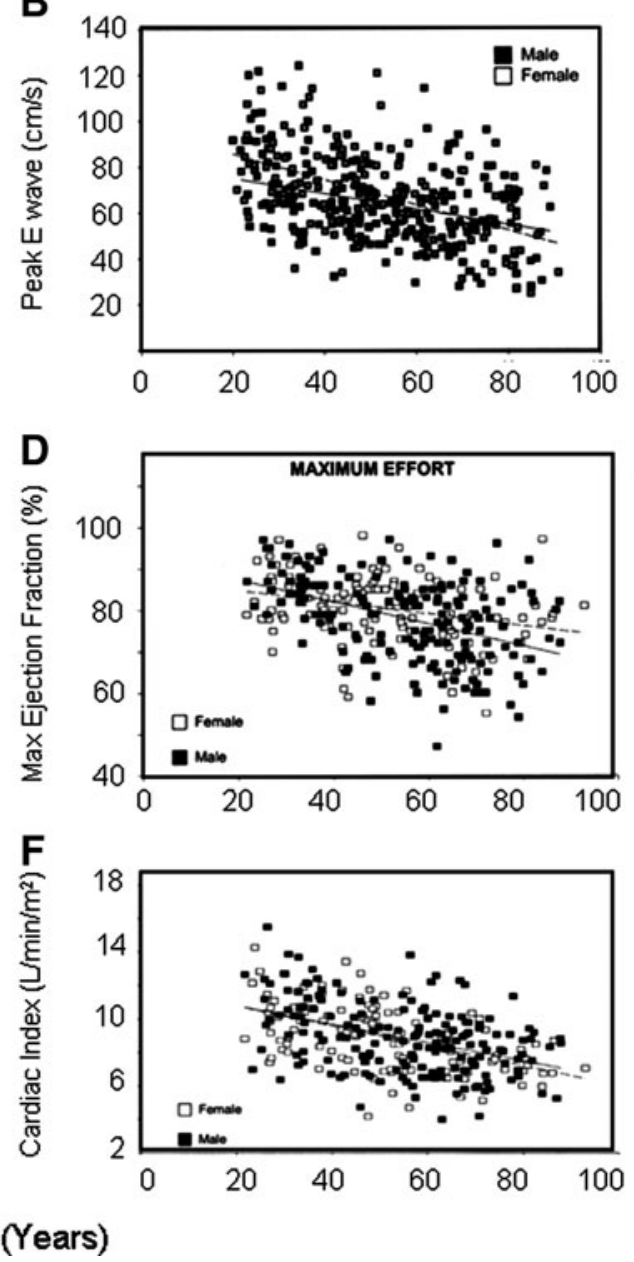

cardiac index with age, which is mostly due to a decline in maximal heart rate (Fig. 2F).

\section{B. Valvular changes}

Age-dependent valvular changes mainly include myxomatous degeneration and collagen deposition called valvular sclerosis. Aortic valve sclerosis is present in $30 \%-80 \%$ of elderly individuals $(145,227,306)$. It is most accurately detected by echocardiographic examination. Some of the echocardiographic features include calcification of aortic valve leaflets and aortic annulus that increase with age $(94,246)$. While a systolic ejection murmur can sometimes be detected during physical examination, many patients with aortic valve sclerosis do not exhibit this murmur. Consequently, echocardiography is a more effective diagnostic tool for detection of this condition. Individuals with hypertension, LVH, hyperlipidemia, smoking, end-stage renal disease, and congenital bicuspid aortic valves are at an increased risk of having aortic valve sclerosis progression (242). In addition, elderly patients with aortic valve sclerosis have an increased occurrence of cardiovascular events and mortality $(17,246)$, as aortic sclerosis often develops in parallel with progression of atherosclerosis in other vessels (245). Unlike stenosis, aortic valve sclerosis does not obstruct blood flow. However, it can advance into aortic stenosis when severe thickening, stiffening, and calcification of the leaflet result in obstruction of the aortic valve. The presence of this progression is an indicator of increased risks of CVDs. Increased leaflet calcification and decreased leaflet mobility may serve as early signs of this progression.

In the elderly, fibrosis and valvular calcification are the most common factors contributing to the development of aortic stenosis, which occurs when the aortic valve opening narrows due to the stiffening and calcification of the aortic valve leaflets (242). This narrowing prevents blood from being pumped effectively, creating a pressure gradient between the aorta and the left ventricle. To compensate for this hindrance, the walls of the left ventricle thicken with myocardial hypertrophy to maintain sufficient systolic function. Later in progression, the increased wall stress causes the left ventricle to dilate, leading to deterioration of systolic function. The prevalence of aortic valve stenosis increases in an age-dependent manner, with the estimated prevalence of $2 \%$ for severe stenosis, $5 \%$ for moderate stenosis, and $9 \%$ for severe stenosis in elderly patients. In addition, aortic regurgitation, also related to the calcification of the aortic cusps and annulus, also increases with age, and is present in $13 \%-16 \%$ of the elderly population (227). The presence of aortic regurgitation indicates that the aortic valve does not close properly; the flow of blood back to the left ventricle from the aorta during diastole results in the left ventricle working harder and increasing in size.

Mitral annular calcification (MAC), commonly found with aortic valve sclerosis given their overlapping pathological 
appearance $(85,139)$, is a degenerative process involving the fibrous annulus of the mitral valve, and is associated with aging. Frequently found during an echocardiographic examination, MAC results when calcium deposits accumulate along and beneath the mitral valve annulus (97). Individuals with hypertension, end-stage renal disease, aortic stenosis, and mitral valve prolapse are commonly found to have MAC. Individuals with MAC have increased risks of mitral stenosis and regurgitation, heart failure, atrial fibrillation, conduction system diseases, stroke, coronary and vascular diseases, mortality, and adverse cardiovascular events (145).

Mitral valve regurgitation is another abnormality common in the aging population. This condition occurs when the mitral valve fails to seal firmly, allowing the backward flow of blood into the heart and subsequently resulting in an insufficient delivery of blood to the rest of the body. Physical symptoms include shortness of breath and fatigue. Two of the leading causes of mitral valve regurgitation are myxomatous degeneration and ischemic heart disease (138). Chronic mitral valve regurgitation is one of the most common indications for valve surgery in the older population (7).

These ventricular and valvular changes in cardiac aging result in a severe compromise in the cardiac functional reserve capacity as well as lower the threshold for symptoms and signs of heart failure (63). This makes the aged heart more susceptible to stress and disease-related challenges, leading to increased prevalence of heart failure and cardiovascular mortality in the geriatric population.

\section{Animal Models of Cardiac Aging}

\section{A. Rodents}

Cardiac aging in mouse models recapitulates the agerelated changes found in human hearts $(38,71)$. Using echocardiography to examine the age-related changes in cardiac structure and function in a mouse longevity cohort, we found a significant age-dependent increase in left ventricular mass index (LVMI, Fig. 3A) and left atrial dimension (71). Systolic function measured by fractional shortening showed only a modest decline with age (Fig. 3B). Diastolic function, measured by tissue Doppler imaging $\mathrm{Ea} / \mathrm{Aa}$, significantly declined with age (Fig. 3C), with a substantial increase in the proportion of diastolic dysfunction (defined by $\mathrm{Ea} / \mathrm{Aa}<1$ ), up to $55 \%$ in mice older than 24 months.(71). Myocardial performance index (MPI), an indicator of global systolic and diastolic function, was significantly impaired with age (Fig. 3D). The oldest group of mice had a $\sim 75 \%$ increase in LVMI compared with that in the young adult group, indicating $\mathrm{LVH}$ in aged mice. The decline in systolic and diastolic function in the aged heart, including the increased LV enddiastolic pressure, resulted in the enlargement of the left atrium. Likewise, a greater fraction of the systole is spent on coping with the pressure changes during isovolemic phases, as reflected in the worsening of the MPI with age (71). All of the phenotypes just mentioned are also found in middleaged mitochondrial mutator mice with "premature aging" (Polg ${ }^{m / m}$, Fig. 3E-H, see section VI.A). Histopathologic changes in mouse hearts with age were increased interstitial and subendocardial fibrosis, along with hyaline cytoplasmic change, vacuolization of cytoplasm, variable and hypertro- phic myocyte fiber size, collapse of sarcomeres, mineralization, and arteriolosclerosis (71). Morphometric analysis indicated an increased myocardial fiber size, increased fibrosis, and amyloid deposition with age, especially in the subendocardial areas (71).

Contributions to diastolic dysfunction with age include fibrosis, as just noted, and a reduced abundance of Sarco(endo)plasmic reticulum calcium ATP-ase (SERCA2), which affected the rate of diastolic calcium reuptake (71). Previous authors, who similarly noted increased LV end-diastolic dimensions and increased wall thickness in murine aging, also demonstrated changes in the extracellualr matrix, including increased matrix metalloproteinase (MMP) and decreased tissue inhibitor of metalloproteinase abundance (196). Thus, diastolic dysfunction in aging appears to be multifactorial in etiology. This is discussed in greater detail in Section VII.B, given next.

Several earlier studies of Fischer rat heart aging using pressure-volume catheter and more recent studies applying echocardiography consistently revealed age-dependent LVH, impairment of systolic and diastolic function, and increased prevalence of mitral regurgitation in rat hearts $(13,36,91)$. Histopathology of aged rat hearts demonstrated cardiomyocytes hypertrophy and increased LV fibrosis (91), both of which reduce LV elastance and might cause diastolic dysfunction. Aging rat hearts also demonstrated decreased responsiveness to sympathetic and dobutamine stimulation (5). Interestingly, coronary blood flow and coronary reserve measured by radioactive microsphere also significantly declined with age, compatible with the findings that aging hearts are more susceptible to injury induced by pressure overload or ischemia (114).

\section{B. Drosophila}

In recent years, the adult Drosophila heart has been used to study cardiac function and aging, surmounting the limitations posed by the long lifespan of mammals. Using new techniques for analysis, including high-speed video imaging, many parameters related to cardiac functions in Drosophila were found to change with increasing age. Intact fruit flies under anesthesia in the first week after eclosion have an average heart rate of $3 \mathrm{~Hz}$ (345). Semi-intact and isolated hearts showed similar results $(236,314)$. Aging is accompanied by declines in this heart rate in both genders when measured in anesthetized flies or isolated hearts. Aging in Drosophila also affects the rhythmicity of their heartbeat. Experts in fruit fly research have derived an arrhythmia index, and have found the index to increase approximately linearly with age (237). The level of disorganization of the myofibrillar arrays within the cardiomyocytes, as detected using antibody staining, also increases with aging $(65,314,348)$. Evidence of misalignment appears by 5 weeks of age, which contributes to the impairment of age-dependent cardiac functionality (314). The power of the genetic study of Drosophila allowed Bodmer and colleagues to identify the mammalian target of rapamycin (mTOR) pathway as a critical step in the aging of the fly heart, described in greater detail in section VI C given next. The emergence of Drosophila as a genetic model for studying cardiac aging should bring about significant advancements, increasing the pace of discovery of genes regulating cardiac aging. 
FIG. 3. Echocardiographic changes in aging and mitochondrial mutator mice. Echocardiographic analysis of WT and mCAT C57Bl/6 mice in a longevity $\mathrm{CO}^{-}$ hort (A-D) and $\mathrm{Polg}^{m / m}$ in the presence or absence of mCAT '(E-H). (A, E) Left ventricular mass index $(\mathrm{LVMI}=\mathrm{calcu}-$ lated LVM/body weight), (B, F) systolic function measured by percentage of fractional shortening (FS), (C, G) diastolic function measured by tissue Doppler imaging $\mathrm{Ea} / \mathrm{Aa},(\mathbf{D}, \mathbf{H})$ the myocardial performance index (MPI) were analyzed. The linear trends across ages in WT mice were significant for all parameters $(p<0.05$ for all, left panels). The beneficial effect of mCAT versus WT was analyzed by the interaction between genotype and the linear age trend, and was significant in all cases $(p<0.01$ for all except fractional shortening, $p=0.03$ ). ${ }^{*} p<0.05$ versus $\mathrm{Polg}^{\mathrm{m} / \mathrm{m}}$ at 4-6 months old, ${ }^{\#} p<0.05$ versus Polg ${ }^{m /}$ $m$ at 13-14 months old (right panels). Data reanalyzed from Dai, et al. $(67,71)$. LVMI, Left ventricular mass index; mCAT, catalase targeted to mitochondria.
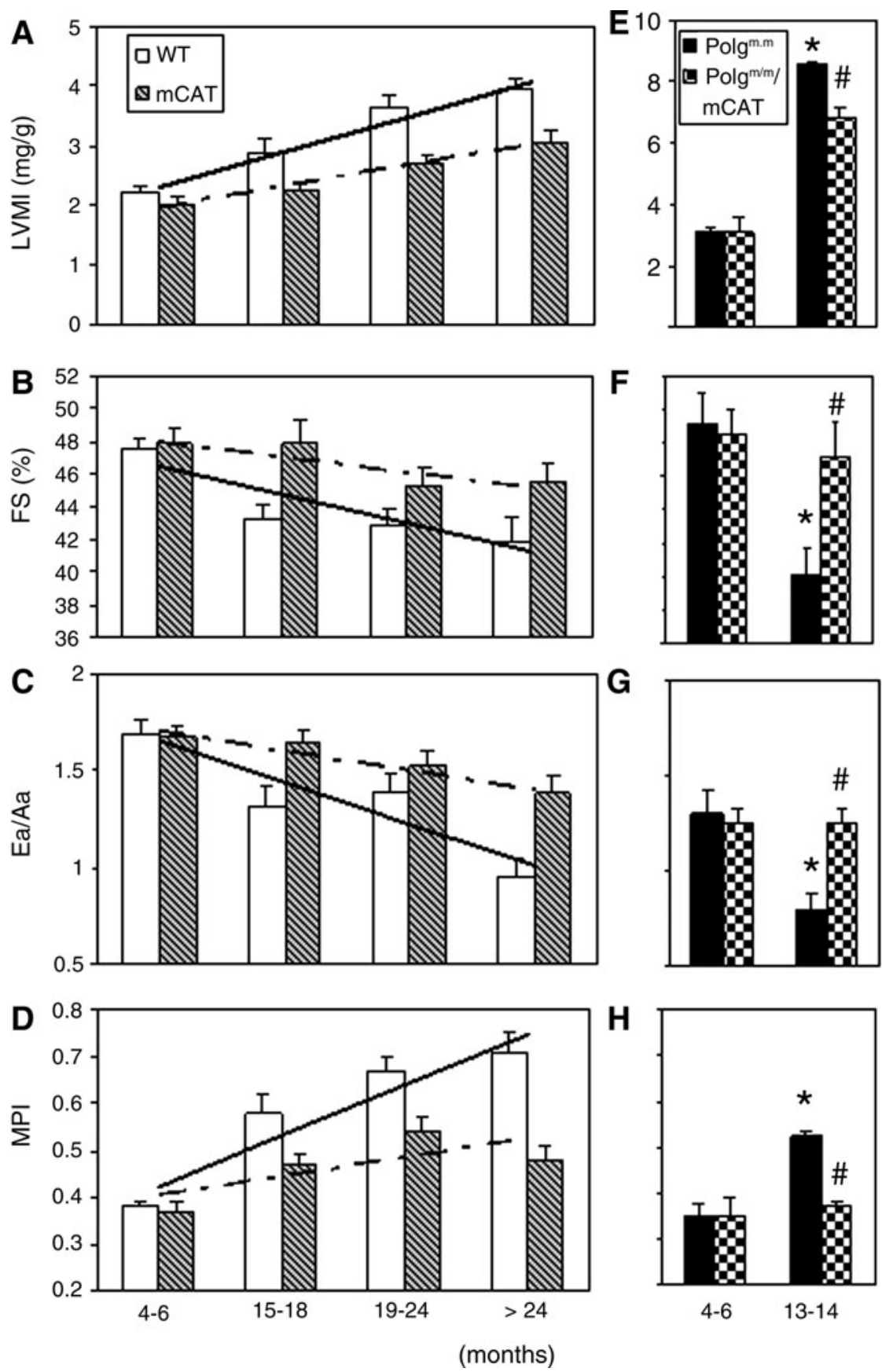

$\mathbf{H}$

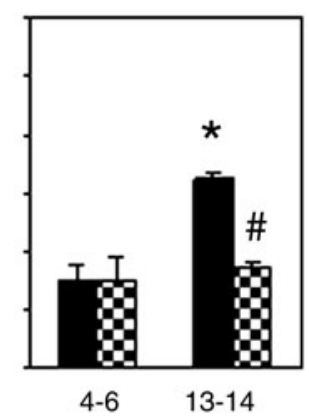

\section{Canines}

Canines are among the most commonly used large animal models for cardiovascular research, as the bridge from rodent model to clinical research. The application of canine models include the study for cardiac arrhythmia (118), ischemiareperfusion (IR) injury, and genetic models of heart failure such as in Duchene cardiomyopathy (156).

Canine hearts developed several aging changes: myocardial hypertrophy, with accumulation of lipofuscin and amyloid, which increased myocardial stiffness. Degenerative valvular heart diseases are common in dogs older than 16 years, the prevalence of which approached $75 \%$. The most common is mitral valve myxomatous degeneration, followed by aortic valve calcification and stenosis. These myocardial and valvular aging changes increased cardiac failure in aged animals (112). The dog model has been widely used for the electrophysiological study, as the distribution of cardiac conduction system and activation sequence (electrophysiological properties) in dogs closely resembles that in the human heart (119). Aged dog hearts demonstrated prolonged action potential duration and decreased responsiveness to adrenergic stimulation as well as an increased risk of developing sick sinus syndrome and atrial fibrillation (14).

\section{Nonhuman primates}

Rodents are the most common model organisms used in mammalian aging research; however, models that are phylogenetically closer to humans, similar to nonhuman primates, 


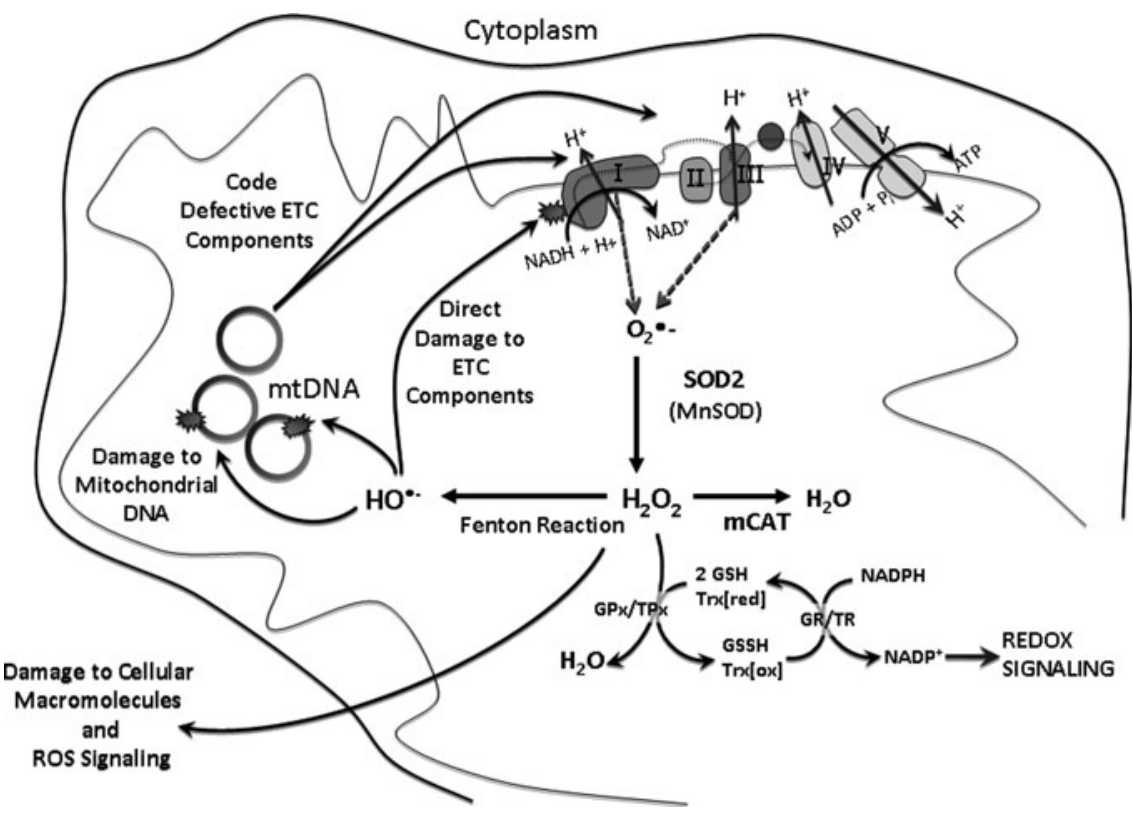

FIG. 4. Mitochondrial ROS theory of aging: ROS vicious cycle. Mitochondria are primary producers and targets of ROS. ROS production as a byproduct of escape of electrons from the electron transport chain (ETC) can directly damage ETC components or damage to mitochondrial DNA, which, in turn, results in altered levels or function of ETC components (complexes I-V are shown). In either case, the compromised ETC produces increased ROS, resulting in increased damage and a vicious cycle of mitochondrial ROS induced ROS. The end results are decreased ETC efficiency, damage to cellular macromolecules, and activation of cellular ROS and redox signaling. ROS, reactive oxygen species. better recapitulate complex human physiology, pharmacokinetics, and electrophysiology. The National Institute of Aging's longitudinal study of aging in rhesus monkeys (Macaca mulatta) reported that monkeys fed with normal diets develop many age-related cardiac pathologies. These include aortic and mitral valves degenerative calcifications, loss or degeneration of myocardial fibers with hypertrophy of remaining cardiomyocytes, lipofuscin accumulation and variable degree of myocarditis, multifocal interstitial fibrosis, myocardial infarction, and congestive heart failure $(175,176,201,279)$. Interestingly, monkeys did not develop spontaneous atherosclerotic plaques unless they were fed high fat diets. Research using the rhesus monkeys and other nonhuman primates will be valuable for study of the biology of human aging, as well as for allowing potential anti-aging interventions to be evaluated before actual clinical trials are performed in humans.

\section{Mitochondria and the Free Radical Theory of Aging}

\section{A. ROS and aging}

First formally proposed by Denham Harman in the 1950s, the free radical theory of aging suggests that aging is a degenerative process driven primarily by the accumulation of damage to cellular macromolecules as a result of their reaction with free radicals (121). Harman modified this theory in 1972 to specify mitochondria as both the primary producers and primary targets of harmful reactive oxygen species (ROS) (122). In his revised theory, Harman noted the failures of dietary antioxidants in extending the murine maximum lifespan and suggested that this observation could be explained by the inability of the exogenous antioxidants to effectively accumulate in the mitochondria. Harmon proposed that if researchers were able to target antioxidant therapies to the primary source and target of ROS, the mitochondria, then the result would be an increase in both the median and maximum lifespan of the organism treated. The mitochondrial ROS theory of aging is, in many ways, an attractive model. Implicating mitochondria as the primary source and target of
ROS suggests a mechanism for the progressive nature of aging (ROS-induced damage of mitochondrial macromolecules leads to the development of dysfunctional mitochondria and a concomitant increase in ROS production), and provides a suggestive link between metabolic rate and the rate of aging (Fig. 4). Supportive evidence of the central role of mitochondrial ROS in aging was provided by the mice overexpressing catalase targeted to mitochondria (mCAT), which showed an $18 \%$ prolongation of lifespan, while mice overexpressing wild-type peroxisomal catalase (pCAT) did not (289).

Harman's theory, while a useful model for many years, has proved to be a greatly oversimplified view of the role of ROS and mitochondria in the biology of aging. Contrary to Harman's original theory, cellular organisms are now known to efficiently sense and neutralize ROS under normal conditions. Cellular antioxidant systems include the superoxide dismutases (SOD), catalase, and the glutathione peroxidases (GPxs), among others, and are both redundant and complementary in many cases. The complexity of antioxidant systems is surprising. Genetic manipulation of antioxidant system components has resulted in a plethora of seemingly inconsistent data. In the nematode Caenorhabditis elegans, for example, single or double SOD mutants have a normal lifespan, except in the case of the mitochondrial SOD2 mutants (single or double with cytoplasmic SOD1) where lifespan is actually increased (329). Fly researchers have been able to extend the lifespan of Drosophila melanogaster by overexpressing exogenous antioxidant proteins under specific conditions $(213,250)$, but this is complicated by the observations that mitochondrial- targeted antioxidants Euk-8, Euk-134, and MitoQ (198), as well as ectopic expression of the hydrogen peroxide neutralizing enzyme catalase (212), fail to extend fly lifespan under normal conditions. This confusion is not limited to the invertebrate models; a series of lifespan studies using transgenic mice demonstrate that overexpression of several endogenous antioxidants do not prolong mouse lifespan, including CuZnSOD (cytoplasmic SOD1), MnSOD (mitochondrial SOD2), catalase, or a combination of CuZnSOD/catalase and CuZnSOD/MnSOD $(132,137,253)$. 
Furthermore, not only does antioxidant enzyme overexpression fail to extend murine lifespan, but also deletion of the same components (SOD's, GPx, etc), even in combination, typically does not decrease lifespan in the absence of additional perturbation $(132,137,253,354)$.

\section{B. Pleiotropy of ROS}

During recent years, observations in multiple model systems have highlighted numerous biological roles for ROS in signaling and stress response [reviewed in $(116,117,199)]$. A decade-long perspective of ROS as a primary proximal cause of aging and disease is challenged by the realization that ROS are crucial mediators of normal cellular responses. Mitochondrial ROS are now known to be required for a proper response to hypoxia in the heart $(44,49,113)$ through activation of hypoxia inducible factor 1 (HIF-1), are necessary for ischemic preconditioning $(45,81)$, and play a fundamental role in the phenomena of hormesis (270), an idea which is validated by recent work in Caenorabditis elegans demonstrating that some conditions which increase mitochondrial ROS production also significantly increase lifespan via mitochondrial ROS-mediated activation of HIF-1 (179). Given these results, it is becoming increasingly clear that antioxidant therapies are unlikely to provide significant benefits to lifespan or healthspan without further characterization of the role of ROS in signaling and disease and refinement of drugs that specifically target the detrimental reactive species and/or specific compartment of cells (e.g., mitochondria). This conclusion is supported by a large 2007 meta-analysis that examined the effects of nonspecific antioxidant therapies (beta carotene, vitamins A, C, and E, and selenium) on mortality over a total of 232,606 participants and found all but vitamin $C$ and selenium to slightly but significantly increase mortality (34) (See Section VIIIB).

\section{Mitochondrial hormesis in aging}

Interestingly, recent evidence suggests that oxidative stress might promote longevity and metabolic health. Dietary restriction (DR), especially glucose restriction, has been shown to preferentially induce mitochondrial metabolism to extend lifespan in various model organisms, including Saccharomyces cerevisae (193), Drosophila melanogaster (359), and C. elegans (290), and increased mitochondrial respiration is expected to increase the production of ROS. For instance, glucose restriction in C. elegans extends lifespan by inducing mitochondrial respiration and increasing oxidative stress, and this adenosine monophosphate-activated protein kinase (AMPK)-dependent lifespan extension is abolished by pretreatment of antioxidant $\mathrm{N}$-acetyl cysteine (NAC), indicating that oxidative stress is crucial in the signaling to induce stress resistance (290). This concept of mitochondrial hormesis (mitohormesis) hypothesizes that a low dose of oxidative stress, induced by caloric restriction, exercise (271), or other stimuli, may trigger an adaptive response that improves overall stress resistance (such as increased endogenous antioxidant defense) which may cause a long-term reduction of oxidative stress (270) and the extension of lifespan.

\section{Mitochondrial turnover in aging}

A recent understanding of the involvement of mitochondria and mitochondrial ROS in the aging of postreplicative

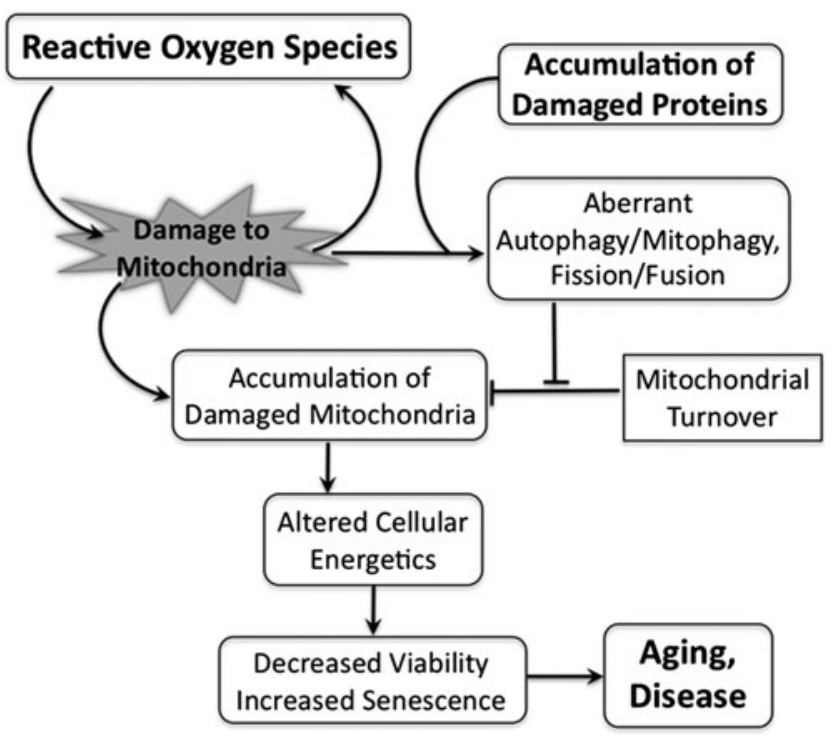

FIG. 5. Mitochondrial-lysosomal axis theory of aging. Damaged mitochondria accumulate when normal autophagy/mitophagy or mitochondrial fission/fusion are disrupted. According to the mitochondrial-lysosomal axis theory of aging, this accumulation of damaged mitochondria is a key step in the progression of aging and mitochondriaassociated disease.

tissues such as cardiac tissue has highlighted the role of mitochondrial turnover, mediated by fission, fusion, and mitophagy. This has in the past been termed the mitochondrial-lysosomal axis theory of aging [see reviews $(42,108,318-$ 322)]. According to this theory, proper regulation of mitochondrial turnover is vital to the maintenance of a functional pool of mitochondria, with removal of damaged mitochondria occurring primarily through fusion, fission, autophagy, and lysosomal degradation. When mitochondrial turnover is perturbed by changes in the rates of mitochondrial fission or fusion or alterations in autophagy/mitophagy, the result is an accumulation of damaged and dysfunctional mitochondria (Fig. 5). Dysfunctional mitochondria produce high levels of ROS, have reduced membrane potential and impaired ATP production capacity, and likely participate in aberrant signaling $(218,300)$. This accumulation of damaged and dysfunctional mitochondria produces cells that have compromised respiratory capacity, increased oxidative stress, and aberrant mitochondrial signaling. Tissues become affected by senescence or apoptosis when a critical level of dysfunctional mitochondria have accumulated, or when the tissue is challenged with an external stress and is unable to properly respond because of the cellular or subcellular dysfunction that has accrued.

A large body of experimental evidence supports this theory of aging in metabolically active, postreplicative tissues. Damaged, high-ROS producing mitochondria have been demonstrated to accumulate in aging cardiac tissue (218,300)(Fig. 6), and are thought to play a major role in pathologic cardiac hypertrophy by accumulating in the cell and forcing a compensatory increase in the total number of mitochondria in order to offset the decreased energy output of the damaged mitochondria (42). Inhibition of autophagy by 3-methyladenine, an inhibitor of autophagosome formation, results in an 


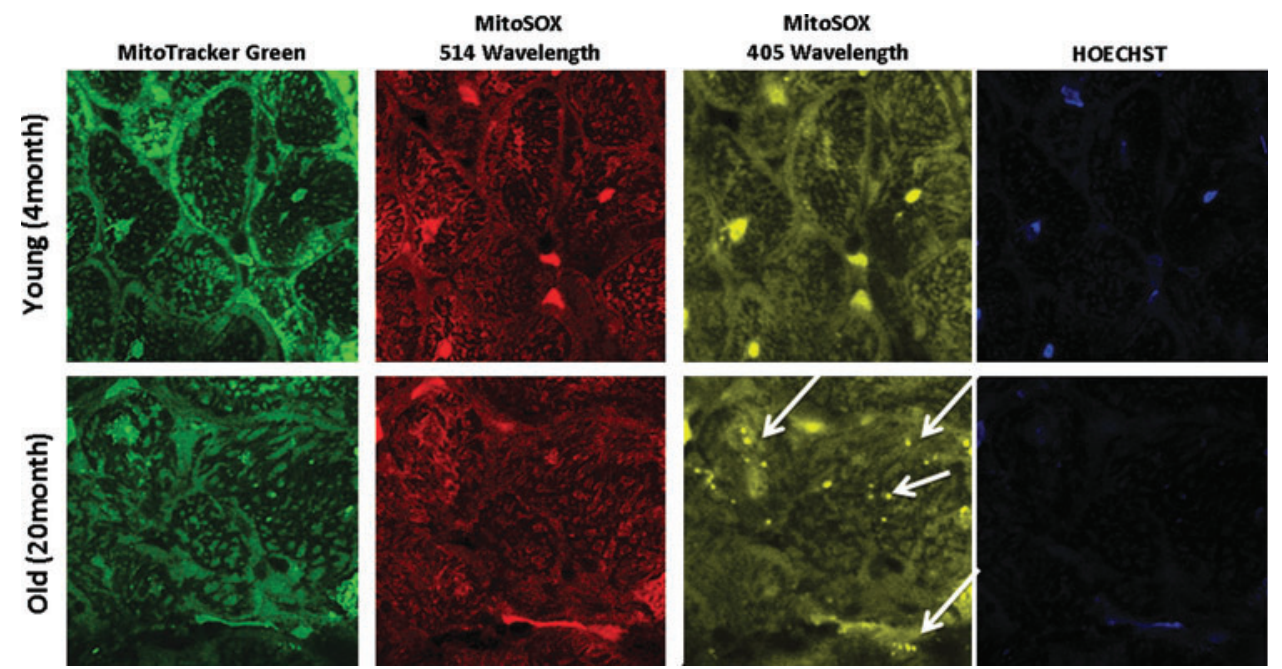

FIG. 6. Increased production of ROS in mitochondria of old mouse cardiac tissue. Ex-vivo live staining of cardiac tissue from 4 month (top row) and 20 month (bottom row) old male mice. MitoSOX has unique excitation/emission spectra for superoxide specific products (405 wavelength, shown in yellow) and nonspecific products of oxidation (514, shown in red). White arrows point to focal high-superoxide producing mitochondria. (To see this illustration in color the reader is referred to the web version of this article at www.liebertonline.com/ars). accumulation of dysfunctional and oversized mitochondria $(30,126,281)$. Furthermore, the two best-documented interventions in mammalian aging, DR and inhibition of mTOR by treatment with the drug rapamycin, have both been demonstrated to increase autophagy and prevent or delay mitochondrial dysfunction (although the mechanistic link between these two effects has not been fully explored) $(130,204,244,263)$. A further discussion of the role of autophagy in DR and pharmaceutical interventions of aging is provided in subsequent sections.

The mitochondrial turnover/lysosomal axis theory of aging is also an attractive model of cardiac aging, because it is able to account for a number of observations that other models of aging cannot. For example, ROS production among mitochondria becomes highly heterogeneous in aged tissue (see above). The model of mitochondrial damage accumulation in aging cannot directly explain this heterogeneity. In the damage accumulation model, ROS production is uniform within the cell, and damage accumulation is stochastic. This model would predict that all mitochondria should be damaged in a relatively uniform (Poisson-distributed) pattern of damage accumulation among the mitochondria of a given cell. In contrast, the mitochondrial-lysosomal axis theory of aging is defined by the production of a heterogeneous population of mitochondria, with distinctly dysfunctional outliers. Furthermore, the mitochondrial-lysosomal axis theory of aging would predict that while ROS are important contributors to the aging process, increased ROS production is secondary to mitochondrial dysfunction. This prediction allows ROS to be separable from the process of aging under the proper conditions. As discussed, this separation is well supported by experimental results in systems where knockout of antioxidant system components fails to decrease lifespan or overexpression of antioxidant proteins fails to increase lifespan.

Mitochondrial homoplasmy is another phenomenon that is difficult to reconcile with the damage accumulation models of aging. Homoplasmy occurs when a mutant or variant form of mitochondrial DNA becomes the predominant form existing within a cell (338). Heteroplasmic cells that contain both mutant and wildtype mtDNA could accumulate 60\%-90\% pathogenic mtDNA molecules without showing any defect in respiratory activity $(56,277)$. Damage accumulation models would lead us to expect aging cells to exhibit vast heteroge- neity in mitochondrial DNA mutations, as mutations are stochastic and the model does not provide for a clear mechanism by which any single variant could become dominant. Under the mitochondrial-lysosomal theory of aging, mitochondrial homoplasmy is explained by the clonal expansion of variant mitochondria as a result of a mutation that allows the abnormal organelles to escape normal autophagosomal degradation or enables the dysfunctional mitochondria to expand through mitochondrial fission at an uncontrolled rate (42). Given the success of the mitochondrial-turnover/lysosomal theory in describing the biology of cardiac aging and the growing body of evidence detailing the role of autophagic dysfunction in aging, it seems clear that aberrant autophagy will prove to be a major component of the aging process in postreplicative tissues such as cardiac tissue.

Another important factor related to mitochondrial damage accumulation, mitochondrial repair, and turnover in aging is the phenomenon of mitochondrial dynamics-a dynamic network within which the mitochondria regularly exchange proteins, mtDNA, and lipids by rapid fusion and fission processes (47). Mitochondrial fusion allows two mitochondria to mix their contents, and this physiological process is crucial to control mitochondrial morphology and function. The mechanism of mitochondrial fusion requires three large GTPase: mitofusins 1 and 2 (MFN1 and MFN2) and optic atrophy 1 (OPA1) [see review (50)]. A recent study using mice with skeletal muscle specific deletion of the MFN 1 and MFN 2 demonstrates that mitochondrial fusion is required for mtDNA stability as well as tolerance to mtDNA mutations (51). Due to the mixing of mtDNA from mitochondria with different levels of heteroplasmy (different proportions of mutated mtDNA), mitochondrial fusion has been proposed to mediate the functional complementation of pathogenic mtDNA genes $(222,223)$. On the other hand, mitochondrial fission is shown to separate dysfunctional mitochondria with a reduced membrane potential and a decreased level of mitochondrial fusion proteins, which are subsequently targeted for mitophagy $(326,48)$. Although the mechanisms and the exact role of mitochondrial fusion and fission in aging remains unclear, due to the importance of mitochondrial dynamics in mitochondrial homeostasis and DNA stability, it has been postulated that mitochondrial dynamics play a crucial role in aging (161). 


\section{Molecular Mechanisms of Cardiac Aging}

\section{A. Mitochondrial oxidative stress in cardiac aging}

Several studies have documented that an increase in mitochondrial dysfunction with age is correlated with abnormal mtROS production and detoxification [reviewed in $(199,323,324)]$. An age-dependent reduction in mitochondrial oxidative phosphorylation function is related to the decline in mitochondrial state 3 respiration (maximal stimulated respiration) due to diminished activity of electron transport complexes I and IV; some parts of the complexes include mitochondrial DNA-encoded subunits (Fig. 4), while complexes II, III, and V are relatively unaffected [see review (228)]. Impaired electron transport function is likely to be directly related to elevated electron leakage and generation of mtROS.

As an organ with a high metabolic demand and rich in mitochondria, the heart is particularly vulnerable to mitochondrial oxidative damage. Deficiency of mitochondrial energetics has been documented in human and experimental animals with heart failure (333), the mechanisms of which may include mitochondrial biogenesis that does not keep up with the increasing demand [see review (105)], mitochondrial uncoupling and decreased substrate availability (217), and increased mitochondrial DNA deletions (69).

As shown in Figure 6, damaged mitochondria from aged mouse hearts produce more ROS than healthy mitochondria in young hearts. Consistent with this, studies from our laboratory displayed an age-dependent increase in mitochondrial protein carbonylation in mice (Fig. 7A), which is indicative of increased oxidative damage to mitochondrial proteins $(67,71)$. Furthermore, we found that aged hearts had a 3-4-fold increase in mitochondrial DNA point mutation and deletion frequencies. This mitochondrial damage stimulates signaling for mitochondrial biogenesis, manifest in the aged heart by an increase in mtDNA copy number concomitant with significant upregulation of the master regulator peroxisome proliferator-activated receptor gamma coactivator-1 alpha (PGC- $1 \alpha$ ) and its downstream transcription factors (71).

The most direct evidence for the critical role of mitochondrial ROS in cardiac aging was shown by our experiments using mice overexpressing mCAT. We demonstrated that mCAT mice were significantly protected from the agedependent increase in LVMI (Fig. 3A, $p<0.01$ for WT vs. mCAT), a decline in diastolic function measured by $\mathrm{Ea} / \mathrm{Aa}$ (Fig. 3C, $p<0.01$ ) and an increased prevalence of diastolic dysfunction, as well as a decline in systolic function (FS\%, Fig. $3 \mathrm{~B}, p=0.03$ ) and impairment of myocardial performance (Fig. $3 \mathrm{D}, p<0.01)(71)$. Consistent with this, we found that mCAT attenuates age-dependent mitochondrial oxidative damage, as displayed by significant reductions of mitochondrial protein carbonyls and mtDNA deletion frequencies (Fig. 7A, B).

Another line of evidence for the critical role of mitochondria in aging is demonstrated by mice with proofreadingdeficient homozygous mutation of mitochondrial polymerase gamma (Polg D257A/D257A designated as $\operatorname{Polg}^{m / m}$ ), which induces a substantial increase in mtDNA point mutations and deletions $(166,325)$. The accumulation of mitochondrial DNA mutations has been shown to increase apoptosis (166). These mice were shown to have a shortened lifespan and "accelerated aging-like" phenotypes, such as kyphosis, graying and
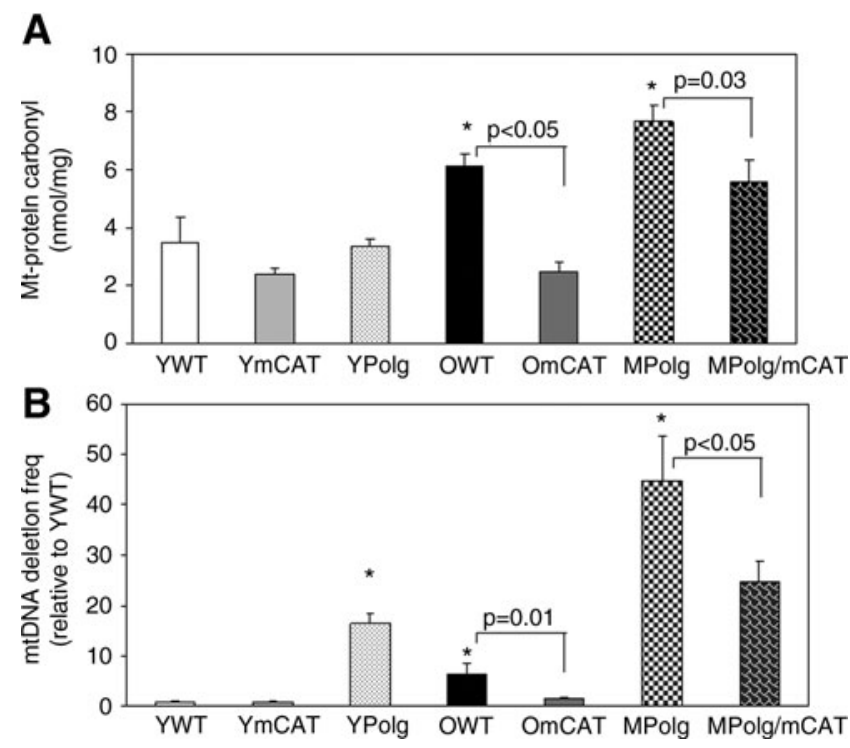

FIG. 7. Mitochondrial oxidative damage in cardiac aging. (A). Mitochondrial protein carbonyl $(\mathrm{nmol} / \mathrm{mg})$ significantly increased in old WT (OWT, > 24 months) and even more in middle-aged Polg (MPolg, 13.5 months) mouse hearts when compared with young WT mouse hearts. mCAT significantly reduced these age-dependent mitochondrial protein carbonylation. (B). Mitochondrial DNA deletion frequency significantly increased in old WT ( $>24$ months) and young Polg (4 months) when compared with young WT, and this is dramatically increased in middle-aged Polg (13.5 months). mCAT overexpression significantly reduced the deletion frequency for both. ${ }^{*} p<0.05$ compared with YWT.

loss of hair, anemia, osteoporosis, and age-dependent cardiomyopathy $(67,325)$, which include marked LV hypertophy (Fig. 3E), systolic and diastolic dysfunction (Fig. 3F, G, respectively), and impairment of myocardial performance (increased MPI, Fig. $3 \mathrm{H}$ ). The observations that mitochondrial damage and cardiomyopathy in these mice can be partially rescued by mCAT (Fig. 3E-H) suggest that mitochondrial ROS and mitochondrial DNA damage are part of a vicious cycle of ROS-induced ROS release (Figs. 4, 7A, B) (67). Furthermore, it has been shown that accumulation of mtDNA deletions is better correlated with the "premature" aging-like phenotype in these mice than are mtDNA point mutations (335).

A recent paper reports the striking result that endurance exercise in Polg ${ }^{D 257 A} D 257 A$ mutant mice can prevent both their skeletal muscle and cardiac progeroid phenotypes (283). The authors suggest that the augmented level of mitochondrial biogenesis seen with exercise in these mice is a critical factor in maintaining mitochondrial and organ function. This is a highly relevant observation, as age-associated accumulation of mtDNA deletions have been documented in various tissues in man, including the heart $(62,353)$.

The success of targeted, specific ROS scavenging intervention by mCAT suggests that a key to successful intervention lies in specificity. Given the complexity of the systems involved, it seems possible that mitochondrial dysfunction and aberrant ROS production may contribute to aging through interference with normal signaling and energetics as much, or more than by the direct damaging effect to cellular 
macromolecules. Age-dependent decline in the rate of mitochondrial electron transfer also favors mitochondrial superoxide production, leading to a positive feedback between complex I inhibition and mitochondrial ROS production, as well as the more classical viscous cycle of mitochondrial DNA mutation and protein damage amplifying ROS. When viewed in the light of alterations in both signaling and energetics, this may be a critical factor in cardiac (and other organ system) aging.

Finally, there are potential shared mechanisms between intrinsic cardiac aging and cardiac hypertrophy and failure. These mechanisms are discussed in Section VII. A. Oxidative stress and mitochondria in CVDs are discussed next.

\section{B. Neurohormonal regulation of cardiac aging}

1. Renin-angiotensin system in cardiac aging. As the key neurohormonal system that regulates hypertension and stress induced cardiac hypertrophy, the renin-angiotensin aldosterone system (RAAS) has been linked to cardiovascular disease and age-related declines in cardiac function. We and others have found that intracardiac Ang II concentrations significantly increased with age, and many structural, functional, and molecular changes found in aged hearts are consistent with the effects of Ang II $(71,111)$. Direct evidence for the role of Ang II in cardiac aging came in 2007, when Basso, et al reported that inhibition of Ang II signaling by either angiotensin converting enzyme inhibitor enalapril or angiotensin receptor type I inhibitor losartan extended the lifespan of normal male Wistar rats and slowed the onset of agerelated cardiovascular pathologies (22). These drugs have also been shown to reduce myocardial fibrosis and fibrosis-related arrhythmias in aged mice (304). This was confirmed by a study which demonstrated that mice with disruption of angiotensin receptor type I prolong mouse survival (29). The RAAS appears to be involved not only in disease but also in tissue aging in multiple angiotensin responsive tissues, and angiotensin blockade has also proved to be beneficial in the aging kidney (133).

Mechanistically, angiotensin has been shown to induce an increase in total cellular and mitochondrial ROS, and the increased ROS appears to be a clear proximal cause of cardiac disease in this case $(69,125)$. A part of the pathologic increase in ROS is likely mediated by an ROS-induced ROS feedback loop of signaling and damage, in which cardiac mitochondria play a key role by virtue of the mitochondrial localization of the NOX4 isozyme of NADPH oxidase (NOX) (See section VII.A.). Support for this model is provided by the success of mitochondria targeted antioxidants that attenuate cardiac hypertrophy and failure (see below).

2. B-adrenergic signaling. The detrimental effects of $\beta$ adrenergic signaling on cardiovascular health are well understood. These effects are mediated by the demand for augmented cardiac output that results from sympathetic signaling for increased heart rate and blood pressure. Clinical trials of beta-blockers ( $\beta$-adrenergic receptor inhibitors) have demonstrated a clear benefit for survival in patients with heart failure [reviewed in (95)]. $\beta$-adrenergic signaling has been implicated in aging because of the observation that adenylyl cyclase type 5 (AC5- an enzyme involved in $\beta$ adrenergic downstream signaling) disruption leads to mice that are protected against age-dependent cardiac hypertrophy, systolic dysfunction, apoptosis, and fibrosis and which have an increased lifespan $(240,241,351)$.

There is mounting evidence that important effects of $\beta$ adrenergic signaling are mediated by mitochondrial ROS. Chronic $\beta$-adrenergic stimulation induces mitochondrial membrane depolarization and apoptosis in adult rat cardiomyocytes that is inhibited by Mn-SOD/catalase mimetics and by overexpression of catalase (267). Furthermore, it has recently been shown that acute $\beta$-adrenergic stimulation induces a cAMP and PKA-dependent increase in mitochondrial ROS in ventricular mouse cardiomyocytes in vitro. That this increase in ROS plays a significant role in the $\beta$-adrenergic inotropic effect was indicated by observations that the $\beta$ adrenergic induced increase in $\mathrm{Ca} 2+$ transient amplitude was diminished in the presence of the antioxidant NAC as well as the mitochondria-targeted antioxidant SS31 (11).

Although beta-adrenergic antagonists are well tolerated and commonly used in the treatment of heart disease (82), their effects on lifespan are yet to be determined. It will be also important to determine safe and effective ways to combine such inhibitors with those of other signaling pathways, and potentially, with inhibitors of mitochondrial ROS, in order to obtain the maximal positive effects.

3. Insulin/insulin-like growth factor 1/PI3K signaling. Insulin-like growth factor signaling is one of the bestcharacterized determinants of longevity in model systems. Nematodes deficient in the insulin-like receptor DAF-2 have greatly increased median and maximum lifespans $(15,77)$. Insulin-like signaling also regulates lifespan in flies (317) and mammals, the latter demonstrated by the increased lifespans of the Ames and Snell dwarf mice [deficiency in growth hormone and prolactin, reviewed in (189)] as well as Klotho mice with overexpression of the insulin/insulin-like growth factor signaling inhibitor (169). Drosophila and mouse models have also demonstrated the specific benefits of reduced insulin-like growth factor 1 (IGF1) signaling on cardiac aging $(188,345)$. Unfortunately, the role of IGF1 signaling in human cardiac aging is complicated by the observations that IGF1 levels significantly decrease with age (61), and low serum IGF1 correlates with an increased risk of heart failure among elderly patients with no previous history of heart disease (332), and that growth hormone therapy, which increases signaling through IGF1 pathways, may actually be beneficial in some patients with heart failure (40). These correlations between lowered IGF1 and an increased risk of disease complicate our understanding of the role of IGF1 in aging and lifespan, and as a result, the role of IGF1 in human cardiac aging remains unclear. Careful studies involving wellcontrolled participant groups will be needed to address the discrepancies and determine the role of IGF1 signaling in human aging and disease. This is further discussed next in the context of nutrient signaling in cardiac aging.

Insulin receptor signaling activates the phosphoinositide-3 kinase (PI3K) signaling cascade, which phosphorylates and activates AKT. Activated Akt translocates into nucleus and inactivates the Forkhead box $\mathrm{O}$ (FOXO) by phosphorylation. The FOXO transcription factors have an anti-aging role, as supported by the evidence of increased lifespan in C. elegans with activated DAF-16 (the homolog of FOXO in worms) $(152,192)$ and in Drosophila with constitutively active dFOXO 
(the homolog of FOXO in flies) (103). In Drosophila, suppression of insulin signaling by creating insulin receptor mutation or overexpressing $\mathrm{dFOXO}$ prevents the decline in cardiac performance with age (345). In the heart, the FOXO family is thought to function in response to oxidative stress (157), regulation of metabolism (260), and apoptosis (303) [see review (276)]. The mechanism of FOXO in preventing cardiac aging involves activation of endogenous antioxidants and sirtuin-1 (SIRT1) (103), which has been shown to prevent aging phenotypes in several tissues (see section VI.C on nutrient signaling). Mice with cardiac-specific moderate overexpression of SIRT1 are protected against oxidative stress through FOXO-dependent upregulation of endogenous antioxidants, including catalase (8), SOD, and peroxiredoxin (53). Suppression of insulin/PI3K signaling activates transcription factor FOXO, which transcribes target genes including atrogin-1, a ubiquitin ligase that promotes calcineurin degradation and prevents NFAT activation $(185,186)$, thereby attenuating cardiac aging, as the calcineurin-NFAT pathway activation is associated with LVH in cardiac aging (71).

4. Natriuretic peptides signaling. Although the role of natriuretic peptides in cardiac aging remains unclear, it has been shown that plasma levels of atrial natriuretic peptide (ANP) and brain natriuretic peptide (BNP) increase with age in populations without CVDs $(180,266)$ as well as in rodent models (352). ANP and BNP bind to membrane-bound guanylase cyclase receptors to exert the physiological effect of maintaining hemodynamics through body fluid and electrolyte homeostasis. Most circulating ANP and BNP in healthy subjects are secreted by atrial cardiomyocytes at the basal levels. Stimulated by cardiac wall stretch, BNP is secreted by ventricular cardiomyocytes in the setting of volume or pressure overload and ischemia, as well as in response to various neuroendocrine or cytokine stimuli, with endothelin I and Ang II being the most powerful of these stimuli. In a small clinical study, human ANP (carperitide) has been shown to suppress thioredoxin (TRX), reduce oxidative stress, and improve the symptoms and hemodynamics of patients with heart failure (297). A recent study demonstrated that Cnatriuretic peptide (CNP) has an antiproliferative effect on cardiac fibroblasts in vitro. The concentration of circulating CNP progressively declines with age in Fischer rats, and this is reciprocally associated with LV fibrosis and precedes the impairment of diastolic as well as systolic function (284).

\section{Nutrient signaling in cardiac aging}

DR is an extremely well-established intervention that has been clearly demonstrated as increasing lifespan and reducing the onset and severity of a variety of age-related pathologies. This intervention has been demonstrated in a wide array of model organisms, from yeast and nematodes to mice, rats, and, most recently, rhesus monkeys $(59,64,92,146,203)$. DR has been shown to be a powerful preventative for cardiovascular disease in rodents and nonhuman primates $(64,230,294)$. Similar protective effects have also been observed in human and animal trials of alternate-day fasting (330), demonstrating that even transient activation of the pathways involved in the DR response can be beneficial. These studies have shown that DR reduces risk factors associated with heart disease: resting heart rate and blood pres- sure are decreased, insulin sensitivity is enhanced, lipid profiles are improved, and inflammatory processes that likely contribute to atherosclerosis are reduced [reviewed by Mattson and Wan, 2005 (202)]. However, the evidence that DR improves intrinsic cardiac aging is less abundant. Taffett et al. found that DR of mice had a large positive effect on agerelated impaired diastolic function (313). A recent study suggested that in humans undertaking DR for a mean of 6.5 years, there is lower blood pressure, lower systemic oxidative stress, and improved diastolic function (206). In another recent study, the Dahl salt-sensitive rat, which develops gradual, hypertension-associated diastolic dysfunction, was compared in DR versus ad libitum animals. Moderate DR markedly attenuated changes in heart weight, left ventricular mass, and wall thickness in these rats, and echocardiography demonstrated that DR reduced cardiac diastolic dysfunction in this model (291).

Recently, there has been growing interest in the role of the mTOR pathway in nutrient signaling, bolstered by data implicating mTOR activity in aging. Target of rapamycin (TOR) kinase is an evolutionarily conserved gatekeeper that integrates nutrient and hormonal cues to modulate growth and longevity (151). When nutrients are abundant, TOR activity is high, which favors faster growth and cell division; when nutrients become limiting, TOR activity is decreased, leading to reduced growth, enhanced resistance to stress, and increased life span. The nutrient-sensitive target of rapamycin complex 1 (TORC1) branch of the mTOR pathway is illustrated in Figure 8. The TORC2 branch (not shown) controls the organization of the actin cytoskeleton, for which there is much less evidence for implication in aging. TORC1 is a complex of mTOR and raptor (regulatory associated protein of mTOR), and activity of this complex is inhibited by rapamycin. Active TORC1 phosphorylates p70S6K, which accelerates ribosome biogenesis. TORC1 also phosphorylates $4 \mathrm{E}$ binding protein 1 (4EBP1), which results in its release from the inactive 4EBP1/eukaryotic initiation factor $4 \mathrm{E}$ (eIF4E) complex, allowing the mRNA cap binding protein eIF4E to associate with eIF4G and eIF4A to form the active eIF4F complex. This complex is required for cap-dependent translation initiation, the major translation initiation pathway in eukaryotes.

The relevance of the mTOR pathway to cardiac health is indicated by data showing that rapamycin is protective in models of cardiac hypertrophy and heart failure. Administration of rapamycin inhibits Ang II-induced increases in protein synthesis in cardiac myocytes (282) and markedly (67\%) suppresses transverse aortic constriction (TAC) induced cardiac hypertrophy (295). Even more strikingly, rapamycin treatment can cause regression of established TAC pressure overload induced LVH: rapamycin improved left ventricular end-systolic dimensions, fractional shortening, ejection fraction, and regressing left ventricular fibrosis in mice with hypertrophy and heart failure $(100,204)$. This is accompanied by suppression of activated phosphorylated ribosomal S6 protein and eIF4E due to pressure overload (100). Rapamycin also attenuates hypoxia-induced pulmonary vascular remodeling and right ventricular hypertrophy in mice (247).

Studies in Rolf Bodmer's laboratory using a Drosophila model of aging-related attenuation of cardiac function confirmed that inhibition of the mTOR pathway in flies could attenuate the aging-related decline (197). Subsequently, they 


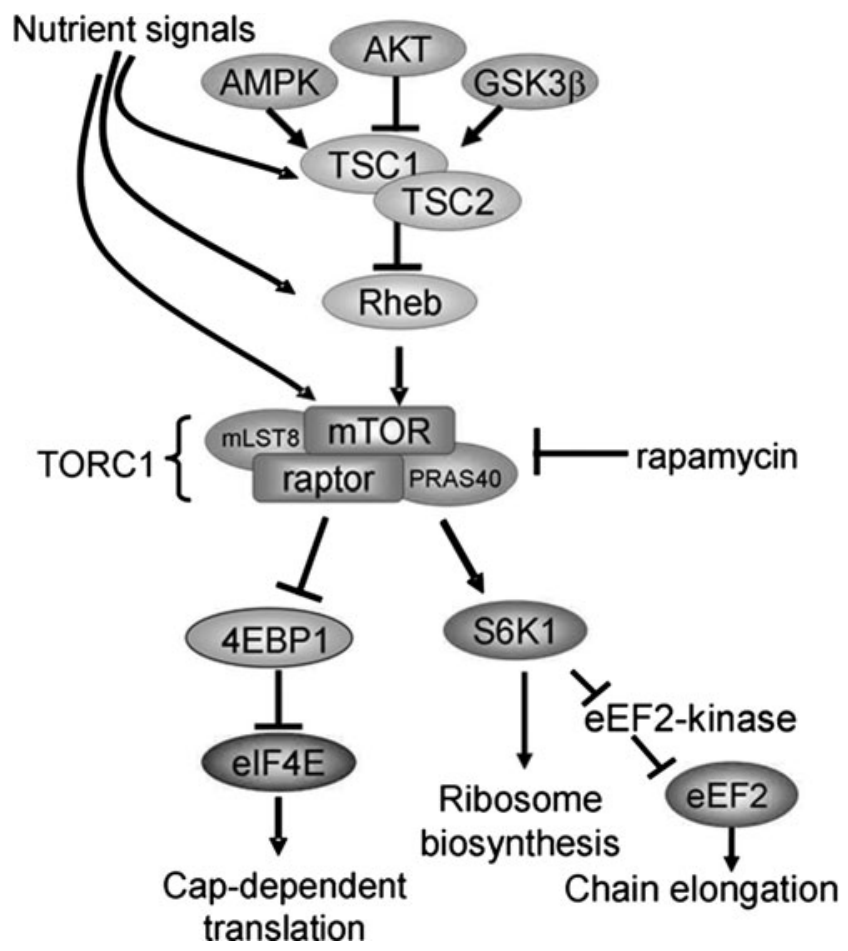

FIG. 8. mTOR pathway in aging. A simplified diagram of key nutrient signaling inputs to $\mathrm{mTOR}$ and key targets of TORC1 phosphorylation (4EBP1 and S6K1 (also known as p70S6K). mTOR, mammalian target of rapamycin; TORC, target of rapamycin complex.

determined that overexpression of 4EBP prevented the aging cardiac decline to the same extent as overexpression of the TOR antagonist tuberous sclerosis complex (TSC), and that, conversely, overexpression of eIF4E leads to a more rapid decline of myocardial function with age (344). They concluded that the level of 4EBP activity regulated cardiomyocyte growth in the fly heart by controlling the initiation of translation. Consistent with this model, work from George Thomas's laboratory using transgenic mouse models showed that deletion of both p70S6K11 and p70S6K12 had no impact on the development of cardiac hypertrophy after TAC, exercise-induced hypertrophy, or cardiac hypertrophy in IGF1 receptor or PI3K mutants (205). Thus, while activation of P70S6K1 was previously conjectured to play a role in cardiomyocyte hypertrophy, these data indicate that P70S6K signaling alone is not critical for the induction of cardiac hypertrophy.

While there are still many unanswered questions with regard to the mechanisms of DR, the robust effects of DR in preventing cardiovascular disease and cardiac aging are evident. However, the use of DR as a clinical intervention in humans is problematic; hence, the search for DR "mimetics" is a very active discipline with the potential to yield important clinical interventions for the treatment and prevention of heart disease and cardiac aging.

SIRTs are a conserved family of NAD+-dependent deacetylases (class III histone deacetylases). In Saccharomyces cerevisiae, Caenorhabditis elegans, and Drosophila, extra copies of the Sirt genes are associated with an extended lifespan $(21,24,170)$. In yeast, Sir2 has been previously reported to mediate the extension of replicative lifespan in response to DR (reduced glucose) $(10,191)$, although later studies have shown controversial results $(141,143)$. Mammals have 7 isoforms of SIRTs, SIRT1-7, of which SIRT1 has the closest amino acid sequence homology to yeast SIR2. Mice deficient in SIRT1 displayed several developmental defects and shortened lifespan compared with wild-type mice. Mice with an extra copy of Sirt1 have been created by transgenesis, and these mice demonstrated a metabolic phenotype similar to wild-type mice that are dietary restricted (37). Although lifespan extension in these mice has never been reported, it is possible that Sirt1 could mediate some of the effects of DR. In the cardiomyocyte mitochondrion, we have previously noted the potential importance of nicotinamide adenine dinucleotide metabolism and SIRTs. Sirt3 expression was reported to be reduced with age in sedentary individuals, but elevated by endurance training in both young and old persons (177). In transgenic mice, low to moderate overexpression of Sirt1 in hearts attenuated age-dependent increases in cardiac hypertrophy, apoptosis/fibrosis, cardiac dysfunction, and senescence markers; whereas a high level (12.5-fold) of Sirt1 increased apoptosis and hypertrophy and decreased cardiac function (8). It has recently been reported that SIRT3 deacetylates the regulatory component of the $\mathrm{MPTP}$, cyclophilin D, preventing the mitochondrial permeability transition in cardiac tissue during aging, and that Sirt3 knockout mice show accelerated signs of aging in the heart, including cardiac hypertrophy and accelerated fibrosis (115). Perhaps most intriguing, increased expression of SIRT3 due to polymorphism in the Sirt3 promoter was found to be associated with an extended lifespan of man (27). Resveratrol was also shown to extend the lifespan of S. cerevisiae, C.elegans, and Drosophila through an Sirt1-dependent mechanism $(131,349)$, but this effect was not reproducible in later studies $(21,144)$. In mammals, resveratrol has been reported to ameliorate shortened lifespan and metabolic derangement in mice fed with a high fat diet, probably through activation of SIRT1 and PGC$1 \alpha$, hence improving mitochondrial function $(23,171)$.

The involvement of SIRTs in nutrient signaling and cardiac aging directly implicates histone deacetylation and epigenetic regulation of DNA expression in these processes. This is consistent with an increasing awareness of the potential role of epigenetic modification in aging (110) and cardiovascular disease (104). DNA methylation is the second of these two most-cited mechanisms of epigenetic modification. DNA hypomethylation has been associated with conditions related to cardiovascular risk (18), but while such observations have been made in smooth-muscle cells, atherosclerotic lesions, and peripheral blood leukocytes, they have not yet been documented directly in the heart. It is easy to predict, however, that this will be an area of vigorous study in the future.

\section{Cardiac stem cell aging and telomeres}

Although an attractive target for therapeutic interventions in cardiac aging, the existence and role of adult cardiac stem cells in cardiac physiology remains under debate. There is evidence suggesting the existence of multipotent populations of cells in the heart capable of differentiating into cardiomyocytes after isolation and culture $(28,140)$; however, these cells are clearly incapable of preventing the progression of cardiovascular disease during cardiac aging and after acute ischemic events in humans. A high impact report by 
Bergmann et al. in 2009 attempted to address the conflicting opinions in the adult cardiac stem cell field by addressing the question of whether human hearts experience cell turnover. Using data from environmental exposure to ${ }^{14} \mathrm{C}$ in human tissues (caused by increases in atmospheric ${ }^{14} \mathrm{C}$ after the atomic bomb testing of the mid-20th century) and mathematical modeling of the rate of DNA turnover, they estimated that cardiomyocyte turnover decreases from $1 \%$ per year at the age of 25 to $0.45 \%$ per year at the age of 75 in adult human hearts (31). Unfortunately, this approach has limitations, including numerous assumptions made during the modeling process, and the rate reported does not account for DNA repair mechanisms. Furthermore, there remains the inability of cardiac tissue to mount a significant regenerative response after acute ischemic injury or during the aging process in man.

Telomere length data and genetic models of telomere deficiency have provided some intriguing data concerning the role of cardiac stem cells in aging. Endomyocardial biopsies of hearts from old patients with dilated cardiomyopathy show decreased telomere length, increased levels of senescence markers, and increased cell death compared with agematched control hearts (52). While the shortened telomeres could be a secondary result of an increase in cellular ROS, the increased expression of senescence markers indicates that senescence may play a role in heart disease and cardiac aging. Telomere shortening may be an initiating factor in the progression of cardiac progenitor senescence and a contributor to cardiac aging. Cardiac progenitor cells were described in rats after BrdU labeling of the adult rat myocardium, and the myocardial cells thst incorporated BrdU were found to be telomerase positive (106). Mouse genetic models of telomere deficiency support this observation, with telomere reverse transcriptase (280) or telomerase RNA (35) showing an increase in age-related cardiac hypertrophy, while mice overexpressing telomerase present a nonpathologic cardiac hypertrophy and a resistance to the acute ischemic insult of myocardial infarction (238). Additional evidence for the importance of cardiac stem cells in heart aging comes from a study in which the knockout of the prosenescent gene p66shc (involved in senescence and apoptosis after oxidative stress and in response to telomere shortening) was shown to prevent age-related cardiac pathologies in a diabetic mouse model (278). Given these data, it seems reasonable that cardiac stem cells may someday play an important role in the treatment and prevention of cardiac dysfunction and cardiac aging. At the present time, however, a much larger research effort is underway to define a therapeutic role for other sources of induced pluripotent stems cells in cardiac regeneration (163).

\section{Aging, Oxidative Stress, and CVDs}

\section{A. Oxidative stress and mitochondria in CVDs}

Increased oxidative stress is well known to play an important role in the pathogenesis of CVDs, such as hypertension, atherosclerosis, cardiac hypertrophy related to aging or pressure overload, cardiac IR injury, and cardiac failure. Several important sources of ROS have been reported in the cardiovascular system, including NOXs, mitochondria, xanthine oxidase, monoamine oxidase, and nitric oxide synthase. Free radicals generated by these sources are usually maintained at the physiological levels by several endogenous an- tioxidant systems, including SOD, catalase, GPxs, and glutathione reductase (GR). Other antioxidant systems involving thiol-disulphide oxidoreductase systems include the cytosolic proteins TRX and glutaredoxin. At physiological levels, ROS acts as a signaling mediator, but at pathological levels in response to noxious stimuli, an acute increase of ROS may activate autophagy (part of the cellular defense mechanism that prevents propagation of ROS through damaged mitochondria) or incite opening of the mitochondrial permeability transition pore (mPTP), which will cause cytochrome c release and activation of apoptosis.

1. The central role of mitochondrial oxidative stress and redox status in hypertension and heart failure. As discussed in section III, the prevalence of hypertension increases dramatically with age, with up to $70 \%$ of the population older than 70 years having hypertensive cardiovascular disease. Hypertension is the most common cause of $\mathrm{LVH}$, which predisposes to chamber dilatation, heart failure, and sudden cardiac death (101). As a key molecule in the Renin-Angiotensin System, which plays a pivotal role in hypertension, Ang II is well known to cause LVH and fibrosis (190). Inhibition of the Renin-Angiotensin System by angiotensin converting enzyme inhibitor or angiotensin receptor blocker is a standard clinical practice that improves the survival of patients with congestive heart failure.

Mutations of genes encoding mitochondrial enzymes have been shown to be associated with various forms of idiopathic hypertrophic and dilated cardiomyopathies, as seen in various mitochondrial diseases (76). Furthermore, mitochondrial DNA deletions have been found in experimental models of heart failure (200). We have demonstrated that Ang II delivered for 4 weeks using an osmotic minipump increased cardiac mitochondrial protein carbonyl content and the prevalence of mitochondrial DNA deletions (Fig. 9A, B) (69), both of which indicate oxidative damage to mitochondria. Accumulation of this damage activated mitophagy, as evident by an increased number of autophagosomes having the characteristic double-membrane structure seen by electron microscopy (Fig. 9C arrows) as well as by a significant increase in the LC-3 II/I ratio (Fig. 9D). As a homeostic mechanism, ROS-induced mitochondrial damage and turnover can result in increased signaling for mitochondrial biogenesis through activation of PGC- $1 \alpha$ and its target genes. This is consistent with the report that PGC- $1 \alpha$ is transcriptionally upregulated by ROS (302).

The central role of mitochondrial ROS in Ang II-induced cardiomyopathy is shown by the observation that mice which overexpress $\mathrm{mCAT}$, but not mice that overexpress wild-type pCAT, are resistant to cardiac hypertrophy, fibrosis, and diastolic dysfunction induced by Ang II (69). As shown in Figure 9, mCAT mice have attenuated AngII induction of protein carbonyls, mtDNA deletions, and autophagy (69). As shown in Figure 10, Ang II exposure for 4 weeks significantly increased normalized heart weights, which was attenuated by mCAT but not pCAT overexpression (Fig. 10A). Echocardiographic analysis demonstrated significant thickening of both interventricular septum and left ventricular posterior wall thickness, which was significantly attenuated by mCAT but not pCAT (Fig. 10B). Likewise, Ang II decreased Ea / Aa in WT mice, indicating diastolic dysfunction, which was again ameliorated by mCAT but not pCAT (Fig. 10B). 
A

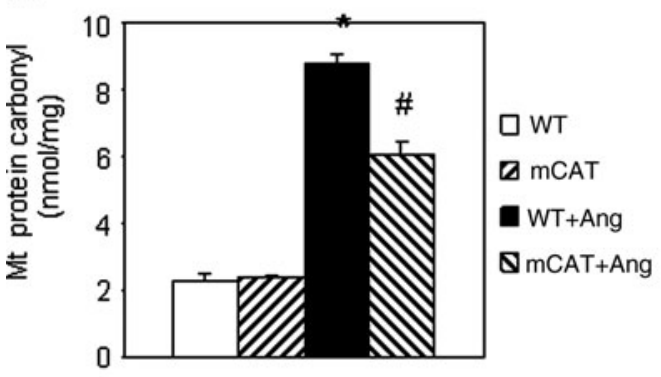

C

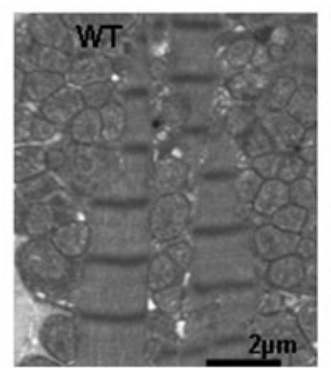

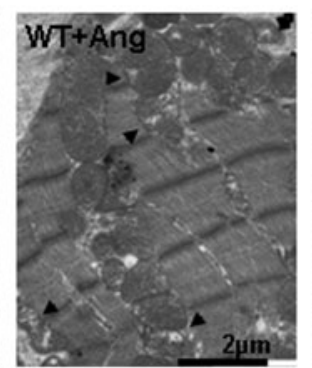

B
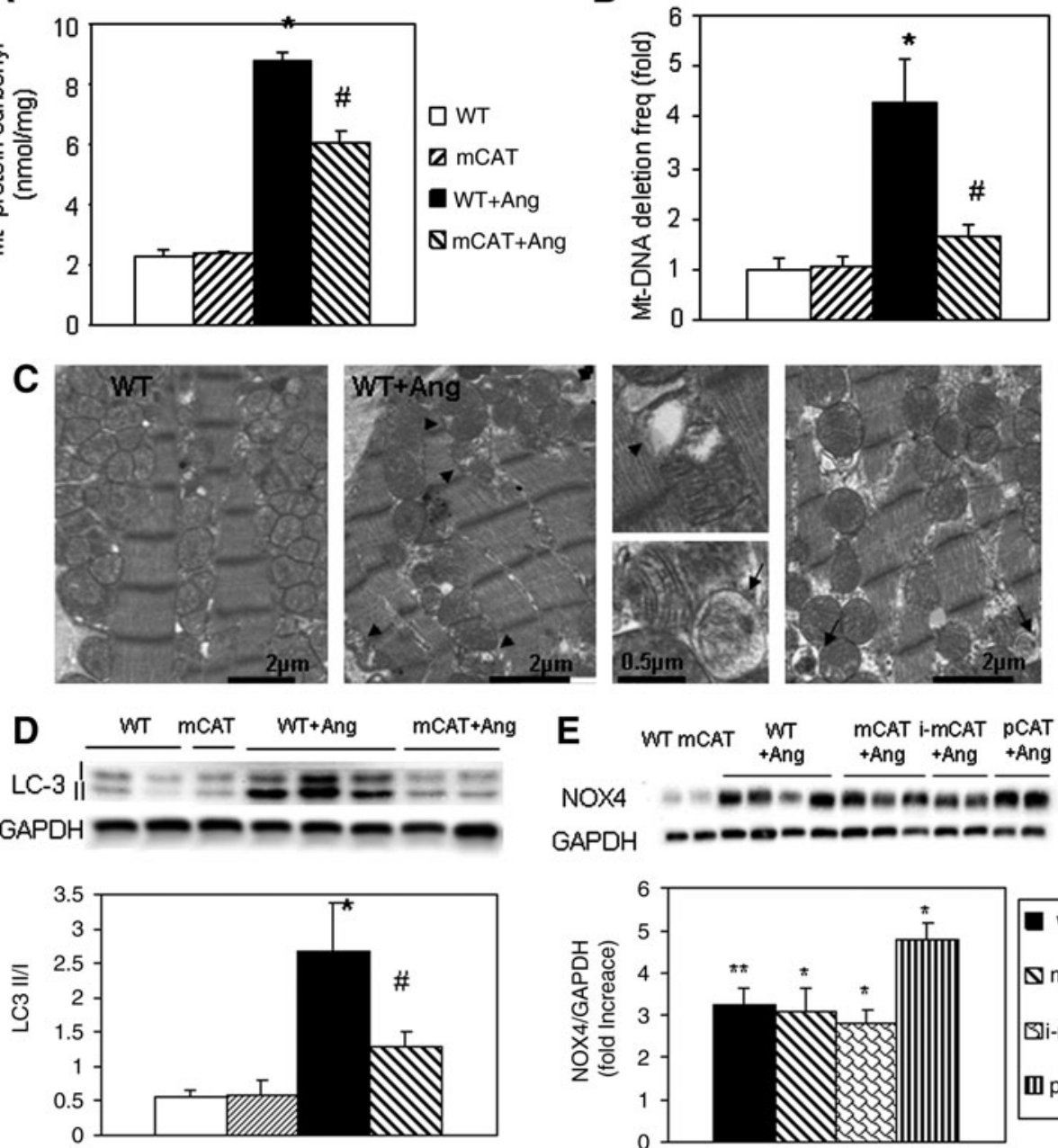
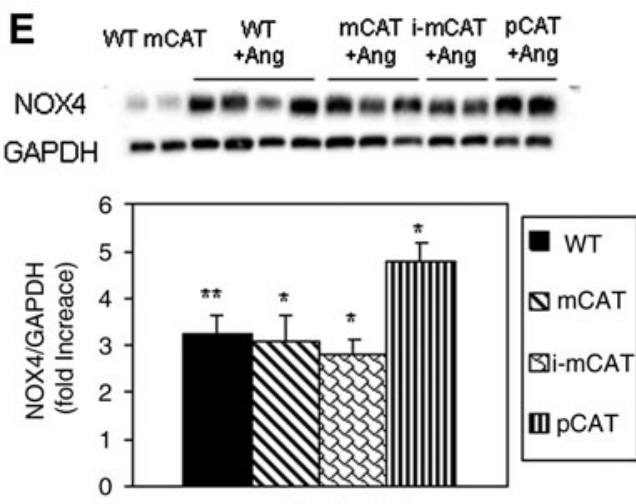

FIG. 9. Mitochondrial oxidative damage after Ang II. Ang II delivered for 4 weeks in an osmotic ominipump $(1.1 \mathrm{mg} / \mathrm{kg} / \mathrm{d})$ significantly increased (A) mitochondrial protein carbonyl (nmol/mg) and (B) mitochondrial DNA deletion frequency in WT hearts, both of which are significantly ameliorated in mCAT hearts. (C). Electron micrographs demonstrate damaged/vacuolated mitochondria (arrowheads) and autophagosomes (arrow) after Ang II in WT hearts. (D) Western blots of LC-3 showed that LC-3 II/I ratio, an indicator of autophagosomes, significantly increased in WT after Ang II, and this was attenuated by mCAT. (E) NADPH oxidase isoform 4 (NOX4) significantly increased after Ang II for 4 weeks. $\quad{ }^{*} p<0.05, \quad{ }^{* *} p<0.01$ compared with saline-treated WT controls, " $p<0.05$ compared with Ang II-treated WT. Ang, Angiotensin II; NADPH, nicotineamide adenine dinucleotide phosphate.
At the molecular level, Ang II binds to Angiotensin II receptor 1, a G $\alpha$ q coupled-receptor, then activates NOX through a protein kinase C (PKC)-dependent manner to produce ROS (214). ROS from NOX might increase mitochondrial ROS production, as previously shown in endothelial and vascular smooth muscle cells $(79,153)$. The data from our laboratory provide direct evidence that amplification of ROS within mitochondria is a key mediator of Angand Gaq-induced cardiac hypertrophy and failure (Fig. 10) (69). Mechanisms of ROS amplification might include ROSinduced ROS release as well as an ROS-mtDNA damage vicious cycle (Fig. 11). ROS production from NOX2/p47 phox at the cell membrane, and more specifically, NOX4 at the mitochondrial membrane can increase electron leakage from the electron transports chain, further stimulating ROS production. NOX4 expression is itself increased by AngII treatment (Fig. 9E) (69). This mechanism is also consistent with observations that primary damage to mtDNA is sufficient to elevate ROS, cause cardiac hypertrophy and accentuate Ang II effect to induce heart failure $(69,71)$. Thus, breaking the ROS vicious cycle within mitochondria by mCAT or mitochondrial-targeted antioxidants (see Section VIII.B) is effective in attenuating both cardiac hypertrophy and failure (Fig. 11).
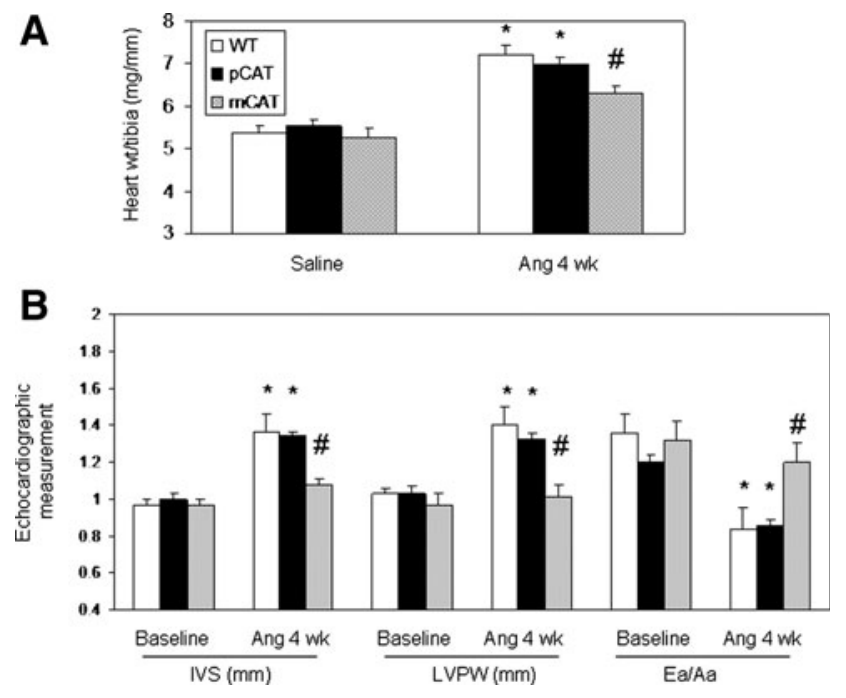

FIG. 10. Mitochondrial oxidative stress in Ang II-induced cardiac hypertrophy. (A) Normalized heart weight, (B) Echocardiography at baseline and after 4-week Ang II. ${ }^{*} p<0.05$, compared with saline-treated WT controls, ${ }^{*} p<0.05$ compared with Ang II-treated WT. 


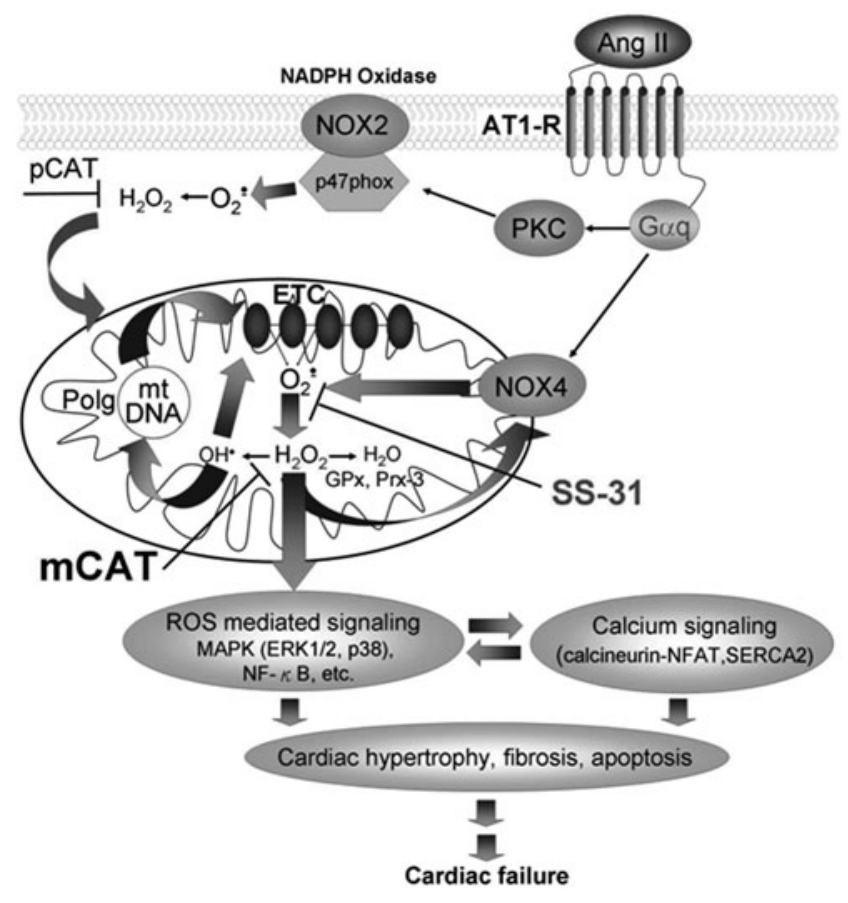

FIG. 11. Mitochondria amplify ROS signaling in cardiac hypertrophy and failure. Ang II binds to ATR1, a G $\alpha$ q coupled-receptor, then activates NADPH oxidases (NOX2 and NOX4). ROS from NOXs may contribute to mitochondrial ROS, which will then be amplified within mitochondria through ROS-induced ROS release and an ROS-mitochondrial DNA damage-increased ROS vicious cycles. Primary mtDNA damage in mice with homozygous mutation of polymerase gamma induces cardiac hypertrophy and failure through increase in mitochondrial ROS secondary to these vicious cycles. Breaking the ROS vicious cycles within mitochondria by mCAT or mitochondrial targeted SS-31 antioxidant is effective in attenuating both cardiac hypertrophy and failure. ATR1, Angiotensin II receptor 1.

The understanding that NOX4 is localized to the mitochondrial membrane increases the importance of considering mitochondrial ROS and nicotinamide adenine dinucleotide metabolism in Ang II-mediated cardiac hypertrophy and failure. Activation of NOX4 consumes nicotineamide adenine dinucleotide phosphate (NADPH) and directly contributes superoxide anions and ROS damage to mitochondria $(3,168)$. Detoxification of hydrogen peroxide derived by dismutation of superoxide is usually performed in mitochondria by Peroxiredoxin-3 (Prx-3) and GPx. After their oxidation by hydrogen peroxide, these enzymes are regenerated using the ultimate reductive power of NADPH. However, the consumption of NADPH by NOX4 establishes another potential mitochondrial vicious cycle. Note that mitochondrial catalase or other mitochondrial antioxidants (see section VIII.C) can bypass this vicious cycle by removing superoxide or hydrogen peroxide without consuming glutathione (GSH) or NADPH. NADPH can itself be regenerated from NADP + by electron exchange with nicotineamide adenine dinucleotide (NADH), catalyzed by nicotinamide nucleotide transhydrogenase. Thus, cardiomyocyte mitochondrial redox status is intimately bound with nicotinamide adenine dinucleotide metabolism. This further implicates SIRTs (sensors of the ratio of NAD + /NADH), particularly SIRT3, in an epigenetic cardiac response to stress (see section VIII.C).

Recently, it has been reported that mitochondrial nitric oxide synthase (mtNOS) is also activated by Ang II subsequent to binding of Ang II to an AT2R receptor located in the mitochondrial inner membrane (mtAT2R) (1). The mtNOS uses NADPH and arginine as substrates to generate the nitric oxide radical (NO·). $\mathrm{NO} \cdot$ has been shown to regulate oxygen consumption by inhibition of Complex IV of the electron transport chain (ETC) $(86,258)$. Thus, while consuming $\mathrm{NADPH}$, production of nitric oxide (NO) could directly compromise respiratory function. In addition, formation of peroxynitrite by reaction of $\mathrm{NO} \cdot$ with $\mathrm{O} 2{ }^{-}$would lead to increase nitrosative stress in the mitochondrial compartment, including damage to respiratory complexes and opening of the MPTP (262).

It is clear from the discussion just conducted that mitochondrial oxidative and nitrosative stress can have a direct impact on glutathione redox status (GSH:GSSG ratio) and nicotinamide nucleotide redox potential (NAD/NADH and NADP/NADPH) and that these are closely interrelated within mitochondrial metabolism. GSH:GSSG ratios have been reported to be lower in hearts of aged mice compared with young mice (264) and rats (167) and senescence-accelerated versus wild-type mice (265). Similar effects have been seen in NAD+ / $\mathrm{NADH}$ ratios in aging rat hearts (39). These interconnections between oxidative stress, GSH and nicotinamide nucleotide redox potential, and Sirt activity motivate the desire to enhance redox balance in aging and disease by pharmacologic treatment. Past and future strategies for such intervention are discussed in section IX, given next.

2. The role of mitochondria and oxidative stress in IR injury. Reperfusion therapy, by either primary percutaneous coronary intervention or thrombolytic therapy to reopen the blocked coronary artery within the "golden period" after ischemia, has become a standard therapy for acute myocardial infarction. Reperfusion therapy is necessary and beneficial to salvage the ischemic myocardium; however, it also exposes the heart to IR injury, which may induce reperfusion arrhythmia, stunned myocardium (transient myocardial dysfunction), and massive myocardial damage that can eventually lead to congestive heart failure, despite the successful revascularization of the coronary artery. Coronary revascularization using coronary artery bypass grafting may also be associated with myocardial stunning and cell necrosis due to IR injury.

At the molecular level, ROS have been well known to be primary mediators in IR injury. ROS begin to accumulate during ischemia (25), causing mitochondrial respiratory complex dysfunction, which, in turn, produces a burst of ROS after reperfusion. Furthermore, the marked acidosis associated with IR may facilitate the conversion of the less potent oxidants superoxide and hydrogen peroxide to the highly reactive oxidants peroxynitrite and the hydroxyl free radical. It has been shown that several conditions associated with post-IR, such as ROS accumulation, acidic $\mathrm{pH}$, and a rise in $\left[\mathrm{Ca}^{2+}{ }_{\mathrm{i}}\right]$, open the $\mathrm{mPTP}$, which, in turn, triggers more mitochondrial ROS generation. This is one of the mechanisms involved in mitochondrial ROS-induced ROS release (360).

The $\mathrm{MPTP}$ is a high conductance channel located in the inner mitochondrial membrane (IMM). The physiological 
roles of the MPTP include regulation of mitochondrial matrix volume and $\mathrm{pH}$ as well as redox reaction, regulation of $\mathrm{Ca} 2$ + release, and pyridine nucleotides rapid exchange across the IMM [see review (74)]. Several factors have been reported as facilitating mPTP opening: increasing matrix [Ca2+], mitochondrial depolarization (drop in $\Delta \psi_{\mathrm{m}}$ ), which is related to increased oxidative stress or a decline in NADPH/NADP + and thiol/disulfide ratios, slight acidic $\mathrm{pH}$ (around 7.3), and the loss of the buffering effect of mitochondrial inorganic phosphate (74). The pathological roles have been widely studied in IR injury, during which the MPTP is in the fully open state and allows passive diffusion of solutes with molecular masses up to $1.5 \mathrm{kDa}$. The $\mathrm{mPTP}$ opening may cause mitochondrial swelling, further collapse of mitochondrial membrane potential $\left(\Delta \psi_{\mathrm{m}}\right)$, ATP depletion, and eventually trigger apoptosis (73).

The aged myocardium is more susceptible to both ischemia and hemodynamic stress than is young myocardium (134). Aged cardiomyocytes have a lower threshold for ROSinduced ROS release and increased susceptibility to $\mathrm{MPTP}$ opening (142). Furthermore, ischemic preconditioning, the endogenous cardioprotective mechanism incited by repetitive ischemia that reduced the area of myocardial infarction, is also impaired in the aged myocardium [reviewed by (142)]. This loss of endogenous protective mechanisms of ischemic preconditioning in the aged heart might include a decrease in mitochondrial heat shock protein-70 (232), decline in NO bioavailability (57), damaged mitochondria that are vulnerable to stress, and diminished PKC translocation, all of which are believed to be required for the protective effect of ischemic preconditioning $(158,316)$.

In support of a critical role for $\mathrm{mPTP}$ opening and apoptosis in human cardiac disease, a small pilot clinical study applying cyclosporine, a mitoprotective agent that blocks the opening of the mitochondrial permeability-transition pore, has shown very promising results in reducing infarct size in patients with acute myocardial infarction receiving reperfusion therapy (256).

\section{B. Mechanisms of progression to heart failure in the aged hypertrophic heart}

In response to chronic stress, the aged myocardium remodels, by a complex of events that includes myocyte growth or hypertrophy, re-expression of a fetal gene program and remodeling of extracellular matrix (ECM). These changes reduce functional reserve and predispose the aged hearts to the development of heart failure. Molecular mechanisms underlying the progression to heart failure are discussed below and in ref. (239).

1. Increased cardiomyocyte death. Increased cardiomyocytes death is observed in various types of cardiomyopathy, such as ischemic and dilated cardiomyopathy, hypertensive cardiomyopathy, and cardiac aging (221). The increase in cardiomyocyte death has been reported to contribute to impaired contractility and induce ventricular remodeling, which may eventually cause symptomatic heart failure (90). Noxious stimuli incite signaling molecules in favor of cell death rather than cell survival, and this perturbation will result in cardiomyocytes death and subsequent cell loss, as is frequently seen in heart failure. Various types of cardiomyocytes cell death, including necrosis, apoptosis, and autophagy have all been reported in heart failure.

Necrosis could be caused by ischemia or IR through increased burst of ROS and augmentation of $\mathrm{Ca}^{2+}$ entry, which triggers the opening of mPTPs by activating cyclophilin D (226). Apoptosis can be elicited by several different stimuli that are also mediated by increased ROS, such as Ang II, sympathetic stimulation, and cytokines. Increased cardiomyocyte apoptosis has been widely documented as contributing to the phenotype of heart failure $(90,343)$. Autophagy is characterized by recycling of proteins within organelles. A study using mice overexpressing cardiac specific diphtheria toxin receptors demonstrated that diphtheria toxin-induced autophagy is associated with cardiomyocyte death and heart failure (6). Decreased cardiac autophagy in mice with heterozygous disruption of the gene coding for beclin 1 was associated with diminished pathological remodeling when challenged by severe pressure overload (358). Conversely, beclin 1 overexpression increased autophagic activity and accentuated pathological remodeling (358). Consistent with this, increased autophagic activity has been observed in human heart failure (159). Interestingly, impairment of autophagy in mice with cardiac specific disruption of Atg5 was also found to have cardiac hypertrophy, left ventricular dilatation, and systolic heart failure, accompanied by increased levels of ubiquitination (225). Collectively, these studies suggest that constitutive autophagy is a homeostatic mechanism in the heart that is required to maintain normal cardiac structure and function, and that genetic models of increased autophagy or upregulation of autophagy as a maladaptive response to hemodynamic stress will cause heart failure. While the term "autophagic cell death" has been used in previous literature, recent studies have shown that autophagy can be a pro-survival rather than a pro-death mechanism. Hence, cell death may often be associated with, but not caused by, the accumulation of autophagosomes $(165,183)$. [see review $(72)]$.

2. ECM remodeling. In response to various injury stimuli, the myocardium can undergo compensatory or pathologic remodeling, with cardiomyoctye death and hypertrophy of the remaining cells, as well as alterations in the composition and structure of the ECM. ECM remodeling might affect cardiac size, structure, and function and directly contribute to the development of heart failure $(80,194,195,274)$ and cardiac aging (196). The ECM is always in an active and continuous turnover process involving the synthesis of ECM by myofibroblasts and the degradation of collagens by MMPs through TGF- $\beta$ dependent signaling (178). Pathological ECM remodeling, especially interstitial fibrosis, increases cardiac stiffness and reduces cardiac compliance as well as disrupts the coordination of myocardial excitation-contraction coupling [reviewed by Berk (32) and Spinale (301)]. Several studies using animal models of heart failure have shown that inhibition of pathological ECM remodeling by MMP inhibitors ameliorates cardiac dysfunction $(80,178,194,195,274)$.

3. Alteration of calcium handling proteins. $\mathrm{Ca}^{2+}$ is the signaling molecule of excitation-contraction coupling. This coupling is initiated by opening of the L-type calcium channels during depolarization (action potential), which allows entry of a small current of $\mathrm{Ca}^{2+}$ that subsequently triggers the ryanodine receptor to release a large scale $\mathrm{Ca}^{2+}$ current from 
sarcoplasmic reticulum $\mathrm{Ca}^{2+}$ storage $\left(\mathrm{SRCa}^{2+}\right)$. This increase in cytosolic $\mathrm{Ca}^{2+}$ binds and activates Troponin $\mathrm{C}$ within the myofilaments and induces myocyte contraction. Relaxation is initiated by reuptake of cytoplasmic $\mathrm{Ca}^{2+}$ into the SR through phospholamban-regulated Calcium-ATPase (SERCA2a) and subsequent trans-sarcolemmal $\mathrm{Ca}^{2+}$ removal through the sodium calcium exchanger. Thus, in normal hearts, electrical propagation (action potential) precedes calcium transients, which triggers the cardiomyocytes contraction-relaxation cycle, and the whole process is called excitation-contraction coupling.

It has been reported that $\mathrm{Ca}^{2+}$ reuptake into the SR is impaired in cardiac aging and congestive heart failure, and consequently, the SR $\mathrm{Ca}^{2+}$ storage is also decreased $(71,127,234)$. The decline in $\mathrm{Ca}^{2+}$ reuptake in heart failure could be explained by decreased SERCA2 protein concentration [as seen in murine cardiac aging (71)], oxidative/nitrative modification that impairs SERCA2 protein function, reduced levels of phospholamban phosphorylation, and the depletion of SR $\mathrm{Ca}^{2+}$ through leaky ryanodine receptor channels (33). Genetic manipulation of mice with improvement of $\mathrm{Ca}^{2+}$ reuptake, such as overexpression of SERCA2 (210) or disruption of phospholamban, has been reported to attenuate heart failure in experimental animals $(129,208)$.

4. Hypoxic response and angiogenesis. Cardiac hypertrophy results in increased myocardial oxygen demand and decreased coronary perfusion pressure; the latter is due to compression of the coronary microcirculation. The mismatch in oxygen/nutrient supply-demand induces a relative ischemia in the hypertrophic heart, which may eventually cause energetic failure. Previous studies in mice with Akt-induced cardiac hypertrophy showed a concomitant increase in angiogenic growth factors such as vascular endothelial growth factor (VEGF) and angiopoeitin 2 during the hypertrophic phase, and that inhibition of VEGF signaling in hypertrophic hearts would induce relative ischemia and progress to heart failure $(135,296)$. Furthermore, the cardiac transcription factor GATA4, a fetal gene reactivated during hypertrophy, is shown to pro-angiogenic to help maintaining the balance between growth of new muscle and capillaries in hypertrophic hearts (123). However, in murine hearts, activation (phosphorylation) of GATA4 is reduced in aging (71).

5. Mitochondrial dysfunction and abnormalities in energetics. Cardiac hypertrophy is associated with upregulation of the signaling for mitochondrial biogenesis, including PGC1 $\alpha$ and its downstream target genes (69). However, mitochondrial proliferation often does not keep pace with the increasing energy demand of the hypertrophic hearts (261). Our recent study demonstrates that Ang II-induced cardiac hypertrophy is associated with depletion of mitochondrial DNA copy number and impairment of mitochondrial respiratory function. Mice with homozygous mutation of the exonuclease domain of mitochondrial polymerase gamma $\left(\right.$ Polg $\left.^{D 257 A / D 257 A}\right)$, which, as just noted, have a progeroid phenotype accompanied by increased mitochondrial DNA mutations, are susceptible to the development of heart failure at middle age or at a young age after challenge with 4 weeks of Ang II $(69,71)$. This suggests that primary damage to mitochondrial DNA contributes directly to the phenotype of systolic heart failure. Studies on human hearts using ${ }^{31} \mathrm{P}$ NMR spectroscopy indicated that the ATP content of failing hearts is generally $20 \%-30 \%$ lower than that of normal hearts (26). Furthermore, phosphocreatine, an important short-term reserve energy source that maintains a high phosphorylation potential to cope with acute increases in energy demand (e.g., exercise), significantly declined by up to $60 \%$ in elderly heart failure patients (341). The magnitude of this reduction is related to the severity of heart failure (224) and is shown to predict mortality in patients with dilated cardiomyopathy (229).

\section{Exercise, Cardiovascular Risks, and Cardiac Aging}

Exercise is broadly accepted as reducing the risk of cardiovascular disease. Several epidemiological and clinical studies have shown an inverse correlation between exercise and the components of metabolic syndrome $(68,147,249)$, which include abdominal obesity, high serum triglyceride and low serum high density lipoprotein (HDL) cholesterol, high blood pressure, and impaired fasting glucose. Lifestyle modification including exercise significantly reduced obesity (337). The beneficial effect of exercise on improvement of serum atherogenic lipoprotein profiles mainly include reduction of serum triglycerides, increase in HDL cholesterol, and increase in average size of low density lipoprotein (LDL) particles $(155,162,181)$ [see review (4)]. The effect of exercise to decrease total cholesterol and LDL cholesterol usually occurs in association with significant weight loss (215). Meta-analyses of exercise programs demonstrate that exercise is effective in reducing blood pressure in hypertensive patients $(75,84)$ and in better controlling blood glucose in diabetic patients $(58,327)$. In addition, higher physical activity has also been shown to reduce carotid artery intima media thickness, a surrogate marker of atherosclerotic burden, which is an independent predictor of cardiovascular events, as shown in the Framingham Offspring Study (259).

Cardiovascular risks, including hypertension and diabetes, have been shown to induce LVH, impairment of cardiac function, and several molecular changes mimicking "premature cardiac aging," including telomere shortening (331), and expression of senescent associated proteins p53, p21 and p16INK4a $(160,278)$. A recent study on patients undergoing cardiac surgery demonstrated that obesity resulted in disturbed mitochondrial biogenesis and respiratory function, increased oxidative stress, and shortening of telomere in cardiomyocytes isolated from young obese patients, at levels comparable to those found in old nonobese patients (231). This study suggests that obesity, similar to hypertension and diabetes, also induces phenotypes of premature cardiac aging in young patients.

Regular aerobic exercise is effective in reducing cardiovascular risks, and it is also expected to attenuate cardiovascular aging. Previous cross-sectional studies revealed that subjects with higher levels of self-reported physical activity are associated with a reduction of age-dependent large artery stiffness, diastolic dysfunction (102,315), and LVH (68). Small longitudinal studies comparing 12 elderly athletes/runners with 12 age-matched healthy sedentary seniors reported that athletes have significantly better LV compliance and diastolic function (16) as well as better aerobic capacity ( $\mathrm{VO}_{2}$ max), independent of the exercise effect on body mass index and lipid profiles (219). An interventional study $(n=12$, age $=50-60$ years, nonobese, 1 year duration) demonstrated that both 
caloric restriction and exercise improved diastolic function, in association with significant weight loss (269). In contrast, progressive and vigorous exercise training of previously sedentary elderly $(n=12$, mean age $=70,1$ year duration) failed to reverse preexisting cardiac stiffness and diastolic dysfunction, although exercise increased maximal exercise capacity and improved arterial elastance (reduced pressureoverload) $(96,235)$.

Since exercise is an inexpensive way to retard aging changes and to reduce the risk of CVDs and cancer, the World Health Organization recommends at least $150 \mathrm{~min}$ of moderateintensity aerobic physical activity throughout the week, or 30 min of aerobic exercise per day, 5 days per week (WHO 2010 Global Recommendations on Physical Activity for Health). For individuals who cannot reach the target recommended by $\mathrm{WHO}$, lower amounts of exercise are also beneficial, as shown by a recent prospective cohort study of more than 400,000 individuals which demonstrated that self-reported low-volume physical activity (exercise $\sim 90 \mathrm{~min}$ per week or $15 \mathrm{~min}$ per day) reduced all-cause mortality by $14 \%$, and every additional $15 \mathrm{~min}$ increase in exercise beyond the minimum amount of $15 \mathrm{~min} /$ day further reduced all-cause mortality by $4 \%$ (342). Since exercise has been shown to improve aerobic capacity and the phenotypes of cardiac aging, this study is consistent with previous animal studies showing the relationship between cardiac aging, aerobic capacity, and lifespan. In rodent models, lifespan was independently predicted by the degree of cardiac aging in the mouse model (71) and by the difference in genetically determined aerobic capacity (treadmill running capacity), which was created by selective breeding of rats with diverse genetic background (154).

In experimental animals, exercise training ameliorated agedependent impairment of adrenergic signaling as well as enhanced responsiveness to sympathetic stimulation in the aged rat heart (182) and in the rabbit model of pacing-induced heart failure (99). The mechanism is mainly through the activation of endogenous antioxidant mechanisms $(99,220)$. As just discussed, endurance exercise induced systemic mitochondrial biogenesis, prevented mtDNA depletion and mutations, and improved mitochondrial oxidative capacity in skeletal muscles of mtDNA mutator mice $\left(\right.$ Polg $\left.{ }^{\mathrm{m} / \mathrm{m}}\right)$, thereby rescuing the "premature aging" phenotypes of these mice (283). The beneficial effect of exercise on improvement of insulin sensitivity, mitochondrial biogenesis, and upregulation of endogenous antioxidant defense is also dependent on ROS, as these effects are blocked by oral vitamin C and vitamin E in humans (271), indicating the mitohormesis effect (see section V.C). Aging is also associated with reductions in AMPK activity and decreased mitochondrial biogenesis in skeletal muscles (268). These aging changes are counteracted by exercise training, which upregulates AMPK. Activation of AMPK phosphorylates and directly activates PGC- $1 \alpha$ (136). In addition, AMPK activation might also increase mitochondrial biogenesis indirectly through SIRT1 and SIRT3 dependent PGC-1 $\alpha$ deacetylation $(187,248)$.

\section{Emerging “Anti-Aging” Interventional Strategies for Cardiac Aging and CVDs}

\section{A. Dietary restriction}

DR is an extremely well-established intervention that has been clearly demonstrated as increasing lifespan and reduc- ing the onset and severity of a variety of age-related pathologies. Whether the effects of DR in multicellular organisms are cell autonomous or neurohormonal is largely still open to discussion. This intervention has been demonstrated in a wide array of model organisms, from yeast and nematodes to mice, rats, and, most recently, rhesus monkeys $(59,64,92,146,203)$. Specific to cardiac aging, DR has been shown to be a powerful preventative for cardiovascular disease in rodents and nonhuman primates $(64,230,294)$. Similar protective effects have also been observed in human and animal trials of alternateday fasting (330), demonstrating that even transient activation of the pathways involved in the DR response can be beneficial. In addition to the role of mTOR in nutrient signaling just discussed (Section VI.C), both DR and exercise signal to some extent through the $\mathrm{NAD}(+)$ dependent deacetylase SIRT3 (248) (the Sirt that is most prevalent in the heart) demonstrating a functional overlap between DR, exercise, and nutrient signaling. DR has also been shown to activate SIRT1, probably dependent on NO signaling $(292,293)$.

DR is mediated primarily through nutrient signaling pathways, but the beneficial effects of DR are difficult to assign to individual processes or pathways downstream of nutrient signaling. A flood of recent work on DR in cardiac aging indicate that cardiac stem cells (294), mitochondrial function $(124,230,275)$, and ROS production $(60,209)$ have all been demonstrated to be beneficially affected by DR, and have all been implicated in the beneficial affects provided by restricting dietary intake.

Adding to the list of potential benefits provided by DR, increased autophagy (see the mitochondrial-lysosomal theory of aging, above) is a well-documented result of DR. Autophagy, though often associated with cardiac disease, is upregulated in both DR and inhibition of mTOR signaling by the drug rapamycin $(107,347)$, and is thought to be a key component of the beneficial effects of DR. While there are still many unanswered questions with regard to the mechanisms of DR, and the use of DR as a clinical intervention is problematic, the robust effects of DR on preventing cardiovascular disease and cardiac aging are clear. The cardiac aging field will undoubtedly continue to benefit from and contribute to the scientific understanding of DR. The search for DR mimetics is an active discipline and may provide important clinical interventions for the treatment and prevention of heart disease and cardiac aging.

\section{B. Antioxidant interventions}

1. Nontargeted antioxidants. Since many animal and clinical observational studies suggest a crucial role for increased ROS in many diseases, including CVDs, the therapeutic application of antioxidant therapies have been evaluated in several placebo-controlled trials involving tens of thousands of patients with the endpoint of cardiovascular events as well as mortality $(164,336)$. The results from these studies are either disappointing or equivocal. Only a few smaller studies with short-term follow-up show the beneficial effects of vitamin $\mathrm{E}$ or $\mathrm{C}$ for secondary prevention of cardiovascular events, while other larger trials with longer followup (up to 12 years, as in the Physicians' Health Study) fail to show any effect [see review by Kris-Etherton, et al. (164)]. A few large-scale meta-analyses of randomized trials have been performed in recent years. In a meta-analysis of 68 
randomized trials including 232,606 participants from the general population or patients with heterogeneous diseases, Bjelakovic et al. reported that antioxidant supplements had no significant effect on overall mortality. When including only the trials with high methodological quality $(180,938$ participants), there was a significant increase in mortality in subjects receiving beta carotene, vitamin $\mathrm{A}$, and vitamin $\mathrm{E}$, either singly or combined (34). In an earlier meta-analysis of 12 randomized trials involving 138,113 participants, there was no effect of vitamin A on all-cause mortality, cardiovascular death, or stroke. Again, beta-carotene was shown to significantly increase all-cause mortality and cardiovascular death (336). This is very disappointing, given the abundance of epidemiologic, clinical pathophysiologic studies, and mechanistic data from animal studies supporting the application of antioxidant therapies in the treatment and prevention of cardiovascular disease. It might, however, be too early to claim that antioxidants as a class are ineffective. Indeed, another recent meta-analysis of 44 observational clinical studies measuring endogenous antioxidant activity in cells or biological fluids demonstrated that there was a significant inverse association between circulating levels of GPx, SOD, and catalase activities with coronary heart disease (89). Given these controversies, it is, therefore, very important to evaluate why most clinical trials have failed to show beneficial effects.

There are many potential explanations for the failure of antioxidants clinical trials for prevention and treatment of CVDs (305): First, the wrong drugs may have been studied. Most studies have used supplementary vitamins as "antioxidants," not because they have better efficacy as antioxidants but rather because they are readily available. Some agents, such as vitamin E, have subsequently been shown to have pro-oxidant effects, consistent with the fact that vitamin $\mathrm{E}$ supplement significantly increases mortality in the metaanalyses just noted.

The endogenous antioxidant enzymes, SOD, catalase, and GPx, are not feasible drug molecules because of their size, rapid degradation, and potential antigenicity. Over the past few years, there have been a number of attempts to develop synthetic molecules that can mimic the activities of these scavenging enzymes. Several major classes of synthetic SOD, catalase, and GPx mimetics have been reported and were recently summarized in a review article (252). The most extensively investigated have been the Mn (III) porphyrins, and these SOD mimetics have been reported to reduce oxidative stress, inflammation, and tissue damage in animal models of human disease. AEOL10150 is currently in phase 2 clinical trial for radiation injury; while M40403 is being developed by Metaphore for inflammatory pain. These metalloporphyrins can also possess varying extents of catalase activity due to their extensive conjugated ring system that can undergo reversible one-electron transfers in addition to the one-electron transfer on the metal center. Another class of synthetic catalytic antioxidants, the Mn (III) salen complexes, are both SOD and catalase mimetics. The EUK series of drugs have demonstrated efficacy in several animal models of human disease, and EUK-8 and EUK-134 were reported to attenuate pressureoverload induced cardiac failure $(272,328)$. Ebselen was one of the first selenium-based GPx mimetics shown to scavenge peroxides in the presence of reducing equivalents such as GSH, NAC, and dihydrolipoate. Ebselen can stimulate the decomposition of several ROS species, including singlet ox- ygen, hypochlorous acid, and peroxynitrite. Ebselen has been shown to be effective in several models of ischemic injury and neurodegenerative disease, but its effectiveness is complicated by its lack of specificity due to its binding to thiol groups on proteins, as many cellular proteins have reactive thiols in their catalytic domains. Despite the promising animal data, there is no evidence that these synthetic catalytic antioxidants can scavenge mitochondrial ROS and protect mitochondria against oxidative stress. Furthermore, since mitochondria are the primary sites of ROS generation in cardiac aging, hypertensive, and ischemic heart diseases, the nontargeted antioxidants might not be as effective as targeted antioxidants (see below).

Second, the wrong patient population may often have been selected. Secondary prevention might have failed, because antioxidants were ineffective to reverse advanced diseases and even in primary prevention, antioxidants might not be effective to reverse established subclinical diseases. Third, inappropriate dosing may often have been used. It is noteworthy that the meta-analyses just mentioned have included multiple different regimens with different dosing. Finally, these studies have included very heterogeneous participants ranging from the general population to patients with myocardial infarction or cancers. Taken together, further highquality prospective studies using well-established antioxidant regimens are required.

2. Mitochondrial-targeted antioxidants. Given the disappointing results from clinical studies of nontargeted antioxidants just noted (34), coupled with the generally negative data from model organisms, also as just noted, it is evident that untargeted antioxidant therapies have as yet failed to provide effective interventions in cardiac aging and, in most cases, disease. This finding supports the idea that antioxidant therapies that are targeted to the mitochondria-the major source of pathogenic ROS and the damaged target of ROS in many diseases-may be a much more effective strategy. There has been some success in the development of therapies targeted to the mitochondria, such as the Szeto-Schiller synthetic antioxidant peptides $(54,310-312,356)$ and the drugs MitoQ and Euk $(309,328,334)$. These therapies have demonstrated some potential effectiveness in models of cardiac stress (see below), although their effectiveness in preventing the progressive functional decline associated with cardiac aging is yet to be determined.

Mitochondria are complex organelles, and it is important to consider the specific mitochondrial compartment that should be targeted for effective antioxidant therapies. Mitochondria are composed of two membranes, an outer mitochondrial membrane (OMM) and an IMM. The protein complexes of the ETC reside on the IMM, and the proton gradient generated across the IMM as a result of electron transfer from NADH to oxygen via Complexes I, III, and IV drives the production of ATP by the $\mathrm{F}_{0} \mathrm{~F}_{1}$ ATP synthase. In fact, many approved drugs can penetrate the OMM and inhibit mitochondrial function, by either inhibiting the protein complexes of the ETC, uncoupling the proton gradient, or directly inhibiting the ATP synthase [for review, see (41)]. The IMM is unique in that it has a very high concentration of proteins and is rich in cardiolipin, a very anionic phospholipid that has four fatty acid chains rather than two. This special composition makes the IMM highly impermeable to most molecules. Thus, it is much more 
difficult for therapeutic molecules to penetrate the IMM and reach the mitochondrial matrix.

Excessive electrons in the ETC results in electron leakage and the generation of superoxide anion, especially at Complex I and Complex III. Superoxide from complex I is released into the matrix, while complex III can release superoxide into the matrix as well as the intermembrane space. The proteins and cardiolipin of the IMM are, therefore, most vulnerable to oxidative damage. Cardiolipin peroxidation will result in loss of cytochrome c and inhibition of electron transfer, thereby setting up a feed-forward cycle of ROS-induced ROS production. Thus, effective antioxidant therapy would need to be targeted to the IMM or mitochondrial matrix to be successful in reducing mitochondrial oxidative damage.

a. $\mathrm{TPP}^{+}$conjugated antioxidants. The most common method for targeting compounds to the mitochondrial matrix takes advantage of the potential gradient $(150-180 \mathrm{mV})$ that is generated as a result of the proton gradient across the IMM. Conjugating lipophilic antioxidants to a cation can result in 100-1000-fold accumulation in the mitochondrial matrix (251). Triphenylalkylphosphonium ion (TPP +) has successfully been used to deliver a number of redox-active compounds such as coenzyme Q (MitoQ) and plastoquinone (SkQ1) (298), into the mitochondrial matrix. MitoQ is taken up rapidly by energized isolated mitochondria, and addition of the uncoupler FCCP caused its immediate efflux (150). Likewise, the cellular uptake of both $\left[{ }^{3} \mathrm{H}\right] \mathrm{MitoQ}$ and SkQR1 (a rhodamine analog of SkQ1) is dramatically reduced in the presence of FCCP $(12,150)$. MitoQ and SkQ1were shown to inhibit lipid peroxidation in isolated mitochondria, with SkQ1 being almost 1000-fold more potent than MitoQ (12). Both MitoQ and SkQ1 protected against oxidative cell death in $\mathrm{nM}$ concentrations, with SkQ1 being more potent (12). This lipophilic-cation approach has been used to generate mitochondria-targeted antioxidants that are designed to decrease superoxide (MitoSOD), hydrogen peroxide (MitoPeroxidase), ferrous iron (MitoTEMPO), and lipid peroxidation (MitoE2) [see review (216)].

The use of this lipophilic cation approach has some limitations. The dependence on mitochondrial potential for their uptake restricts their uptake by mitochondria with compromised potential gradient, which is often seen in disease conditions such as ischemia. Furthermore, MitoQ and SkQ1 have been reported to disrupt mitochondrial potential and inhibit respiration at concentrations above $25 \mu M(12,150)$. The reduction in mitochondrial potential effectively limits further uptake of these lipophilic cations (150). Another potential limitation of MitoQ is its prooxidant action as it is reduced to a semiquinone radical at the level of complex I $(216,233,288)$. The radical formed reacts with $\mathrm{O}_{2}$ to form superoxide radicals. MitoQ only serves as an antioxidant when complex I is inhibited. Thus, the antioxidant activity of MitoQ should be interpreted with caution. The "window" between antioxidant and prooxidant activity of SkQ1 is higher than that of MitoQ (12).

MitoQ and SkQ1have been evaluated in a number of in vivo animal models. Pretreatment of rats with MitoQ for 2 weeks reduced ischemia-induced cardiac dysfunction in the isolated perfused heart (2). Likewise, 3 week pretreatment with SkQ1 reduced infarct size after ligation of the coronary artery in vivo (19). Interestingly, treatment of young spontaneously hyper- tensive rats with MitoQ for 8 weeks produced a significant, but modest, reduction in systolic blood pressure, improved the availability of endothelial $\mathrm{NO}$, and reduced cardiac mass (150). Since only a single dose of MitoQ was examined in this study, it is not known whether higher doses might provide more protection. It is also not possible to determine whether the slight reduction in cardiac mass index in mitoQ treated rats is a direct effect of mitoQ or a secondary response to the decrease in blood pressure. Similarly, daily treatment with SkQ1 for 3 weeks significantly reduced postischemic cardiac arrhythmias and infarct size in rats, although the doseresponse curves were biphasic with loss of protection at higher doses (19).

The effectiveness of these $\mathrm{TPP}^{+}$-conjugated antioxidants appear to require a substantial period of pretreatment before the induction of cardiac stress. When a single dose of SkQ1 was administered 1 day before the disruption of renal blood flow, there was no significant protection of renal function $24 \mathrm{~h}$ after ischemia as measured by blood creatinine concentration (19), The reason for this necessity of a substantial period of pretreatment is not clear, but these potential-dependent antioxidants are unlikely to be effective if administered after ischemia due to mitochondrial depolarization. Thus, these compounds may be more suitable for the treatment of chronic disease than the prevention of acute disease.

There are to date two reports of MitoQ in human trials. In patients with Parkinson's Disease, MitoQ showed no difference from placebo in any measure of disease progression (299). In chronic hepatitic C virus patients, a double-blind, randomized, parallel-design trial of two different doses of MitoQ over a 4 week treatment demonstrated that there was no effect of MitoQ on viral load compared with placebo; however, both MitoQ treatment groups showed significant decreases in serum alanine transaminase from baseline (98). This study was the first report of a potential clinical benefit from the use of mitochondria-targeted antioxidants in humans.

b. Szeto-schiller peptides. The Szeto-Schiller (SS) peptides are the first compounds that selectively target and concentrate in the IMM where ATP and free radical production takes place. These synthetic compounds are tetrapeptides with an alternating aromatic-cationic motif. They are cell-permeable and selectively concentrate in the IMM as demonstrated by confocal laser scanning microscopy and isolated mitochondria studies $(19,78,356)$. The mitochondrial uptake of these SS peptides is not dependent on mitochondrial potential, and they are rapidly taken up even by depolarized mitochondria. Potential-independent uptake is a significant advantage when dealing with diseased mitochondria that are likely to have a reduced mitochondrial potential. SS-02 (H-Dmt-D-Arg-PheLys- $\mathrm{NH}_{2} ;$ Dmt $=2^{\prime} 6^{\prime}$ dimethylTyr) and SS-31 (H-D-Arg-DmtLys-Phe- $\mathrm{NH}_{2}$ ) have been estimated to concentrate $>1000$-fold in the IMM when compared with extracellular concentrations $(78,356)$. Unlike MitoQ and SkQ1, these SS peptides do not cause mitochondrial depolarization even at high concentrations, presumably because they are not distributed into the matrix.

The SS peptides are multi-functional compounds in mitochondria. The Dmt- or Tyr-containing analogs have intrinsic antioxidant activity, because Tyr is known to scavenge oxyradicals, forming relatively unreactive tyrosyl radicals that 
can be followed by radical-radical coupling to give dityrosine, or react with superoxide to form tyrosine hydroperoxide (109). Unlike MitoQ and SkQ1, which are reduced by the respiratory chain and can be recharged, the SS peptides are not rechargeable antioxidants. SS-02 and SS-31 were shown to dose-dependently scavenge hydrogen peroxide, hydroxyl radical, and peroxynitrite in vitro $(311,356)$. Since these peptides are targeted directly to the IMM, SS-02 and SS-31 are positioned to scavenge $\mathrm{H}_{2} \mathrm{O}_{2}$ from both the matrix and the intermembrane space. Both SS-02 and SS-31 reduced spontaneous $\mathrm{H}_{2} \mathrm{O}_{2}$ emission from isolated mitochondria under basal conditions $(311,356)$. SS-02 and SS-31 can also inhibit lipid peroxidation and are, therefore, ideally situated to prevent cardiolipin peroxidation from hydroxyl radicals.

The selective targeting and concentration of SS-02 and SS31 in the IMM makes them extremely potent in reducing mitochondrial oxidative stress in intact cells. An extracellular concentration of $1 \mathrm{nM}$ can produce a concentration of $>1 \mu \mathrm{M}$ in the IMM, which is well within the concentration determined to be sufficient to protect mitochondria in isolated mitochondrial studies (356). SS-02 and SS-31 have been shown to potently inhibit cell death caused by prooxidants including tert-butylhydroperoxid, $\mathrm{H}_{2} \mathrm{O}_{2}$, and hypochlorous acid in cell cultures $(78,128,355)$.

In addition to their antioxidant actions, the SS peptides can also promote mitochondrial respiration and inhibit mitochondrial permeability transition and swelling $(257,356)$. These properties make the SS peptides highly effective in prevention and treatment of IR injury (311). The Tyr-containing SS peptides can significantly reduce reperfusion arrhythmias, myocardial contractile function, and infarct size after myocardial ischemia (54); attenuate infarct size after cerebral injury (254); reduce acute kidney injury after renal IR (346); protect skeletal muscles; and preserve normal cellular architecture after $3 \mathrm{~h}$ of hind limb ischemia (350). Most importantly, these SS peptides are effective even when administered on reperfusion and require no pretreatment. Pretreatment with these peptides protects mitochondrial structure and respiration in early reperfusion and accelerates ATP recovery on reperfusion (346). These preclinical studies support mitochondrial protection as an upstream target for pharmacological intervention in IR injury.

Other preclinical studies support a beneficial role for these SS peptides in age-related problems, including Parkinson's Disease (257), Alzheimer's Disease (131), muscle weakness (55), heart failure (66), and insulin resistance (9). Reduced mitochondrial ETC function in skeletal muscles is associated with insulin resistance, and type 2 diabetes (349). A high fat diet leads to mitochondrial dysfunction and elevated ROS production in skeletal muscle (9). Administration of SS-31 was able to inhibit the increase in skeletal muscle mitochondrial $\mathrm{H}_{2} \mathrm{O}_{2}$ production following a high fat diet in rats, and this prevented the development of insulin resistance (9). Similar findings were seen in mCAT mice, demonstrating that SS-31 can mimic the protective effect of mitochondrial catalase overexpression.

Finally, and most relevant to cardiac aging, SS-31 was able to provide the same protection as the mCAT mice against angiotensin and G $\alpha$ q-induced cardiomyopathy (69). Using the same angiotensin model described earlier for inducing cardiac failure in mice, it was found that treatment with SS-31 significantly prevented $\mathrm{LVH}$ and diastolic failure, while treatment with the untargeted antioxidant, NAC, provided no protection (Fig. 12) (66). These results highlight the importance of antioxidant delivery to mitochondria in order to provide protection against mitochondrial oxidative stress.

These preclinical studies support the therapeutic potential of the SS peptides against age-related decline in physiological function, especially for cardiac aging. Results from a completed first-in-human Phase 1 clinical trial demonstrated linear pharmacokinetics and good tolerability in normal human subjects. Phase 2 clinical trial with a modified form of SS-31 in patients with first-time onset of acute ST elevation myocardial infarction is now ongoing.

\section{Resveratrol and SIRTs activators}

The results in invertebrate models, early data from mammals, and the potential of SIRTs as a DR-mimetic have provoked strong research interest to search for Sirt activators. Among several small molecules that activate SIRTs, resveratrol has been identified as one of the most potent SIRT1 activators (131). Resveratrol (3,5, $4^{\prime}$-trihydroxystilbene) is a natural compound found in grapes and red wine. It was widely believed to be the active compound that explains the cardioprotective effects of red wine. Resveratrol was reported to have anti-inflammatory effects, protect against cardiac IR injury and brain ischemia. This protection might be attributed to the effect of resveratrol to prevent platelet aggregations (339), attenuate atherosclerosis (340), promote vasodilation, enhance endothelial NO signaling $(184,243)$, induce antioxidant activity, and reduce LDL oxidation $(88,93,211)$ [see review (24)].

Dietary resveratrol was found to retard several aging-related physiological changes in aged mice, including cardiac diastolic dysfunction, impaired myocardial performance, and insulin resistance (20). Furthermore, resveratrol effects on global transcriptional profiles overlap strikingly with those
FIG. 12. Mitochondrial-targeted antioxidants SS-31 in Ang II-treated mice. (A). Left ventricular mass index (LVMI), (B). Diastolic function measured by Ea/Aa at baseline and after a 4 week exposure to Ang II. SS-31, but not NAC is protective of cardiac hypertrophy (LVMI) and diastolic function (Ea/Aa). NAC, N-acetyl cysteine.
A

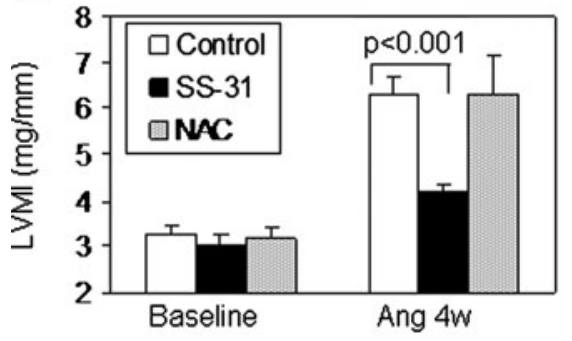

B

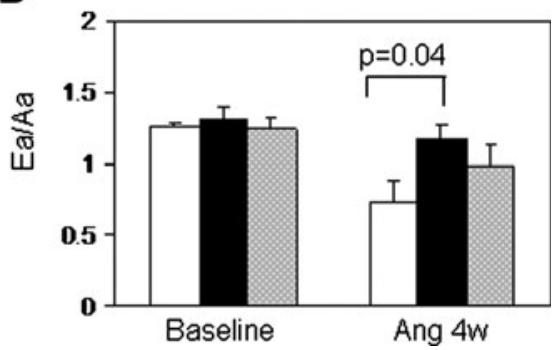


found after DR in heart, skeletal muscle, and brain (20). To translate these encouraging experimental data into clinical practice, several phase 1 and phase 2 clinical trials are being performed. These trials investigate the safety and adverse effect, pharmacokinetics and pharmacodynamics, as well as efficacy of resveratrol in apparently healthy adults, with the clinical outcomes of type 2 diabetes, obesity, Alzheimer disease, and cancer [See review in $(251,252)]$.

Sirt activators promise to provide benefits similar to DR by activating the protein deacetylases that are involved in metabolic remodeling $(46,148,149,349)$. However, the efficacy of these drugs in vitro has been controversial following the discovery that Fleur de Lys assay used to screen these drugs might be prone to artifacts. While the importance of SIRTs in metabolic responses and cardiac aging and disease is clearly supported by a number of reports $(83,115,120,255,285-$ $287,307,308,357)$, the ability of currently recognized Sirt activators to modulate these processes remains to be determined (207).

\section{Conclusion and Future Directions}

CVDs are the leading causes of death in North America and most of the western hemisphere. As just discussed, old age is a significant risk factor for CVDs. Since the number of the elderly in the United States is predicted to double in the next 25 years, by the year 2030, there will be more than 70 million elderly persons or about $20 \%$ of the population. This tremendous increase in the aging population underscores the need to develop therapeutic strategies that prevent myocardial dysfunction in the elderly, especially LVH and diastolic dysfunction. Hypertension and old age are the most common causes of $\mathrm{LVH}$, which increases the risk of coronary heart disease, congestive heart failure, stroke, and sudden death. Understanding the molecular mechanism of hypertrophy in aging and pressure-overload hearts will assist the development of strategies to prevent or ameliorate cardiac hypertrophy and failure, or even to delay cardiac aging changes. The roles of mitochondrial ROS, insulin-IGF-PI3K, catecholamine, and nutrient signaling have been just discussed. Further studies are needed to elucidate the complex interactions between mitochondrial ROS, SIRTs, mTOR, $\mathrm{Ca}^{2+}$, and other cellular signaling.

Although clinical trials applying antioxidants to attenuate the progression of CVDs have been disappointing (305), these may not be the optimal therapeutic agents. As just discussed, nontargeted antioxidants are not effective in the prevention of Ang II-induced cardiac hypertrophy or Gaq overexpressioninduced heart failure. However, there are now several promising mitochondrial-targeted small molecule antioxidants, including mitochondrial-targeted ubiquinone (MitoQ), and SS31 peptide antioxidants $(2,9,328)$. Other mitochondrial targeted mechanisms, such as cyclosporine to block the opening of mitochondrial permeability-transition pore (256), are also attractive treatment strategies. Further clinical trials are necessary to study the potential application of mitochondrialtargeted therapeutics in the treatment or prevention of cardiac aging, hypertensive cardiomyopathy, and heart failure.

\section{Acknowledgment}

Grant supports from National Institute of Health Grants R01 HL101186, P30 AG013280, and P01 AG001751.

\section{Author Disclosure Statement}

H.H. Szeto is the inventor of SS-31 and the Cornell Research Foundation (CRF) holds several patents covering the SS peptides and a patent application has been filed for the findings described in this article, with H.H. Szeto and P.S. Rabinovitch as inventors. CRF has licensed the SS peptide technology for further research and development to a commercial enterprise in which CRF and H.H. Szeto have financial interests.

\section{References}

1. Abadir PM, Foster DB, Crow M, Cooke CA, Rucker JJ, Jain A, Smith BJ, Burks TN, Cohn RD, Fedarko NS, Carey RM, O'Rourke B, and Walston JD. Identification and characterization of a functional mitochondrial angiotensin system. Proc Natl Acad Sci U S A 108: 14849-14854, 2011.

2. Adlam VJ, Harrison JC, Porteous CM, James AM, Smith RA, Murphy MP, and Sammut IA. Targeting an antioxidant to mitochondria decreases cardiac ischemia-reperfusion injury. Faseb J 19: 1088-1095, 2005.

3. Ago T, Kuroda J, Pain J, Fu C, Li H, and Sadoshima J. Upregulation of Nox4 by hypertrophic stimuli promotes apoptosis and mitochondrial dysfunction in cardiac myocytes. Circ Res 106: 1253-1264, 2010.

4. Ahmed HM, Blaha MJ, Nasir K, Rivera JJ, and Blumenthal RS. Effects of physical activity on cardiovascular disease. Am J Cardiol, 109: 288-295, 2012.

5. Ahmet I, Tae HJ, de Cabo R, Lakatta EG, and Talan MI. Effects of calorie restriction on cardioprotection and cardiovascular health. J Mol Cell Cardiol 51: 263-271, 2011.

6. Akazawa H, Komazaki S, Shimomura H, Terasaki F, Zou Y, Takano H, Nagai T, and Komuro I. Diphtheria toxininduced autophagic cardiomyocyte death plays a pathogenic role in mouse model of heart failure. J Biol Chem 279: 41095-41103, 2004.

7. Akins CW, Daggett WM, Vlahakes GJ, Hilgenberg AD, Torchiana DF, Madsen JC, and Buckley MJ. Cardiac operations in patients 80 years old and older. Ann Thorac Surg 64: 606-614; discussion 614-615, 1997.

8. Alcendor RR, Gao S, Zhai P, Zablocki D, Holle E, Yu X, Tian B, Wagner T, Vatner SF, and Sadoshima J. Sirt1 regulates aging and resistance to oxidative stress in the heart. Circ Res 100: 1512-1521, 2007.

9. Anderson EJ, Lustig ME, Boyle KE, Woodlief TL, Kane DA, Lin CT, Price JW, 3rd, Kang L, Rabinovitch PS, Szeto HH, Houmard JA, Cortright RN, Wasserman DH, and Neufer $\mathrm{PD}$. Mitochondrial $\mathrm{H} 2 \mathrm{O} 2$ emission and cellular redox state link excess fat intake to insulin resistance in both rodents and humans. J Clin Invest 119: 573-581, 2009.

10. Anderson RM, Bitterman KJ, Wood JG, Medvedik O, and Sinclair DA. Nicotinamide and PNC1 govern lifespan extension by calorie restriction in Saccharomyces cerevisiae. Nature 423: 181-185, 2003.

11. Andersson DC, Fauconnier J, Yamada T, Lacampagne A, Zhang SJ, Katz A, and Westerblad H. Mitochondrial production of reactive oxygen species contributes to the betaadrenergic stimulation of mouse cardiomycytes. J Physiol 589: 1791-1801, 2011.

12. Antonenko YN, Avetisyan AV, Bakeeva LE, Chernyak BV, Chertkov VA, Domnina LV, Ivanova OY, Izyumov DS, Khailova LS, Klishin SS, Korshunova GA, Lyamzaev KG, Muntyan MS, Nepryakhina OK, Pashkovskaya AA, Pletjushkina OY, Pustovidko AV, Roginsky VA, Rokitskaya TI, 
Ruuge EK, Saprunova VB, Severina II, Simonyan RA, Skulachev IV, Skulachev MV, Sumbatyan NV, Sviryaeva IV, Tashlitsky VN, Vassiliev JM, Vyssokikh MY, Yaguzhinsky LS, Zamyatnin AA, Jr., and Skulachev VP. Mitochondria-targeted plastoquinone derivatives as tools to interrupt execution of the aging program. 1. Cationic plastoquinone derivatives: synthesis and in vitro studies. Biochemistry (Mosc) 73: 1273-1287, 2008.

13. Anversa P, Puntillo E, Nikitin P, Olivetti G, Capasso JM, and Sonnenblick EH. Effects of age on mechanical and structural properties of myocardium of Fischer 344 rats. Am J Physiol 256: H1440-H1449, 1989.

14. Anyukhovsky EP, Sosunov EA, Chandra P, Rosen TS, Boyden PA, Danilo P, Jr., and Rosen MR. Age-associated changes in electrophysiologic remodeling: a potential contributor to initiation of atrial fibrillation. Cardiovasc Res 66: 353-363, 2005.

15. Apfeld J and Kenyon C. Cell nonautonomy of C. elegans daf-2 function in the regulation of diapause and life span. Cell 95: 199-210, 1998.

16. Arbab-Zadeh A, Dijk E, Prasad A, Fu Q, Torres P, Zhang R, Thomas JD, Palmer D, and Levine BD. Effect of aging and physical activity on left ventricular compliance. Circulation 110: 1799-1805, 2004.

17. Aronow WS, Ahn C, Shirani J, and Kronzon I. Comparison of frequency of new coronary events in older subjects with and without valvular aortic sclerosis. Am J Cardiol 83: 599600, A8, 1999.

18. Baccarelli A, Wright R, Bollati V, Litonjua A, Zanobetti A, Tarantini L, Sparrow D, Vokonas P, and Schwartz J. Ischemic heart disease and stroke in relation to blood DNA methylation. Epidemiology 21: 819-828, 2010.

19. Bakeeva LE, Barskov IV, Egorov MV, Isaev NK, Kapelko VI, Kazachenko AV, Kirpatovsky VI, Kozlovsky SV, Lakomkin VL, Levina SB, Pisarenko OI, Plotnikov EY, Saprunova VB, Serebryakova LI, Skulachev MV, Stelmashook EV, Studneva IM, Tskitishvili OV, Vasilyeva AK, Victorov IV, Zorov DB, and Skulachev VP. Mitochondria-targeted plastoquinone derivatives as tools to interrupt execution of the aging program. 2. Treatment of some ROS- and agerelated diseases (heart arrhythmia, heart infarctions, kidney ischemia, and stroke). Biochemistry (Mosc) 73: 1288-1299, 2008.

20. Barger JL, Kayo T, Vann JM, Arias EB, Wang J, Hacker TA, Wang Y, Raederstorff D, Morrow JD, Leeuwenburgh C, Allison DB, Saupe KW, Cartee GD, Weindruch R, and Prolla TA. A low dose of dietary resveratrol partially mimics caloric restriction and retards aging parameters in mice. PLoS One 3: e2264, 2008.

21. Bass TM, Weinkove D, Houthoofd K, Gems D, and Partridge L. Effects of resveratrol on lifespan in Drosophila melanogaster and Caenorhabditis elegans. Mech Ageing Dev 128: 546-552, 2007.

22. Basso N, Cini R, Pietrelli A, Ferder L, Terragno NA, and Inserra F. Protective effect of long-term angiotensin II inhibition. Am J Physiol Heart Circ Physiol 293: H1351-H1358, 2007.

23. Baur JA, Pearson KJ, Price NL, Jamieson HA, Lerin C, Kalra A, Prabhu VV, Allard JS, Lopez-Lluch G, Lewis K, Pistell PJ, Poosala S, Becker KG, Boss O, Gwinn D, Wang M, Ramaswamy S, Fishbein KW, Spencer RG, Lakatta EG, Le Couteur D, Shaw RJ, Navas P, Puigserver P, Ingram DK, de Cabo R, and Sinclair DA. Resveratrol improves health and survival of mice on a high-calorie diet. Nature 444: 337-342, 2006.
24. Baur JA and Sinclair DA. Therapeutic potential of resveratrol: the in vivo evidence. Nat Rev Drug Discov 5: 493-506, 2006.

25. Becker LB, vanden Hoek TL, Shao ZH, Li CQ, and Schumacker PT. Generation of superoxide in cardiomyocytes during ischemia before reperfusion. Am J Physiol 277: H2240-H2246, 1999.

26. Beer M, Seyfarth T, Sandstede J, Landschutz W, Lipke C, Kostler H, von Kienlin M, Harre K, Hahn D, and Neubauer $\mathrm{S}$. Absolute concentrations of high-energy phosphate metabolites in normal, hypertrophied, and failing human myocardium measured noninvasively with (31)P-SLOOP magnetic resonance spectroscopy. J Am Coll Cardiol 40: 1267-1274, 2002.

27. Bellizzi D, Rose G, Cavalcante P, Covello G, Dato S, De Rango F, Greco V, Maggiolini M, Feraco E, Mari V, Franceschi C, Passarino G, and De Benedictis G. A novel VNTR enhancer within the SIRT3 gene, a human homologue of SIR2, is associated with survival at oldest ages. Genomics 85: 258-263, 2005.

28. Beltrami AP, Barlucchi L, Torella D, Baker M, Limana F, Chimenti S, Kasahara H, Rota M, Musso E, Urbanek K, Leri A, Kajstura J, Nadal-Ginard B, and Anversa P. Adult cardiac stem cells are multipotent and support myocardial regeneration. Cell 114: 763-776, 2003.

29. Benigni A, Corna D, Zoja C, Sonzogni A, Latini R, Salio M, Conti S, Rottoli D, Longaretti L, Cassis P, Morigi M, Coffman TM, and Remuzzi G. Disruption of the Ang II type 1 receptor promotes longevity in mice. J Clin Invest 119: 524530, 2009.

30. Beregi E and Regius O. Comparative morphological study of age related mitochondrial changes of the lymphocytes and skeletal muscle cells. Acta Morphol Hung 35: 219-224, 1987.

31. Bergmann O, Bhardwaj RD, Bernard S, Zdunek S, BarnabeHeider F, Walsh S, Zupicich J, Alkass K, Buchholz BA, Druid $\mathrm{H}$, Jovinge $\mathrm{S}$, and Frisen J. Evidence for cardiomyocyte renewal in humans. Science 324: 98-102, 2009.

32. Berk BC, Fujiwara K, and Lehoux S. ECM remodeling in hypertensive heart disease. J Clin Invest 117: 568-575, 2007.

33. Bers DM. Altered cardiac myocyte Ca regulation in heart failure. Physiology (Bethesda) 21: 380-387, 2006.

34. Bjelakovic G, Nikolova D, Gluud LL, Simonetti RG, and Gluud C. Mortality in randomized trials of antioxidant supplements for primary and secondary prevention: systematic review and meta-analysis. JAMA 297: 842-857, 2007.

35. Blasco MA, Lee HW, Hande MP, Samper E, Lansdorp PM, DePinho RA, and Greider CW. Telomere shortening and tumor formation by mouse cells lacking telomerase RNA. Cell 91: 25-34, 1997.

36. Boluyt MO, Converso K, Hwang HS, Mikkor A, and Russell MW. Echocardiographic assessment of age-associated changes in systolic and diastolic function of the female F344 rat heart. J Appl Physiol 96: 822-828, 2004.

37. Bordone L, Cohen D, Robinson A, Motta MC, van Veen E, Czopik A, Steele AD, Crowe H, Marmor S, Luo J, Gu W, and Guarente L. SIRT1 transgenic mice show phenotypes resembling calorie restriction. Aging Cell 6: 759-767, 2007.

38. Boyle AJ, Shih H, Hwang J, Ye J, Lee B, Zhang Y, Kwon D, Jun K, Zheng D, Sievers R, Angeli F, Yeghiazarians Y, and Lee R. Cardiomyopathy of aging in the mammalian heart is characterized by myocardial hypertrophy, fibrosis and a predisposition towards cardiomyocyte apoptosis and autophagy. Exp Gerontol 46: 549-559, 2011. 
39. Braidy N, Guillemin GJ, Mansour H, Chan-Ling T, Poljak A, and Grant R. Age related changes in NAD+metabolism oxidative stress and Sirt1 activity in wistar rats. PLoS One 6: e19194, 2011.

40. Broglio F, Fubini A, Morello M, Arvat E, Aimaretti G, Gianotti L, Boghen MF, Deghenghi R, Mangiardi L, and Ghigo E. Activity of GH/IGF-I axis in patients with dilated cardiomyopathy. Clin Endocrinol (Oxf) 50: 417-430, 1999.

41. Brown VA, Patel KR, Viskaduraki M, Crowell JA, Perloff M, Booth TD, Vasilinin G, Sen A, Schinas AM, Piccirilli G, Brown K, Steward WP, Gescher AJ, and Brenner DE. Repeat dose study of the cancer chemopreventive agent resveratrol in healthy volunteers: safety, pharmacokinetics, and effect on the insulin-like growth factor axis. Cancer Res 70: 9003-9011, 2010.

42. Brunk UT and Terman A. The mitochondrial-lysosomal axis theory of aging: accumulation of damaged mitochondria as a result of imperfect autophagocytosis. Eur J Biochem 269: 1996-2002, 2002.

43. Bursi F, Weston SA, Redfield MM, Jacobsen SJ, Pakhomov S, Nkomo VT, Meverden RA, and Roger VL. Systolic and diastolic heart failure in the community. Jama 296: 22092216, 2006.

44. Cadenas S, Aragones J, and Landazuri MO. Mitochondrial reprogramming through cardiac oxygen sensors in ischaemic heart disease. Cardiovasc Res 88: 219-228, 2010.

45. Cai Z, Zhong H, Bosch-Marce M, Fox-Talbot K, Wang L, Wei C, Trush MA, and Semenza GL. Complete loss of ischaemic preconditioning-induced cardioprotection in mice with partial deficiency of HIF-1 alpha. Cardiovasc Res 77: 463-470, 2008.

46. Camins A, Sureda FX, Junyent F, Verdaguer E, Folch J, Pelegri C, Vilaplana J, Beas-Zarate C, and Pallas M. Sirtuin activators: designing molecules to extend life span. Biochim Biophys Acta 1799: 740-749, 2010.

47. Chan DC. Mitochondria: dynamic organelles in disease, aging, and development. Cell 125: 1241-1252, 2006.

48. Chan NC, Salazar AM, Pham AH, Sweredoski MJ, Kolawa NJ, Graham RL, Hess S, and Chan DC. Broad activation of the ubiquitin-proteasome system by Parkin is critical for mitophagy. Hum Mol Genet 20: 1726-1737, 2011.

49. Chandel NS, Maltepe E, Goldwasser E, Mathieu CE, Simon $\mathrm{MC}$, and Schumacker PT. Mitochondrial reactive oxygen species trigger hypoxia-induced transcription. Proc Natl Acad Sci U S A 95: 11715-11720, 1998.

50. Chen $\mathrm{H}$ and Chan DC. Physiological functions of mitochondrial fusion. Ann N Y Acad Sci 1201: 21-25, 2010.

51. Chen H, Vermulst M, Wang YE, Chomyn A, Prolla TA, McCaffery JM, and Chan DC. Mitochondrial fusion is required for mtDNA stability in skeletal muscle and tolerance of mtDNA mutations. Cell 141: 280-289, 2010.

52. Chimenti C, Kajstura J, Torella D, Urbanek K, Heleniak H, Colussi C, Di Meglio F, Nadal-Ginard B, Frustaci A, Leri A, Maseri A, and Anversa P. Senescence and death of primitive cells and myocytes lead to premature cardiac aging and heart failure. Circ Res 93: 604-613, 2003.

53. Chiribau CB, Cheng L, Cucoranu IC, Yu YS, Clempus RE, and Sorescu D. FOXO3A regulates peroxiredoxin III expression in human cardiac fibroblasts. J Biol Chem 283: 8211-8217, 2008.

54. Cho J, Won K, Wu D, Soong Y, Liu S, Szeto HH, and Hong MK. Potent mitochondria-targeted peptides reduce myocardial infarction in rats. Coron Artery Dis 18: 215-220, 2007.
55. Cho S, Szeto HH, Kim E, Kim H, Tolhurst AT, and Pinto JT. A novel cell-permeable antioxidant peptide, SS31, attenuates ischemic brain injury by down-regulating CD36. J Biol Chem 282: 4634-4642, 2007.

56. Chomyn A, Meola G, Bresolin N, Lai ST, Scarlato G, and Attardi G. In vitro genetic transfer of protein synthesis and respiration defects to mitochondrial DNA-less cells with myopathy-patient mitochondria. Mol Cell Biol 11: 22362244, 1991.

57. Chou TC, Yen MH, Li CY, and Ding YA. Alterations of nitric oxide synthase expression with aging and hypertension in rats. Hypertension 31: 643-648, 1998.

58. Chudyk A and Petrella RJ. Effects of exercise on cardiovascular risk factors in type 2 diabetes: a meta-analysis. Diabetes Care 34: 1228-1237, 2011.

59. Colman RJ, Anderson RM, Johnson SC, Kastman EK, Kosmatka KJ, Beasley TM, Allison DB, Cruzen C, Simmons HA, Kemnitz JW, and Weindruch R. Caloric restriction delays disease onset and mortality in rhesus monkeys. Science 325: 201-204, 2009.

60. Colom B, Oliver J, Roca P, and Garcia-Palmer FJ. Caloric restriction and gender modulate cardiac muscle mitochondrial $\mathrm{H} 2 \mathrm{O} 2$ production and oxidative damage. Cardiovasc Res 74: 456-465, 2007.

61. Corpas E, Harman SM, and Blackman MR. Human growth hormone and human aging. Endocr Rev 14: 20-39, 1993.

62. Corral-Debrinski M, Stepien G, Shoffner JM, Lott MT, Kanter K, and Wallace DC. Hypoxemia is associated with mitochondrial DNA damage and gene induction. Implications for cardiac disease. Jama 266: 1812-1816, 1991.

63. Correia LC, Lakatta EG, O'Connor FC, Becker LC, Clulow J, Townsend S, Gerstenblith G, and Fleg JL. Attenuated cardiovascular reserve during prolonged submaximal cycle exercise in healthy older subjects. I Am Coll Cardiol 40: 1290-1297, 2002.

64. Cruzen C and Colman RJ. Effects of caloric restriction on cardiovascular aging in non-human primates and humans. Clin Geriatr Med 25: 733-743, ix-x, 2009.

65. Curtis NJ, Ringo JM, and Dowse HB. Morphology of the pupal heart, adult heart, and associated tissues in the fruit fly, Drosophila melanogaster. J Morphol 240: 225-235, 1999.

66. Dai DF, Chen T, Szeto H, Nieves-Cintron M, Kutyavin V, Santana LF, and Rabinovitch PS. Mitochondrial targeted antioxidant peptide ameliorates hypertensive cardiomyopathy. J Am Coll Cardiol 58: 73-82, 2011.

67. Dai DF, Chen T, Wanagat J, Laflamme M, Marcinek DJ, Emond MJ, Ngo CP, and Prolla TA, Rabinovitch PS. Agedependent cardiomyopathy in mitochondrial mutator mice is attenuated by overexpression of catalase targeted to mitochondria. Aging Cell 9: 536-544, 2010.

68. Dai DF, Hwang JJ, Chen CL, Chiang FT, Lin JL, Hsu KL, Tseng CD, and Tseng YZ. Effect of physical activity on the prevalence of metabolic syndrome and left ventricular hypertrophy in apparently healthy adults. J Formos Med Assoc 109: 716-724, 2010.

69. Dai DF, Johnson SC, Villarin JJ, Chin MT, Nieves-Cintron M, Chen T, Marcinek DJ, Dorn GW, 2nd, Kang YJ, Prolla TA, Santana LF, and Rabinovitch PS. Mitochondrial oxidative stress mediates angiotensin II-induced cardiac hypertrophy and G\{alpha\}q overexpression-Induced heart failure. Circ Res 108: 837-846, 2011.

70. Dai DF and Rabinovitch PS. Cardiac aging in mice and humans: the role of mitochondrial oxidative stress. Trends Cardiovasc Med 19: 213-220, 2009. 
71. Dai DF, Santana LF, Vermulst M, Tomazela DM, Emond MJ, MacCoss MJ, Gollahon K, Martin GM, Loeb LA, Ladiges WC, and Rabinovitch PS. Overexpression of catalase targeted to mitochondria attenuates murine cardiac aging. Circulation 119: 2789-2797, 2009.

72. De Meyer GR, De Keulenaer GW, and Martinet W. Role of autophagy in heart failure associated with aging. Heart Fail Rev 15: 423-430, 2010.

73. Di Lisa F and Bernardi P. Mitochondria and ischemia-reperfusion injury of the heart: fixing a hole. Cardiovasc Res 70: 191-199, 2006.

74. Di Lisa F and Bernardi P. A CaPful of mechanisms regulating the mitochondrial permeability transition. J Mol Cell Cardiol 46: 775-780, 2009.

75. Dickinson HO, Mason JM, Nicolson DJ, Campbell F, Beyer FR, Cook JV, Williams B, and Ford GA. Lifestyle interventions to reduce raised blood pressure: a systematic review of randomized controlled trials. J Hypertens 24: 215233, 2006.

76. DiMauro $S$ and Schon EA. Mitochondrial respiratory-chain diseases. N Engl J Med 348: 2656-2668, 2003.

77. Dorman JB, Albinder B, Shroyer T, and Kenyon C. The age1 and daf- 2 genes function in a common pathway to control the lifespan of Caenorhabditis elegans. Genetics 141: 13991406, 1995.

78. Doughan AK and Dikalov SI. Mitochondrial redox cycling of mitoquinone leads to superoxide production and cellular apoptosis. Antioxid Redox Signal 9: 1825-1836, 2007.

79. Doughan AK, Harrison DG, and Dikalov SI. Molecular mechanisms of angiotensin II-mediated mitochondrial dysfunction: linking mitochondrial oxidative damage and vascular endothelial dysfunction. Circ Res 102: 488-496, 2008.

80. Ducharme A, Frantz S, Aikawa M, Rabkin E, Lindsey M, Rohde LE, Schoen FJ, Kelly RA, Werb Z, Libby P, and Lee RT. Targeted deletion of matrix metalloproteinase- 9 attenuates left ventricular enlargement and collagen accumulation after experimental myocardial infarction. J Clin Invest 106: 55-62, 2000.

81. Eckle T, Kohler D, Lehmann R, El Kasmi K, and Eltzschig HK. Hypoxia-inducible factor-1 is central to cardioprotection: a new paradigm for ischemic preconditioning. Circulation 118: 166-175, 2008.

82. Ellison KE and Gandhi G. Optimising the use of betaadrenoceptor antagonists in coronary artery disease. Drugs 65: 787-797, 2005.

83. Evans GB, Furneaux RH, Gainsford GJ, Hanson JC, Kicska GA, Sauve AA, Schramm VL, and Tyler PC. 8-Azaimmucillins as transition-state analogue inhibitors of purine nucleoside phosphorylase and nucleoside hydrolases. J Med Chem 46: 155-160, 2003.

84. Fagard RH. Effects of exercise, diet and their combination on blood pressure. J Hum Hypertens 19 Suppl 3: S20-S24, 2005.

85. Faggiano P, Antonini-Canterin F, Erlicher A, Romeo C, Cervesato E, Pavan D, Piazza R, Huang G, and Nicolosi GL. Progression of aortic valve sclerosis to aortic stenosis. Am J Cardiol 91: 99-101, 2003.

86. Finocchietto PV, Franco MC, Holod S, Gonzalez AS, Converso DP, Antico Arciuch VG, Serra MP, Poderoso JJ, and Carreras MC. Mitochondrial nitric oxide synthase: a masterpiece of metabolic adaptation, cell growth, transformation, and death. Exp Biol Med (Maywood) 234: 1020-1028, 2009.
87. Fleg JL, O'Connor F, Gerstenblith G, Becker LC, Clulow J, Schulman SP, and Lakatta EG. Impact of age on the cardiovascular response to dynamic upright exercise in healthy men and women. J Appl Physiol 78: 890-900, 1995.

88. Floreani M, Napoli E, Quintieri L, and Palatini P. Oral administration of trans-resveratrol to guinea pigs increases cardiac DT-diaphorase and catalase activities, and protects isolated atria from menadione toxicity. Life Sci 72: 27412750, 2003.

89. Flores-Mateo G, Carrillo-Santisteve P, Elosua R, Guallar E, Marrugat J, Bleys J, and Covas MI. Antioxidant enzyme activity and coronary heart disease: meta-analyses of observational studies. Am J Epidemiol 170: 135-147, 2009.

90. Foo RS, Mani K, and Kitsis RN. Death begets failure in the heart. J Clin Invest 115: 565-571, 2005.

91. Forman DE, Cittadini A, Azhar G, Douglas PS, and Wei JY. Cardiac morphology and function in senescent rats: gender-related differences. J Am Coll Cardiol 30: 1872-1877, 1997.

92. Fowler CG, Chiasson KB, Leslie TH, Thomas D, Beasley TM, Kemnitz JW, and Weindruch R. Auditory function in rhesus monkeys: effects of aging and caloric restriction in the Wisconsin monkeys five years later. Hear Res 261: 7581, 2010.

93. Frankel EN, Waterhouse AL, and Kinsella JE. Inhibition of human LDL oxidation by resveratrol. Lancet 341: 11031104, 1993.

94. Freeman RV and Otto CM. Spectrum of calcific aortic valve disease: pathogenesis, disease progression, and treatment strategies. Circulation 111: 3316-3326, 2005.

95. Frishman WH. Fifty years of beta-adrenergic blockade: a golden era in clinical medicine and molecular pharmacology. Am J Med 121: 933-934, 2008.

96. Fujimoto N, Prasad A, Hastings JL, Arbab-Zadeh A, Bhella PS, Shibata S, Palmer D, and Levine BD. Cardiovascular effects of 1 year of progressive and vigorous exercise training in previously sedentary individuals older than 65 years of age. Circulation 122: 1797-1805, 2010.

97. Fulkerson PK, Beaver BM, Auseon JC, and Graber HL. Calcification of the mitral annulus: etiology, clinical associations, complications and therapy. Am J Med 66: 967-977, 1979.

98. Gane EJ, Weilert F, Orr DW, Keogh GF, Gibson M, Lockhart MM, Frampton CM, Taylor KM, Smith RA, and Murphy MP. The mitochondria-targeted anti-oxidant mitoquinone decreases liver damage in a phase II study of hepatitis C patients. Liver Int 30: 1019-1026, 2010.

99. Gao L, Wang W, Liu D, and Zucker IH. Exercise training normalizes sympathetic outflow by central antioxidant mechanisms in rabbits with pacing-induced chronic heart failure. Circulation 115: 3095-3102, 2007.

100. Gao XM, Wong G, Wang B, Kiriazis H, Moore XL, Su YD, Dart $\mathrm{A}$, and $\mathrm{Du} \mathrm{XJ}$. Inhibition of $\mathrm{mTOR}$ reduces chronic pressure-overload cardiac hypertrophy and fibrosis. $J \mathrm{Hy}$ pertens 24: 1663-1670, 2006.

101. Gardin JM and Lauer MS. Left ventricular hypertrophy: the next treatable, silent killer? Jama 292: 2396-2398, 2004.

102. Gates PE, Tanaka H, Graves J, and Seals DR. Left ventricular structure and diastolic function with human ageing. Relation to habitual exercise and arterial stiffness. Eur Heart J 24: 2213-2220, 2003.

103. Giannakou ME, Goss M, Junger MA, Hafen E, Leevers SJ, and Partridge L. Long-lived Drosophila with overexpressed dFOXO in adult fat body. Science 305: 361, 2004. 
104. Gluckman PD, Hanson MA, Buklijas T, Low FM, and Beedle AS. Epigenetic mechanisms that underpin metabolic and cardiovascular diseases. Nat Rev Endocrinol 5: 401-408, 2009.

105. Goffart S, von Kleist-Retzow J-C, and Wiesner RJ. Regulation of mitochondrial proliferation in the heart: powerplant failure contributes to cardiac failure in hypertrophy. Cardiovascular Research 64: 198-207, 2004.

106. Gonzalez A, Rota M, Nurzynska D, Misao Y, Tillmanns J, Ojaimi C, Padin-Iruegas ME, Muller P, Esposito G, Bearzi C, Vitale S, Dawn B, Sanganalmath SK, Baker M, Hintze TH, Bolli R, Urbanek K, Hosoda T, Anversa P, Kajstura J, and Leri A. Activation of cardiac progenitor cells reverses the failing heart senescent phenotype and prolongs lifespan. Circ Res 102: 597-606, 2008.

107. Goswami SK and Das DK. Autophagy in the myocardium: dying for survival? Exp Clin Cardiol 11: 183-188, 2006.

108. Gottlieb RA and Carreira RS. Autophagy in health and disease. 5. Mitophagy as a way of life. Am J Physiol Cell Physiol 299: C203-C210, 2010.

109. Graham D, Huynh NN, Hamilton CA, Beattie E, Smith RA, Cocheme HM, Murphy MP, and Dominiczak AF. Mitochondria-targeted antioxidant MitoQ10 improves endothelial function and attenuates cardiac hypertrophy. Hypertension 54: 322-328, 2009.

110. Gravina S and Vijg J. Epigenetic factors in aging and longevity. Pflugers Arch 459: 247-258, 2010.

111. Groban L, Pailes NA, Bennett CD, Carter CS, Chappell MC, Kitzman DW, and Sonntag WE. Growth hormone replacement attenuates diastolic dysfunction and cardiac angiotensin II expression in senescent rats. J Gerontol A Biol Sci Med Sci 61: 28-35, 2006.

112. Guglielmini C. Cardiovascular diseases in the ageing dog: diagnostic and therapeutic problems. Vet Res Commun 27 Suppl 1: 555-560, 2003.

113. Guzy RD, Hoyos B, Robin E, Chen H, Liu L, Mansfield KD, Simon MC, Hammerling U, and Schumacker PT. Mitochondrial complex III is required for hypoxia-induced ROS production and cellular oxygen sensing. Cell Metab 1: 401-408, 2005.

114. Hachamovitch R, Wicker P, Capasso JM, and Anversa P. Alterations of coronary blood flow and reserve with aging in Fischer 344 rats. Am J Physiol 256: H66-H73, 1989.

115. Hafner AV, Dai J, Gomes AP, Xiao CY, Palmeira CM, Rosenzweig A, and Sinclair DA. Regulation of the mPTP by SIRT3-mediated deacetylation of CypD at lysine 166 suppresses age-related cardiac hypertrophy. Aging (Albany NY) 2: 914-923, 2010.

116. Hamanaka RB and Chandel NS. Mitochondrial reactive oxygen species regulate hypoxic signaling. Curr Opin Cell Biol 21: 894-899, 2009.

117. Hamanaka RB and Chandel NS. Mitochondrial reactive oxygen species regulate cellular signaling and dictate biological outcomes. Trends Biochem Sci 35: 505-513, 2010.

118. Hamlin RL. Animal models of ventricular arrhythmias. Pharmacol Ther 113: 276-295, 2007.

119. Hamlin RL and Smith CR. Anatomical and physiologic basis for interpretation of the electrocardiogram. Am J Vet Res 21: 701-708, 1960.

120. Hariharan N, Maejima Y, Nakae J, Paik J, Depinho RA, and Sadoshima J. Deacetylation of FoxO by Sirt1 Plays an Essential Role in Mediating Starvation-Induced Autophagy in Cardiac Myocytes. Circ Res 107: 1470-1482, 2010.
121. Harman D. Aging: a theory based on free radical and radiation chemistry. J Gerontol 11: 298-300, 1956.

122. Harman D. The biologic clock: the mitochondria? J Am Geriatr Soc 20: 145-147, 1972.

123. Heineke J, Auger-Messier M, Xu J, Oka T, Sargent MA, York A, Klevitsky R, Vaikunth S, Duncan SA, Aronow BJ, Robbins J, Crombleholme TM, and Molkentin JD. Cardiomyocyte GATA4 functions as a stress-responsive regulator of angiogenesis in the murine heart. J Clin Invest 117: 31983210, 2007.

124. Hepple RT, Baker DJ, McConkey M, Murynka T, and Norris R. Caloric restriction protects mitochondrial function with aging in skeletal and cardiac muscles. Rejuvenation Res 9: 219-222, 2006.

125. Herbert KE, Mistry Y, Hastings R, Poolman T, Niklason L, and Williams B. Angiotensin II-mediated oxidative DNA damage accelerates cellular senescence in cultured human vascular smooth muscle cells via telomere-dependent and independent pathways. Circ Res 102: 201-208, 2008.

126. Hesselink RP, Schaart G, Wagenmakers AJ, Drost MR, and van der Vusse GJ. Age-related morphological changes in skeletal muscle cells of acid alpha-glucosidase knockout mice. Muscle Nerve 33: 505-513, 2006.

127. Hobai IA and O'Rourke B. Decreased sarcoplasmic reticulum calcium content is responsible for defective excitationcontraction coupling in canine heart failure. Circulation 103: 1577-1584, 2001.

128. Horton KL, Stewart KM, Fonseca SB, Guo Q, and Kelley SO. Mitochondria-penetrating peptides. Chem Biol 15: 375382, 2008.

129. Hoshijima M, Ikeda $Y$, Iwanaga $Y$, Minamisawa S, Date MO, Gu Y, Iwatate M, Li M, Wang L, Wilson JM, Wang Y, Ross J, Jr., and Chien KR. Chronic suppression of heartfailure progression by a pseudophosphorylated mutant of phospholamban via in vivo cardiac rAAV gene delivery. Nat Med 8: 864-871, 2002.

130. Hosoi H, Dilling MB, Shikata T, Liu LN, Shu L, Ashmun RA, Germain GS, Abraham RT, and Houghton PJ. Rapamycin causes poorly reversible inhibition of mTOR and induces p53-independent apoptosis in human rhabdomyosarcoma cells. Cancer Res 59: 886-894, 1999.

131. Howitz KT, Bitterman KJ, Cohen HY, Lamming DW, Lavu S, Wood JG, Zipkin RE, Chung P, Kisielewski A, Zhang LL, Scherer B, and Sinclair DA. Small molecule activators of sirtuins extend Saccharomyces cerevisiae lifespan. Nature 425: 191-196, 2003.

132. Huang TT, Carlson EJ, Gillespie AM, Shi Y, and Epstein CJ. Ubiquitous overexpression of $\mathrm{CuZn}$ superoxide dismutase does not extend life span in mice. J Gerontol A Biol Sci Med Sci 55: B5-B9, 2000.

133. Inserra F, Basso N, Ferder M, Userpater M, Stella I, Paglia $\mathrm{N}$, Inserra $\mathrm{P}$, Tenembaum $\mathrm{D}$, and Ferder L. Changes seen in the aging kidney and the effect of blocking the reninangiotensin system. Ther Adv Cardiovasc Dis 3: 341-346, 2009.

134. Isoyama $S$ and Nitta-Komatsubara Y. Acute and chronic adaptation to hemodynamic overload and ischemia in the aged heart. Heart Fail Rev 7: 63-69, 2002.

135. Izumiya Y, Shiojima I, Sato K, Sawyer DB, Colucci WS, and Walsh K. Vascular endothelial growth factor blockade promotes the transition from compensatory cardiac hypertrophy to failure in response to pressure overload. Hypertension 47: 887-893, 2006.

136. Jager S, Handschin C, St-Pierre J, and Spiegelman BM. AMP-activated protein kinase (AMPK) action in skeletal 
muscle via direct phosphorylation of PGC-1alpha. Proc Natl Acad Sci U S A 104: 12017-12022, 2007.

137. Jang YC, Perez VI, Song W, Lustgarten MS, Salmon AB, Mele J, Qi W, Liu Y, Liang H, Chaudhuri A, Ikeno Y, Epstein CJ, Van Remmen H, and Richardson A. Overexpression of Mn superoxide dismutase does not increase life span in mice. J Gerontol A Biol Sci Med Sci 64: 1114-1125, 2009.

138. Jebara VA, Dervanian P, Acar C, Grare P, Mihaileanu S, Chauvaud S, Fabiani JN, Deloche A, and Carpentier A. Mitral valve repair using Carpentier techniques in patients more than 70 years old. Early and late results. Circulation 86: II53- II59, 1992.

139. Jeon DS, Atar S, Brasch AV, Luo H, Mirocha J, Naqvi TZ, Kraus R, Berman DS, and Siegel RJ. Association of mitral annulus calcification, aortic valve sclerosis and aortic root calcification with abnormal myocardial perfusion single photon emission tomography in subjects age $<$ or $=65$ years old. J Am Coll Cardiol 38: 1988-1993, 2001.

140. Jian B, Narula N, Li QY, Mohler ER, 3rd, and Levy RJ. Progression of aortic valve stenosis: TGF-beta1 is present in calcified aortic valve cusps and promotes aortic valve interstitial cell calcification via apoptosis. Ann Thorac Surg 75: 457-465; discussion 465-6, 2003.

141. Jiang JC, Wawryn J, Shantha Kumara HM, and Jazwinski $\mathrm{SM}$. Distinct roles of processes modulated by histone deacetylases Rpd3p, Hda1p, and Sir2p in life extension by caloric restriction in yeast. Exp Gerontol 37: 1023-1030, 2002.

142. Juhaszova M, Rabuel C, Zorov DB, Lakatta EG, and Sollott SJ. Protection in the aged heart: preventing the heart-break of old age? Cardiovasc Res 66: 233-244, 2005.

143. Kaeberlein M, Kirkland KT, Fields S, and Kennedy BK. Sir2-independent life span extension by calorie restriction in yeast. PLoS Biol 2: E296, 2004.

144. Kaeberlein M, McDonagh T, Heltweg B, Hixon J, Westman EA, Caldwell SD, Napper A, Curtis R, DiStefano PS, Fields S, Bedalov A, and Kennedy BK. Substrate-specific activation of sirtuins by resveratrol. J Biol Chem 280: 17038-17045, 2005.

145. Karavidas A, Lazaros G, Tsiachris D, and Pyrgakis V. Aging and the cardiovascular system. Hellenic J Cardiol 51: 421-427, 2010.

146. Kastman EK, Willette AA, Coe CL, Bendlin BB, Kosmatka KJ, McLaren DG, Xu G, Canu E, Field AS, Alexander AL, Voytko ML, Beasley TM, Colman RJ, Weindruch RH, and Johnson SC. A calorie-restricted diet decreases brain iron accumulation and preserves motor performance in old rhesus monkeys. J Neurosci 30: 7940-7947, 2010.

147. Katzmarzyk PT, Leon AS, Wilmore JH, Skinner JS, Rao DC, Rankinen T, and Bouchard C. Targeting the metabolic syndrome with exercise: evidence from the HERITAGE Family Study. Med Sci Sports Exerc 35: 1703-1709, 2003.

148. Kelly G. A review of the sirtuin system, its clinical implications, and the potential role of dietary activators like resveratrol: part 1. Altern Med Rev 15: 245-263, 2010.

149. Kelly GS. A review of the sirtuin system, its clinical implications, and the potential role of dietary activators like resveratrol: part 2. Altern Med Rev 15: 313-328, 2010.

150. Kelso GF, Porteous CM, Coulter CV, Hughes G, Porteous WK, Ledgerwood EC, Smith RA, and Murphy MP. Selective targeting of a redox-active ubiquinone to mitochondria within cells: antioxidant and antiapoptotic properties. J Biol Chem 276: 4588-4596, 2001.

151. Kennedy BK, Steffen KK, and Kaeberlein M. Ruminations on dietary restriction and aging. Cell Mol Life Sci 64: 13231328, 2007.
152. Kenyon C, Chang J, Gensch E, Rudner A, and Tabtiang R. A C. elegans mutant that lives twice as long as wild type. Nature 366: 461-464, 1993.

153. Kimura S, Zhang GX, Nishiyama A, Shokoji T, Yao L, Fan YY, Rahman M, and Abe Y. Mitochondria-derived reactive oxygen species and vascular MAP kinases: comparison of angiotensin II and diazoxide. Hypertension 45: 438-444, 2005.

154. Koch LG, Kemi OJ, Qi N, Leng SX, Bijma P, Gilligan LJ, Wilkinson JE, Wisloff H, Hoydal MA, Rolim N, Abadir PM, van Grevenhof EM, Smith GL, Burant CF, Ellingsen O, Britton SL, and Wisloff U. Intrinsic aerobic capacity sets a divide for aging and longevity. Circ Res 109: 1162-1172, 2011.

155. Kodama S, Tanaka S, Saito K, Shu M, Sone Y, Onitake F, Suzuki E, Shimano H, Yamamoto S, Kondo K, Ohashi Y, Yamada $\mathrm{N}$, and Sone $\mathrm{H}$. Effect of aerobic exercise training on serum levels of high-density lipoprotein cholesterol: a meta-analysis. Arch Intern Med 167: 999-1008, 2007.

156. Koh GY, Soonpaa MH, Klug MG, Pride HP, Cooper BJ, Zipes DP, and Field LJ. Stable fetal cardiomyocyte grafts in the hearts of dystrophic mice and dogs. J Clin Invest 96: 2034-2042, 1995.

157. Kops GJ, Dansen TB, Polderman PE, Saarloos I, Wirtz KW, Coffer PJ, Huang TT, Bos JL, Medema RH, and Burgering BM. Forkhead transcription factor FOXO3a protects quiescent cells from oxidative stress. Nature 419: 316-321, 2002.

158. Korzick DH, Holiman DA, Boluyt MO, Laughlin MH, and Lakatta EG. Diminished alpha1-adrenergic-mediated contraction and translocation of PKC in senescent rat heart. Am J Physiol Heart Circ Physiol 281: H581-H589, 2001.

159. Kostin S, Pool L, Elsasser A, Hein S, Drexler HC, Arnon E, Hayakawa Y, Zimmermann R, Bauer E, Klovekorn WP, and Schaper J. Myocytes die by multiple mechanisms in failing human hearts. Circ Res 92: 715-724, 2003.

160. Kosugi R, Shioi T, Watanabe-Maeda K, Yoshida Y, Takahashi K, Machida Y, and Izumi T. Angiotensin II receptor antagonist attenuates expression of aging markers in diabetic mouse heart. Circ J 70: 482-488, 2006.

161. Kowald A, Kirkwood TB. Evolution of the mitochondrial fusion-fission cycle and its role in aging. Proc Natl Acad Sci U S A 108: 10237-42, 2011.

162. Kraus WE, Houmard JA, Duscha BD, Knetzger KJ, Wharton MB, McCartney JS, Bales CW, Henes S, Samsa GP, Otvos JD, Kulkarni KR, and Slentz CA. Effects of the amount and intensity of exercise on plasma lipoproteins. $N$ Engl J Med 347: 1483-1492, 2002.

163. Krause K, Schneider C, Kuck KH, and Jaquet K. Stem cell therapy in cardiovascular disorders. Cardiovasc Ther 28: e101-e110, 2010.

164. Kris-Etherton PM, Lichtenstein AH, Howard BV, Steinberg D, and Witztum JL. Antioxidant vitamin supplements and cardiovascular disease. Circulation 110: 637-641, 2004.

165. Kroemer G and Levine B. Autophagic cell death: the story of a misnomer. Nat Rev Mol Cell Biol 9: 1004-1010, 2008.

166. Kujoth GC, Hiona A, Pugh TD, Someya S, Panzer K, Wohlgemuth SE, Hofer T, Seo AY, Sullivan R, Jobling WA, Morrow JD, Van Remmen H, Sedivy JM, Yamasoba T, Tanokura M, Weindruch R, Leeuwenburgh C, and Prolla TA. Mitochondrial DNA mutations, oxidative stress, and apoptosis in mammalian aging. Science 309: 481-484, 2005.

167. Kumaran S, Savitha S, Anusuya Devi M, and Panneerselvam C. L-carnitine and DL-alpha-lipoic acid reverse the age-related deficit in glutathione redox state in skeletal 
muscle and heart tissues. Mech Ageing Dev 125: 507-512, 2004.

168. Kuroda J, Ago T, Matsushima S, Zhai P, Schneider MD, and Sadoshima J. NADPH oxidase 4 (Nox4) is a major source of oxidative stress in the failing heart. Proc Natl Acad Sci U S A 107: 15565-15570, 2010.

169. Kurosu H, Yamamoto M, Clark JD, Pastor JV, Nandi A, Gurnani P, McGuinness OP, Chikuda H, Yamaguchi M, Kawaguchi H, Shimomura I, Takayama Y, Herz J, Kahn CR, Rosenblatt KP, and Kuro-o M. Suppression of aging in mice by the hormone Klotho. Science 309: 1829-1833, 2005.

170. Kusama S, Ueda R, Suda T, Nishihara S, and Matsuura ET. Involvement of Drosophila Sir2-like genes in the regulation of life span. Genes Genet Syst 81: 341-348, 2006.

171. Lagouge M, Argmann C, Gerhart-Hines Z, Meziane $H$, Lerin C, Daussin F, Messadeq N, Milne J, Lambert P, Elliott P, Geny B, Laakso M, Puigserver P, and Auwerx J. Resveratrol improves mitochondrial function and protects against metabolic disease by activating SIRT1 and PGC1alpha. Cell 127: 1109-1122, 2006.

172. Lakatta EG. Arterial and cardiac aging: major shareholders in cardiovascular disease enterprises: part III: cellular and molecular clues to heart and arterial aging. Circulation 107: 490-497, 2003.

173. Lakatta EG and Levy D. Arterial and cardiac aging: major shareholders in cardiovascular disease enterprises: part I: aging arteries: a "set up" for vascular disease. Circulation 107: 139-146, 2003.

174. Lakatta EG and Levy D. Arterial and cardiac aging: major shareholders in cardiovascular disease enterprises: part II: the aging heart in health: links to heart disease. Circulation 107: 346-354, 2003.

175. Lane MA, Ingram DK, and Roth GS. Calorie restriction in nonhuman primates: effects on diabetes and cardiovascular disease risk. Toxicol Sci 52: 41-48, 1999.

176. Lane MA, Mattison J, Ingram DK, and Roth GS. Caloric restriction and aging in primates: relevance to humans and possible CR mimetics. Microsc Res Tech 59: 335-338, 2002.

177. Lanza IR, Short DK, Short KR, Raghavakaimal S, Basu R, Joyner MJ, McConnell JP, and Nair KS. Endurance exercise as a countermeasure for aging. Diabetes 57: 2933-2942, 2008.

178. Lee RT. Matrix metalloproteinase inhibition and the prevention of heart failure. Trends Cardiovasc Med 11: 202-205, 2001.

179. Lee SJ, Hwang AB, and Kenyon C. Inhibition of respiration extends $C$. elegans life span via reactive oxygen species that increase HIF-1 activity. Curr Biol 20: 2131-2136, 2010.

180. Lennox SD, Mulkerrin E, Penney M, and Woodhouse K. Plasma atrial natriuretic polypeptide in the elderly: age or hypertension? Arch Gerontol Geriatr 19: 1-5, 1994.

181. Leon AS, Rice T, Mandel S, Despres JP, Bergeron J, Gagnon J, Rao DC, Skinner JS, Wilmore JH, and Bouchard C. Blood lipid response to 20 weeks of supervised exercise in a large biracial population: the HERITAGE Family Study. Metabolism 49: 513-520, 2000.

182. Leosco D, Rengo G, Iaccarino G, Filippelli A, Lymperopoulos A, Zincarelli C, Fortunato F, Golino L, Marchese M, Esposito G, Rapacciuolo A, Rinaldi B, Ferrara N, Koch WJ, and Rengo F. Exercise training and beta-blocker treatment ameliorate age-dependent impairment of beta-adrenergic receptor signaling and enhance cardiac responsiveness to adrenergic stimulation. Am J Physiol Heart Circ Physiol 293: H1596- H1603, 2007.
183. Levine B and Yuan J. Autophagy in cell death: an innocent convict? J Clin Invest 115: 2679-2688, 2005.

184. Li HF, Chen SA, and Wu SN. Evidence for the stimulatory effect of resveratrol on $\mathrm{Ca}(2+)$-activated $\mathrm{K}+$ current in vascular endothelial cells. Cardiovasc Res 45: 1035-1045, 2000.

185. Li HH, Kedar V, Zhang C, McDonough H, Arya R, Wang DZ, and Patterson C. Atrogin-1/muscle atrophy F-box inhibits calcineurin-dependent cardiac hypertrophy by participating in an SCF ubiquitin ligase complex. J Clin Invest 114: 1058-1071, 2004.

186. Li HH, Willis MS, Lockyer P, Miller N, McDonough H, Glass DJ, and Patterson C. Atrogin-1 inhibits Akt-dependent cardiac hypertrophy in mice via ubiquitin-dependent coactivation of Forkhead proteins. J Clin Invest 117: 3211-3223, 2007.

187. Li L, Pan R, Li R, Niemann B, Aurich AC, Chen Y, and Rohrbach S. Mitochondrial biogenesis and peroxisome proliferator-activated receptor-gamma coactivator-1alpha (PGC-1alpha) deacetylation by physical activity: intact adipocytokine signaling is required. Diabetes 60: 157-167, 2011.

188. Li Q, Ceylan-Isik AF, Li J, and Ren J. Deficiency of insulinlike growth factor 1 reduces sensitivity to aging-associated cardiomyocyte dysfunction. Rejuvenation Res 11: 725-733, 2008.

189. Liang H, Masoro EJ, Nelson JF, Strong R, McMahan CA, and Richardson A. Genetic mouse models of extended lifespan. Exp Gerontol 38: 1353-1364, 2003.

190. Lifton RP, Gharavi AG, and Geller DS. Molecular mechanisms of human hypertension. Cell 104: 545-556, 2001.

191. Lin J, Wu H, Tarr PT, Zhang CY, Wu Z, Boss O, Michael LF, Puigserver P, Isotani E, Olson EN, Lowell BB, Bassel-Duby $\mathrm{R}$, and Spiegelman BM. Transcriptional co-activator PGC-1 alpha drives the formation of slow-twitch muscle fibres. Nature 418: 797-801, 2002.

192. Lin K, Dorman JB, Rodan A, and Kenyon C. daf-16: an HNF-3/forkhead family member that can function to double the life-span of Caenorhabditis elegans. Science 278: 1319-1322, 1997.

193. Lin SJ, Kaeberlein M, Andalis AA, Sturtz LA, Defossez PA, Culotta VC, Fink GR, and Guarente L. Calorie restriction extends Saccharomyces cerevisiae lifespan by increasing respiration. Nature 418: 344-348, 2002.

194. Lindsey ML, Escobar GP, Dobrucki LW, Goshorn DK, Bouges S, Mingoia JT, McClister DM, Jr., Su H, Gannon J, MacGillivray C, Lee RT, Sinusas AJ, and Spinale FG. Matrix metalloproteinase-9 gene deletion facilitates angiogenesis after myocardial infarction. Am J Physiol Heart Circ Physiol 290: H232-H239, 2006.

195. Lindsey ML, Gannon J, Aikawa M, Schoen FJ, Rabkin E, Lopresti-Morrow L, Crawford J, Black S, Libby P, Mitchell PG, and Lee RT. Selective matrix metalloproteinase inhibition reduces left ventricular remodeling but does not inhibit angiogenesis after myocardial infarction. Circulation 105: 753-758, 2002.

196. Lindsey ML, Goshorn DK, Squires CE, Escobar GP, Hendrick JW, Mingoia JT, Sweterlitsch SE, and Spinale FG. Age-dependent changes in myocardial matrix metalloproteinase/tissue inhibitor of metalloproteinase profiles and fibroblast function. Cardiovasc Res 66: 410-419, 2005.

197. Luong N, Davies CR, Wessells RJ, Graham SM, King MT, Veech R, Bodmer R, and Oldham SM. Activated FOXOmediated insulin resistance is blocked by reduction of TOR activity. Cell Metab 4: 133-142, 2006. 
198. Magwere T, West M, Riyahi K, Murphy MP, Smith RA, and Partridge L. The effects of exogenous antioxidants on lifespan and oxidative stress resistance in Drosophila melanogaster. Mech Ageing Dev 127: 356-370, 2006.

199. Mammucari C and Rizzuto R. Signaling pathways in mitochondrial dysfunction and aging. Mech Ageing Dev 131: 536-543, 2010.

200. Marin-Garcia J, Goldenthal MJ, and Moe GW. Abnormal cardiac and skeletal muscle mitochondrial function in pacing-induced cardiac failure. Cardiovasc Res 52: 103-110, 2001.

201. Mattison JA, Lane MA, Roth GS, and Ingram DK. Calorie restriction in rhesus monkeys. Exp Gerontol 38: 35-46, 2003.

202. Mattson MP and Wan R. Beneficial effects of intermittent fasting and caloric restriction on the cardiovascular and cerebrovascular systems. J Nutr Biochem 16: 129-137, 2005.

203. McKiernan SH, Colman RJ, Lopez M, Beasley TM, Aiken JM, Anderson RM, and Weindruch R. Caloric restriction delays aging-induced cellular phenotypes in rhesus monkey skeletal muscle. Exp Gerontol 46: 23-29, 2011.

204. McMullen JR, Sherwood MC, Tarnavski O, Zhang L, Dorfman AL, Shioi T, and Izumo S. Inhibition of mTOR signaling with rapamycin regresses established cardiac hypertrophy induced by pressure overload. Circulation 109: 3050-3055, 2004.

205. McMullen JR, Shioi T, Zhang L, Tarnavski O, Sherwood MC, Dorfman AL, Longnus S, Pende M, Martin KA, Blenis J, Thomas G, and Izumo S. Deletion of ribosomal S6 kinases does not attenuate pathological, physiological, or insulinlike growth factor 1 receptor-phosphoinositide 3-kinaseinduced cardiac hypertrophy. Mol Cell Biol 24: 6231-6240, 2004.

206. Meyer TE, Kovacs SJ, Ehsani AA, Klein S, Holloszy JO, and Fontana L. Long-term caloric restriction ameliorates the decline in diastolic function in humans. J Am Coll Cardiol 47: 398-402, 2006.

207. Miller RA, Harrison DE, Astle CM, Baur JA, Boyd AR, de Cabo R, Fernandez E, Flurkey K, Javors MA, Nelson JF, Orihuela CJ, Pletcher S, Sharp ZD, Sinclair D, Starnes JW, Wilkinson JE, Nadon NL, and Strong R. Rapamycin, but not resveratrol or simvastatin, extends life span of genetically heterogeneous mice. J Gerontol A Biol Sci Med Sci 66: 191-201, 2011.

208. Minamisawa S, Hoshijima M, Chu G, Ward CA, Frank K, Gu Y, Martone ME, Wang Y, Ross J, Jr., Kranias EG, Giles WR, and Chien KR. Chronic phospholamban-sarcoplasmic reticulum calcium ATPase interaction is the critical calcium cycling defect in dilated cardiomyopathy. Cell 99: 313-322, 1999.

209. Minamiyama Y, Bito Y, Takemura S, Takahashi Y, Kodai S, Mizuguchi S, Nishikawa Y, Suehiro S, and Okada S. Calorie restriction improves cardiovascular risk factors via reduction of mitochondrial reactive oxygen species in type II diabetic rats. J Pharmacol Exp Ther 320: 535-543, 2007.

210. Miyamoto MI, del Monte F, Schmidt U, DiSalvo TS, Kang ZB, Matsui T, Guerrero JL, Gwathmey JK, Rosenzweig A, and Hajjar RJ. Adenoviral gene transfer of SERCA2a improves left-ventricular function in aortic-banded rats in transition to heart failure. Proc Natl Acad Sci U S A 97: 793798, 2000.

211. Mizutani K, Ikeda K, Kawai Y, and Yamori Y. Protective effect of resveratrol on oxidative damage in male and female stroke-prone spontaneously hypertensive rats. Clin Exp Pharmacol Physiol 28: 55-59, 2001.
212. Mockett RJ, Bayne AC, Kwong LK, Orr WC, and Sohal RS. Ectopic expression of catalase in Drosophila mitochondria increases stress resistance but not longevity. Free Radic Biol Med 34: 207-217, 2003.

213. Mockett RJ, Sohal RS, and Orr WC. Overexpression of glutathione reductase extends survival in transgenic Drosophila melanogaster under hyperoxia but not normoxia. FASEB J 13: 1733-1742, 1999.

214. Mollnau H, Wendt M, Szocs K, Lassegue B, Schulz E, Oelze M, Li H, Bodenschatz M, August M, Kleschyov AL, Tsilimingas N, Walter U, Forstermann U, Meinertz T, Griendling K, and Munzel T. Effects of angiotensin II infusion on the expression and function of $\mathrm{NAD}(\mathrm{P}) \mathrm{H}$ oxidase and components of nitric oxide/cGMP signaling. Circ Res 90: E58-E65, 2002.

215. Mora S, Lee IM, Buring JE, and Ridker PM. Association of physical activity and body mass index with novel and traditional cardiovascular biomarkers in women. JAMA 295: 1412-1419, 2006.

216. Murphy MP and Smith RA. Targeting antioxidants to mitochondria by conjugation to lipophilic cations. Annu Rev Pharmacol Toxicol 47: 629-656, 2007.

217. Murray AJ, Anderson RE, Watson GC, Radda GK, and Clarke K. Uncoupling proteins in human heart. Lancet 364: 1786-1788, 2004.

218. Muscari C, Caldarera CM, and Guarnieri C. Age-dependent production of mitochondrial hydrogen peroxide, lipid peroxides and fluorescent pigments in the rat heart. Basic Res Cardiol 85: 172-178, 1990.

219. Muster AJ, Kim H, Kane B, and McPherson DD. Ten-year echo/doppler determination of the benefits of aerobic exercise after the age of 65 years. Echocardiography 27: 5-10, 2010.

220. Muthusamy VR, Kannan S, Sadhaasivam K, Gounder SS, Davidson CJ, Boeheme C, Hoidal JR, Wang L, and Soorappan RN. Acute exercise stress activates Nrf2/ARE signaling and promotes antioxidant mechanisms in the myocardium. Free Radic Biol Med, 52: 366-376, 2012.

221. Nadal-Ginard B, Kajstura J, Leri A, and Anversa P. Myocyte death, growth, and regeneration in cardiac hypertrophy and failure. Circ Res 92: 139-150, 2003.

222. Nakada K, Inoue K, Ono T, Isobe K, Ogura A, Goto YI, Nonaka I, and Hayashi JI. Inter-mitochondrial complementation: mitochondria-specific system preventing mice from expression of disease phenotypes by mutant mtDNA. Nat Med 7: 934-940, 2001.

223. Nakada K, Sato A, and Hayashi J. Mitochondrial functional complementation in mitochondrial DNA-based diseases. Int J Biochem Cell Biol 41: 1907-1913, 2009.

224. Nakae I, Mitsunami K, Omura T, Yabe T, Tsutamoto T, Matsuo S, Takahashi M, Morikawa S, Inubushi T, Nakamura Y, Kinoshita M, and Horie M. Proton magnetic resonance spectroscopy can detect creatine depletion associated with the progression of heart failure in cardiomyopathy. J Am Coll Cardiol 42: 1587-1593, 2003.

225. Nakai A, Yamaguchi O, Takeda T, Higuchi Y, Hikoso S, Taniike M, Omiya S, Mizote I, Matsumura Y, Asahi M, Nishida K, Hori M, Mizushima N, and Otsu K. The role of autophagy in cardiomyocytes in the basal state and in response to hemodynamic stress. Nat Med 13: 619-624, 2007.

226. Nakayama $H$, Chen $X$, Baines $C P$, Klevitsky R, Zhang $X$, Zhang H, Jaleel N, Chua BH, Hewett TE, Robbins J, Houser SR, and Molkentin JD. Ca2+- and mitochondrial-dependent cardiomyocyte necrosis as a primary mediator of heart failure. J Clin Invest 117: 2431-2444, 2007. 
227. Nassimiha D, Aronow WS, Ahn C, and Goldman ME. Association of coronary risk factors with progression of valvular aortic stenosis in older persons. Am J Cardiol 87: 1313-1314, 2001

228. Navarro A and Boveris A. The mitochondrial energy transduction system and the aging process. Am J Physiol Cell Physiol 292: C670-C686, 2007.

229. Neubauer S, Horn M, Cramer M, Harre K, Newell JB, Peters W, Pabst T, Ertl G, Hahn D, Ingwall JS, and Kochsiek K. Myocardial phosphocreatine-to-ATP ratio is a predictor of mortality in patients with dilated cardiomyopathy. Circulation 96: 2190-2196, 1997.

230. Niemann B, Chen $Y$, Issa H, Silber RE, and Rohrbach S. Caloric restriction delays cardiac ageing in rats: role of mitochondria. Cardiovasc Res 88: 267-276, 2010.

231. Niemann B, Chen Y, Teschner M, Li L, Silber RE, and Rohrbach S. Obesity induces signs of premature cardiac aging in younger patients: the role of mitochondria. J Am Coll Cardiol 57: 577-585, 2011.

232. Nitta Y, Abe K, Aoki M, Ohno I, and Isoyama S. Diminished heat shock protein $70 \mathrm{mRNA}$ induction in aged rat hearts after ischemia. Am J Physiol 267: H1795-H1803, 1994.

233. O'Malley Y, Fink BD, Ross NC, Prisinzano TE, and Sivitz WI. Reactive oxygen and targeted antioxidant administration in endothelial cell mitochondria. J Biol Chem 281: 39766-39775, 2006.

234. O'Rourke B, Kass DA, Tomaselli GF, Kaab S, Tunin R, and Marban E. Mechanisms of altered excitation-contraction coupling in canine tachycardia-induced heart failure, I: experimental studies. Circ Res 84: 562-570, 1999.

235. O'Rourke MF and Hashimoto J. Mechanical factors in arterial aging: a clinical perspective. J Am Coll Cardiol 50: 113, 2007.

236. Ocorr K, Akasaka T, and Bodmer R. Age-related cardiac disease model of Drosophila. Mech Ageing Dev 128: 112116, 2007.

237. Ocorr K, Reeves NL, Wessells RJ, Fink M, Chen HS, Akasaka T, Yasuda S, Metzger JM, Giles W, Posakony JW, and Bodmer R. KCNQ potassium channel mutations cause cardiac arrhythmias in Drosophila that mimic the effects of aging. Proc Natl Acad Sci U S A 104: 3943-3948, 2007.

238. Oh H, Taffet GE, Youker KA, Entman ML, Overbeek PA, Michael LH, and Schneider MD. Telomerase reverse transcriptase promotes cardiac muscle cell proliferation, hypertrophy, and survival. Proc Natl Acad Sci U S A 98: 10308-10313, 2001.

239. Oka T and Komuro I. Molecular mechanisms underlying the transition of cardiac hypertrophy to heart failure. Circulation J Supp A: A13-A16, 2008.

240. Okumura S, Takagi G, Kawabe J, Yang G, Lee MC, Hong C, Liu J, Vatner DE, Sadoshima J, Vatner SF, and Ishikawa Y. Disruption of type 5 adenylyl cyclase gene preserves cardiac function against pressure overload. Proc Natl Acad Sci U S A 100: 9986-9990, 2003.

241. Okumura S, Vatner DE, Kurotani R, Bai Y, Gao S, Yuan Z, Iwatsubo K, Ulucan C, Kawabe J, Ghosh K, Vatner SF, and Ishikawa Y. Disruption of type 5 adenylyl cyclase enhances desensitization of cyclic adenosine monophosphate signal and increases Akt signal with chronic catecholamine stress. Circulation 116: 1776-1783, 2007.

242. Olsen MH, Wachtell K, Bella JN, Gerdts E, Palmieri V, Nieminen MS, Smith G, Ibsen H, and Devereux RB. Aortic valve sclerosis relates to cardiovascular events in patients with hypertension (a LIFE substudy). Am J Cardiol 95: 132136, 2005.

243. Orallo F, Alvarez E, Camina M, Leiro JM, Gomez E, and Fernandez P. The possible implication of trans-Resveratrol in the cardioprotective effects of long-term moderate wine consumption. Mol Pharmacol 61: 294-302, 2002.

244. Oshiro N, Yoshino K, Hidayat S, Tokunaga C, Hara K, Eguchi S, Avruch J, and Yonezawa K. Dissociation of raptor from mTOR is a mechanism of rapamycin-induced inhibition of mTOR function. Genes Cells 9: 359-366, 2004

245. Otto CM. Why is aortic sclerosis associated with adverse clinical outcomes? I Am Coll Cardiol 43: 176-178, 2004.

246. Otto CM, Lind BK, Kitzman DW, Gersh BJ, and Siscovick DS. Association of aortic-valve sclerosis with cardiovascular mortality and morbidity in the elderly. N Engl J Med 341: 142-147, 1999.

247. Paddenberg $R$, Stieger $P$, von Lilien AL, Faulhammer $P$, Goldenberg A, Tillmanns HH, Kummer W, and BraunDullaeus RC. Rapamycin attenuates hypoxia-induced pulmonary vascular remodeling and right ventricular hypertrophy in mice. Respir Res 8: 15, 2007.

248. Palacios OM, Carmona JJ, Michan S, Chen KY, Manabe Y, Ward JL, 3rd, Goodyear LJ, and Tong Q. Diet and exercise signals regulate SIRT3 and activate AMPK and PGC-1alpha in skeletal muscle. Aging (Albany NY) 1: 771-783, 2009.

249. Panagiotakos DB, Pitsavos C, Chrysohoou C, Skoumas J, Tousoulis D, Toutouza M, Toutouzas P, and Stefanadis C. Impact of lifestyle habits on the prevalence of the metabolic syndrome among Greek adults from the ATTICA study. Am Heart J 147: 106-112, 2004.

250. Parkes TL, Elia AJ, Dickinson D, Hilliker AJ, Phillips JP, and Boulianne GL. Extension of Drosophila lifespan by overexpression of human SOD1 in motorneurons. Nat Genet 19: 171-174, 1998.

251. Patel KR, Brown VA, Jones DJ, Britton RG, Hemingway D, Miller AS, West KP, Booth TD, Perloff M, Crowell JA, Brenner DE, Steward WP, Gescher AJ, and Brown K. Clinical pharmacology of resveratrol and its metabolites in colorectal cancer patients. Cancer Res 70: 7392-7399, 2010.

252. Patel KR, Scott E, Brown VA, Gescher AJ, Steward WP, and Brown K. Clinical trials of resveratrol. Ann N Y Acad Sci 1215: 161-169, 2011.

253. Perez VI, Van Remmen H, Bokov A, Epstein CJ, Vijg J, and Richardson A. The overexpression of major antioxidant enzymes does not extend the lifespan of mice. Aging Cell 8: 73-75, 2009.

254. Petri S, Kiaei M, Damiano M, Hiller A, Wille E, Manfredi G, Calingasan NY, Szeto HH, and Beal MF. Cell-permeable peptide antioxidants as a novel therapeutic approach in a mouse model of amyotrophic lateral sclerosis. J Neurochem 98: 1141-1148, 2006.

255. Pillai VB, Sundaresan NR, Kim G, Gupta M, Rajamohan SB, Pillai JB, Samant S, Ravindra PV, Isbatan A, and Gupta MP. Exogenous NAD blocks cardiac hypertrophic response via activation of the SIRT3-LKB1-AMP-activated kinase pathway. J Biol Chem 285: 3133-3144, 2010.

256. Piot C, Croisille P, Staat P, Thibault H, Rioufol G, Mewton N, Elbelghiti R, Cung TT, Bonnefoy E, Angoulvant D, Macia C, Raczka F, Sportouch C, Gahide G, Finet G, Andre-Fouet X, Revel D, Kirkorian G, Monassier JP, Derumeaux G, and Ovize M. Effect of cyclosporine on reperfusion injury in acute myocardial infarction. N Engl J Med 359: 473-481, 2008.

257. Plecita-Hlavata L, Jezek J, and Jezek P. Pro-oxidant mitochondrial matrix-targeted ubiquinone MitoQ10 acts as 
anti-oxidant at retarded electron transport or proton pumping within Complex I. Int J Biochem Cell Biol 41: 16971707, 2009.

258. Poderoso JJ, Carreras MC, Lisdero C, Riobo N, Schopfer F, and Boveris A. Nitric oxide inhibits electron transfer and increases superoxide radical production in rat heart mitochondria and submitochondrial particles. Arch Biochem Biophys 328: 85-92, 1996.

259. Polak JF, Pencina MJ, Pencina KM, O’Donnell CJ, Wolf PA, and D'Agostino RB, Sr. Carotid-wall intima-media thickness and cardiovascular events. N Engl J Med 365: 213-221, 2011.

260. Puigserver P, Rhee J, Donovan J, Walkey CJ, Yoon JC, Oriente F, Kitamura Y, Altomonte J, Dong H, Accili D, and Spiegelman BM. Insulin-regulated hepatic gluconeogenesis through FOXO1-PGC-1alpha interaction. Nature 423: 550555, 2003.

261. Rabinowitz M and Zak R. Mitochondria and cardiac hypertrophy. Circ Res 36: 367-376, 1975.

262. Radi R, Cassina A, Hodara R, Quijano C, and Castro L. Peroxynitrite reactions and formation in mitochondria. Free Radic Biol Med 33: 1451-1464, 2002.

263. Ravikumar B, Vacher C, Berger Z, Davies JE, Luo S, Oroz LG, Scaravilli F, Easton DF, Duden R, O'Kane CJ, and Rubinsztein DC. Inhibition of mTOR induces autophagy and reduces toxicity of polyglutamine expansions in fly and mouse models of Huntington disease. Nat Genet 36: 585-595, 2004.

264. Rebrin I, Kamzalov S, and Sohal RS. Effects of age and caloric restriction on glutathione redox state in mice. Free Radic Biol Med 35: 626-635, 2003.

265. Rebrin I and Sohal RS. Comparison of thiol redox state of mitochondria and homogenates of various tissues between two strains of mice with different longevities. Exp Gerontol 39: 1513-1519, 2004.

266. Redfield MM, Rodeheffer RJ, Jacobsen SJ, Mahoney DW, Bailey KR, and Burnett JC, Jr. Plasma brain natriuretic peptide concentration: impact of age and gender. J Am Coll Cardiol 40: 976-982, 2002.

267. Remondino A, Kwon SH, Communal C, Pimentel DR, Sawyer DB, Singh K, and Colucci WS. Beta-adrenergic receptor-stimulated apoptosis in cardiac myocytes is mediated by reactive oxygen species/c-Jun NH2-terminal kinase-dependent activation of the mitochondrial pathway. Circ Res 92: 136-138, 2003.

268. Reznick RM, Zong H, Li J, Morino K, Moore IK, Yu HJ, Liu ZX, Dong J, Mustard KJ, Hawley SA, Befroy D, Pypaert M, Hardie DG, Young LH, and Shulman GI. Aging-associated reductions in AMP-activated protein kinase activity and mitochondrial biogenesis. Cell Metab 5: 151-156, 2007.

269. Riordan MM, Weiss EP, Meyer TE, Ehsani AA, Racette SB, Villareal DT, Fontana L, Holloszy JO, and Kovacs SJ. The effects of caloric restriction- and exercise-induced weight loss on left ventricular diastolic function. Am J Physiol Heart Circ Physiol 294: H1174- H1182, 2008.

270. Ristow $M$ and Zarse K. How increased oxidative stress promotes longevity and metabolic health: the concept of mitochondrial hormesis (mitohormesis). Exp Gerontol 45: 410-418, 2010.

271. Ristow M, Zarse K, Oberbach A, Kloting N, Birringer M, Kiehntopf M, Stumvoll M, Kahn CR, and Bluher M. Antioxidants prevent health-promoting effects of physical exercise in humans. Proc Natl Acad Sci U S A 106: 8665-8670, 2009.

272. Rodrigo R, Miranda A, and Vergara L. Modulation of endogenous antioxidant system by wine polyphenols in human disease. Clin Chim Acta 412: 410-424, 2011.
273. Roger VL, Go AS, Lloyd-Jones DM, Adams RJ, Berry JD, Brown TM, Carnethon MR, Dai S, de Simone G, Ford ES, Fox CS, Fullerton HJ, Gillespie C, Greenlund KJ, Hailpern SM, Heit JA, Michael Ho P, Howard VJ, Kissela BM, Kittner SJ, Lackland DT, Lichtman JH, Lisabeth LD, Makuc DM, Marcus GM, Marelli A, Matchar DB, McDermott MM, Meigs JB, Moy CS, Mozaffarian D, Mussolino ME, Nichol G, Paynter NP, Rosamond WD, Sorlie PD, Stafford RS, Turan TN, Turner MB, Wong ND, and Wylie-Rosett J. Executive Summary: Heart Disease and Stroke Statistics2011 Update: A Report From the American Heart Association. Circulation 123: 459-463, 2011.

274. Rohde LE, Ducharme A, Arroyo LH, Aikawa M, Sukhova GH, Lopez-Anaya A, McClure KF, Mitchell PG, Libby P, and Lee RT. Matrix metalloproteinase inhibition attenuates early left ventricular enlargement after experimental myocardial infarction in mice. Circulation 99: 3063-3070, 1999.

275. Rohrbach S, Niemann B, Abushouk AM, and Holtz J. Caloric restriction and mitochondrial function in the ageing myocardium. Exp Gerontol 41: 525-531, 2006.

276. Ronnebaum SM and Patterson C. The FoxO family in cardiac function and dysfunction. Annu Rev Physiol 72: 81-94, 2010.

277. Rossignol R, Malgat M, Mazat JP, and Letellier T. Threshold effect and tissue specificity. Implication for mitochondrial cytopathies. J Biol Chem 274: 33426-33432, 1999.

278. Rota M, LeCapitaine N, Hosoda T, Boni A, De Angelis A, Padin-Iruegas ME, Esposito G, Vitale S, Urbanek K, Casarsa C, Giorgio M, Luscher TF, Pelicci PG, Anversa P, Leri A, and Kajstura J. Diabetes promotes cardiac stem cell aging and heart failure, which are prevented by deletion of the p66shc gene. Circ Res 99: 42-52, 2006.

279. Roth GS, Mattison JA, Ottinger MA, Chachich ME, Lane $\mathrm{MA}$, and Ingram DK. Aging in rhesus monkeys: relevance to human health interventions. Science 305: 1423-1426, 2004.

280. Rudolph KL, Chang S, Lee HW, Blasco M, Gottlieb GJ, Greider C, and DePinho RA. Longevity, stress response, and cancer in aging telomerase-deficient mice. Cell 96: 701712, 1999.

281. Sachs HG, Colgan JA, and Lazarus ML. Ultrastructure of the aging myocardium: a morphometric approach. Am J Anat 150: 63-71, 1977.

282. Sadoshima J, Qiu Z, Morgan JP, and Izumo S. Angiotensin II and other hypertrophic stimuli mediated by $G$ proteincoupled receptors activate tyrosine kinase, mitogen-activated protein kinase, and 90-kD S6 kinase in cardiac myocytes. The critical role of $\mathrm{Ca}(2+)$-dependent signaling. Circ Res 76: 1-15, 1995.

283. Safdar A, Bourgeois JM, Ogborn DI, Little JP, Hettinga BP, Akhtar M, Thompson JE, Melov S, Mocellin NJ, Kujoth GC, Prolla TA, and Tarnopolsky MA. Endurance exercise rescues progeroid aging and induces systemic mitochondrial rejuvenation in mtDNA mutator mice. Proc Natl Acad Sci U $S$ A, 2011.

284. Sangaralingham SJ, Huntley BK, Martin FL, McKie PM, Bellavia D, Ichiki T, Harders GE, Chen HH, and Burnett JC, Jr. The aging heart, myocardial fibrosis, and its relationship to circulating C-type natriuretic Peptide. Hypertension 57: 201-207, 2011.

285. Sauve AA, Cahill SM, Zech SG, Basso LA, Lewandowicz A, Santos DS, Grubmeyer C, Evans GB, Furneaux RH, Tyler PC, McDermott A, Girvin ME, and Schramm VL. Ionic states of substrates and transition state analogues at the catalytic sites of N-ribosyltransferases. Biochemistry 42: 5694-5705, 2003. 
286. Sauve AA, Celic I, Avalos J, Deng H, Boeke JD, and Schramm VL. Chemistry of gene silencing: the mechanism of NAD+-dependent deacetylation reactions. Biochemistry 40: 15456-15463, 2001.

287. Sauve AA and Schramm VL. Sir2 regulation by nicotinamide results from switching between base exchange and deacetylation chemistry. Biochemistry 42: 9249-9256, 2003.

288. Scatena R, Bottoni P, Botta G, Martorana GE, and Giardina $B$. The role of mitochondria in pharmacotoxicology: a reevaluation of an old, newly emerging topic. Am J Physiol Cell Physiol 293: C12-C21, 2007.

289. Schriner SE, Linford NJ, Martin GM, Treuting P, Ogburn CE, Emond M, Coskun PE, Ladiges W, Wolf N, Van Remmen H, Wallace DC, and Rabinovitch PS. Extension of murine life span by overexpression of catalase targeted to mitochondria. Science 308: 1909-1911, 2005.

290. Schulz TJ, Zarse K, Voigt A, Urban N, Birringer M, and Ristow M. Glucose restriction extends Caenorhabditis elegans life span by inducing mitochondrial respiration and increasing oxidative stress. Cell Metab 6: 280-293, 2007.

291. Seymour EM, Parikh RV, Singer AA, and Bolling SF. Moderate calorie restriction improves cardiac remodeling and diastolic dysfunction in the Dahl-SS rat. J Mol Cell Cardiol 41: 661-668, 2006.

292. Shinmura K. Cardiovascular protection afforded by caloric restriction: essential role of nitric oxide synthase. Geriatr Gerontol Int 11: 143-156, 2011.

293. Shinmura K, Tamaki K, and Bolli R. Impact of 6-mo caloric restriction on myocardial ischemic tolerance: possible involvement of nitric oxide-dependent increase in nuclear Sirt1. Am J Physiol Heart Circ Physiol 295: H2348- H2355, 2008.

294. Shinmura K, Tamaki K, Sano M, Murata M, Yamakawa H, Ishida $\mathrm{H}$, and Fukuda K. Impact of long-term caloric restriction on cardiac senescence: caloric restriction ameliorates cardiac diastolic dysfunction associated with aging. $J$ Mol Cell Cardiol 50: 117-127, 2011.

295. Shioi T, McMullen JR, Tarnavski O, Converso K, Sherwood MC, Manning WJ, and Izumo S. Rapamycin attenuates load-induced cardiac hypertrophy in mice. Circulation 107: 1664-1670, 2003.

296. Shiojima I, Sato K, Izumiya Y, Schiekofer S, Ito M, Liao R, Colucci WS, Walsh K. Disruption of coordinated cardiac hypertrophy and angiogenesis contributes to the transition to heart failure. J Clin Invest 115: 2108-2118, 2005.

297. Shono M, Yoshimura M, Nakayama M, Yamamuro M, Abe K, Suzuki S, Mizuno Y, Sugiyama S, Saito Y, Nakao K, Yasue $\mathrm{H}$, and Ogawa $\mathrm{H}$. Predominant effect of A-type natriuretic peptide on reduction of oxidative stress during the treatment of patients with heart failure. Circ J 71: 1040-1046, 2007.

298. Skulachev VP, Anisimov VN, Antonenko YN, Bakeeva LE, Chernyak BV, Erichev VP, Filenko OF, Kalinina NI, Kapelko VI, Kolosova NG, Kopnin BP, Korshunova GA, Lichinitser MR, Obukhova LA, Pasyukova EG, Pisarenko OI, Roginsky VA, Ruuge EK, Senin, II, Severina, II, Skulachev MV, Spivak IM, Tashlitsky VN, Tkachuk VA, Vyssokikh MY, Yaguzhinsky LS, and Zorov DB. An attempt to prevent senescence: a mitochondrial approach. Biochim Biophys Acta 1787: 437-461, 2009.

299. Snow BJ, Rolfe FL, Lockhart MM, Frampton CM, O'Sullivan JD, Fung V, Smith RA, Murphy MP, and Taylor KM. A double-blind, placebo-controlled study to assess the mitochondria-targeted antioxidant MitoQ as a diseasemodifying therapy in Parkinson's disease. Mov Disord 25: 1670-1674, 2010.
300. Sohal RS and Sohal BH. Hydrogen peroxide release by mitochondria increases during aging. Mech Ageing Dev 57: 187-202, 1991.

301. Spinale FG. Myocardial matrix remodeling and the matrix metalloproteinases: influence on cardiac form and function. Physiol Rev 87: 1285-1342, 2007.

302. St-Pierre J, Drori S, Uldry M, Silvaggi JM, Rhee J, Jager S, Handschin C, Zheng K, Lin J, Yang W, Simon DK, Bachoo $\mathrm{R}$, and Spiegelman BM. Suppression of reactive oxygen species and neurodegeneration by the PGC-1 transcriptional coactivators. Cell 127: 397-408, 2006.

303. Stahl M, Dijkers PF, Kops GJ, Lens SM, Coffer PJ, Burgering $\mathrm{BM}$, and Medema RH. The forkhead transcription factor FoxO regulates transcription of p27Kip1 and Bim in response to IL-2. J Immunol 168: 5024-5031, 2002.

304. Stein M, Boulaksil M, Jansen JA, Herold E, Noorman M, Joles JA, van Veen TA, Houtman MJ, Engelen MA, Hauer $\mathrm{RN}$, de Bakker JM, and van Rijen HV. Reduction of fibrosisrelated arrhythmias by chronic renin-angiotensin-aldosterone system inhibitors in an aged mouse model. Am J Physiol Heart Circ Physiol 299: H310- H321, 2010.

305. Steinhubl SR. Why have antioxidants failed in clinical trials? Am J Cardiol 101: 14D-19D, 2008.

306. Stewart BF, Siscovick D, Lind BK, Gardin JM, Gottdiener JS, Smith VE, Kitzman DW, and Otto CM. Clinical factors associated with calcific aortic valve disease. Cardiovascular health study. J Am Coll Cardiol 29: 630-634, 1997.

307. Sulaiman M, Matta MJ, Sunderesan NR, Gupta MP, Periasamy M, and Gupta M. Resveratrol, an activator of SIRT1, upregulates sarcoplasmic calcium ATPase and improves cardiac function in diabetic cardiomyopathy. Am J Physiol Heart Circ Physiol 298: H833- H843, 2010.

308. Sundaresan NR, Gupta M, Kim G, Rajamohan SB, Isbatan A, and Gupta MP. Sirt3 blocks the cardiac hypertrophic response by augmenting Foxo3a-dependent antioxidant defense mechanisms in mice. J Clin Invest 119: 2758-2771, 2009.

309. Supinski GS, Murphy MP, and Callahan LA. MitoQ administration prevents endotoxin-induced cardiac dysfunction. Am J Physiol Regul Integr Comp Physiol 297: R1095R1102, 2009.

310. Szeto HH. Development of mitochondria-targeted aromatic-cationic peptides for neurodegenerative diseases. Ann N Y Acad Sci 1147: 112-121, 2008.

311. Szeto HH. Mitochondria-targeted cytoprotective peptides for ischemia-reperfusion injury. Antioxid Redox Signal 10: 601-619, 2008.

312. Szeto HH, Schiller PW, Zhao K, and Luo G. Fluorescent dyes alter intracellular targeting and function of cell-penetrating tetrapeptides. FASEB J 19: 118-120, 2005.

313. Taffet GE, Pham TT, and Hartley CJ. The age-associated alterations in late diastolic function in mice are improved by caloric restriction. J Gerontol A Biol Sci Med Sci 52: B285B290, 1997.

314. Taghli-Lamallem O, Akasaka T, Hogg G, Nudel U, Yaffe D, Chamberlain JS, Ocorr K, and Bodmer R. Dystrophin deficiency in Drosophila reduces lifespan and causes a dilated cardiomyopathy phenotype. Aging Cell 7: 237-249, 2008.

315. Takemoto KA, Bernstein L, Lopez JF, Marshak D, Rahimtoola SH, and Chandraratna PA. Abnormalities of diastolic filling of the left ventricle associated with aging are less pronounced in exercise-trained individuals. Am Heart $J$ 124: 143-148, 1992.

316. Tani M, Honma Y, Hasegawa H, and Tamaki K. Direct activation of mitochondrial $\mathrm{K}(\mathrm{ATP})$ channels mimics 
preconditioning but protein kinase $C$ activation is less effective in middle-aged rat hearts. Cardiovasc Res 49: 56-68, 2001.

317. Tatar M, Kopelman A, Epstein D, Tu MP, Yin CM, and Garofalo RS. A mutant Drosophila insulin receptor homo$\log$ that extends life-span and impairs neuroendocrine function. Science 292: 107-110, 2001.

318. Terman A and Brunk UT. The aging myocardium: roles of mitochondrial damage and lysosomal degradation. Heart Lung Circ 14: 107-114, 2005.

319. Terman A, Gustafsson B, and Brunk UT. The lysosomalmitochondrial axis theory of postmitotic aging and cell death. Chem Biol Interact 163: 29-37, 2006.

320. Terman A, Gustafsson B, and Brunk UT. Autophagy, organelles and ageing. J Pathol 211: 134-143, 2007.

321. Terman A, Kurz T, Gustafsson B, and Brunk UT. The involvement of lysosomes in myocardial aging and disease. Curr Cardiol Rev 4: 107-115, 2008.

322. Terman A, Kurz T, Navratil M, Arriaga EA, and Brunk UT. Mitochondrial turnover and aging of long-lived postmitotic cells: the mitochondrial-lysosomal axis theory of aging. Antioxid Redox Signal 12: 503-535, 2010.

323. Terzioglu M and Larsson NG. Mitochondrial dysfunction in mammalian ageing. Novartis Found Symp 287: 197-208; discussion 208-213, 2007.

324. Trifunovic A and Larsson NG. Mitochondrial dysfunction as a cause of ageing. J Intern Med 263: 167-178, 2008.

325. Trifunovic A, Wredenberg A, Falkenberg M, Spelbrink JN, Rovio AT, Bruder CE, Bohlooly YM, Gidlof S, Oldfors A, Wibom R, Tornell J, Jacobs HT, and Larsson NG. Premature ageing in mice expressing defective mitochondrial DNA polymerase. Nature 429: 417-423, 2004.

326. Twig G, Elorza A, Molina AJ, Mohamed H, Wikstrom JD, Walzer G, Stiles L, Haigh SE, Katz S, Las G, Alroy J, Wu M, Py BF, Yuan J, Deeney JT, Corkey BE, and Shirihai OS. Fission and selective fusion govern mitochondrial segregation and elimination by autophagy. EMBO J 27: 433-446, 2008.

327. Umpierre D, Ribeiro PA, Kramer CK, Leitao CB, Zucatti AT, Azevedo MJ, Gross JL, Ribeiro JP, and Schaan BD. Physical activity advice only or structured exercise training and association with $\mathrm{HbA} 1 \mathrm{c}$ levels in type 2 diabetes: a systematic review and meta-analysis. JAMA 305: 17901799, 2011.

328. van Empel VP, Bertrand AT, van Oort RJ, van der Nagel R, Engelen M, van Rijen HV, Doevendans PA, Crijns HJ, Ackerman SL, Sluiter W, and De Windt LJ. EUK-8, a superoxide dismutase and catalase mimetic, reduces cardiac oxidative stress and ameliorates pressure overload-induced heart failure in the harlequin mouse mutant. J Am Coll Cardiol 48: 824-832, 2006.

329. Van Raamsdonk JM and Hekimi S. Deletion of the mitochondrial superoxide dismutase sod-2 extends lifespan in Caenorhabditis elegans. PLoS Genet 5: e1000361, 2009.

330. Varady KA and Hellerstein MK. Alternate-day fasting and chronic disease prevention: a review of human and animal trials. Am J Clin Nutr 86: 7-13, 2007.

331. Vasan RS, Demissie S, Kimura M, Cupples LA, Rifai N, White C, Wang TJ, Gardner JP, Cao X, Benjamin EJ, Levy D, and Aviv A. Association of Leukocyte Telomere Length With Circulating Biomarkers of the Renin-AngiotensinAldosterone System. The Framingham Heart Study. Circulation 117:1138-1144, 2008.

332. Vasan RS, Sullivan LM, D'Agostino RB, Roubenoff $R$, Harris T, Sawyer DB, Levy D, and Wilson PW. Serum insulin-like growth factor I and risk for heart failure in elderly individuals without a previous myocardial infarction: the Framingham Heart Study. Ann Intern Med 139: 642-648, 2003.

333. Ventura-Clapier R, Garnier A, and Veksler V. Transcriptional control of mitochondrial biogenesis: the central role of PGC-1alpha. Cardiovasc Res 79: 208-217, 2008.

334. Vergeade A, Mulder P, Vendeville-Dehaudt C, Estour F, Fortin D, Ventura-Clapier R, Thuillez C, and Monteil C. Mitochondrial impairment contributes to cocaine-induced cardiac dysfunction: prevention by the targeted antioxidant MitoQ. Free Radic Biol Med 49: 748-756, 2010.

335. Vermulst M, Wanagat J, Kujoth GC, Bielas JH, Rabinovitch PS, Prolla TA, and Loeb LA. DNA deletions and clonal mutations drive premature aging in mitochondrial mutator mice. Nat Genet 40: 392-394, 2008.

336. Vivekananthan DP, Penn MS, Sapp SK, Hsu A, and Topol EJ. Use of antioxidant vitamins for the prevention of cardiovascular disease: meta-analysis of randomised trials. Lancet 361: 2017-2023, 2003.

337. Wadden TA, Berkowitz RI, Womble LG, Sarwer DB, Phelan S, Cato RK, Hesson LA, Osei SY, Kaplan R, and Stunkard AJ. Randomized trial of lifestyle modification and pharmacotherapy for obesity. N Engl J Med 353: 2111-2120, 2005.

338. Wanagat J, Cao Z, Pathare P, and Aiken JM. Mitochondrial DNA deletion mutations colocalize with segmental electron transport system abnormalities, muscle fiber atrophy, fiber splitting, and oxidative damage in sarcopenia. FASEB J 15: 322-332, 2001.

339. Wang Z, Huang Y, Zou J, Cao K, Xu Y, and Wu JM. Effects of red wine and wine polyphenol resveratrol on platelet aggregation in vivo and in vitro. Int J Mol Med 9: 77-79, 2002.

340. Wang Z, Zou J, Cao K, Hsieh TC, Huang Y, and Wu JM. Dealcoholized red wine containing known amounts of resveratrol suppresses atherosclerosis in hypercholesterolemic rabbits without affecting plasma lipid levels. Int $J$ Mol Med 16: 533-540, 2005.

341. Weiss RG, Gerstenblith G, and Bottomley PA. ATP flux through creatine kinase in the normal, stressed, and failing human heart. Proc Natl Acad Sci U S A 102: 808-813, 2005.

342. Wen CP, Wai JP, Tsai MK, Yang YC, Cheng TY, Lee MC, Chan HT, Tsao CK, Tsai SP, and Wu X. Minimum amount of physical activity for reduced mortality and extended life expectancy: a prospective cohort study. Lancet 378: 12441253, 2011.

343. Wencker D, Chandra M, Nguyen K, Miao W, Garantziotis S, Factor SM, Shirani J, Armstrong RC, and Kitsis RN. A mechanistic role for cardiac myocyte apoptosis in heart failure. J Clin Invest 111: 1497-1504, 2003.

344. Wessells R, Hayes M, and Bodmer R. Cardiac functional decline with age is dependent upon regulation of 4EBP activity in the myocardium. A Dros Res Conf 48: 882C, 2007.

345. Wessells RJ, Fitzgerald E, Cypser JR, Tatar M, and Bodmer $\mathrm{R}$. Insulin regulation of heart function in aging fruit flies. Nat Genet 36: 1275-1281, 2004.

346. Whiteman M, Spencer JP, Szeto HH, and Armstrong JS. Do mitochondriotropic antioxidants prevent chlorinative stress-induced mitochondrial and cellular injury? Antioxid Redox Signal 10: 641-650, 2008.

347. Wohlgemuth SE, Julian D, Akin DE, Fried J, Toscano K, Leeuwenburgh C, and Dunn WA, Jr. Autophagy in the heart and liver during normal aging and calorie restriction. Rejuvenation Res 10: 281-292, 2007.

348. Wolf MJ, Amrein H, Izatt JA, Choma MA, Reedy MC, and Rockman HA. Drosophila as a model for the identification 
of genes causing adult human heart disease. Proc Natl Acad Sci U S A 103: 1394-1399, 2006.

349. Wood JG, Rogina B, Lavu S, Howitz K, Helfand SL, Tatar M, and Sinclair D. Sirtuin activators mimic caloric restriction and delay ageing in metazoans. Nature 430: 686-689, 2004.

350. Wu D, Soong Y, Zhao GM, and Szeto HH. A highly potent peptide analgesic that protects against ischemia-reperfusioninduced myocardial stunning. Am J Physiol Heart Circ Physiol 283: H783-H791, 2002.

351. Yan L, Vatner DE, O'Connor JP, Ivessa A, Ge H, Chen W, Hirotani S, Ishikawa Y, Sadoshima J, and Vatner SF. Type 5 adenylyl cyclase disruption increases longevity and protects against stress. Cell 130: 247-258, 2007.

352. Younes A, Boluyt MO, O'Neill L, Meredith AL, Crow MT, and Lakatta EG. Age-associated increase in rat ventricular ANP gene expression correlates with cardiac hypertrophy. Am J Physiol 269: H1003-H1008, 1995.

353. Zhang C, Bills M, Quigley A, Maxwell RJ, Linnane AW, and Nagley P. Varied prevalence of age-associated mitochondrial DNA deletions in different species and tissues: a comparison between human and rat. Biochem Biophys Res Commun 230: 630-635, 1997.

354. Zhang Y, Ikeno Y, Qi W, Chaudhuri A, Li Y, Bokov A, Thorpe SR, Baynes JW, Epstein C, Richardson A, and Van Remmen $\mathrm{H}$. Mice deficient in both $\mathrm{Mn}$ superoxide dismutase and glutathione peroxidase-1 have increased oxidative damage and a greater incidence of pathology but no reduction in longevity. J Gerontol A Biol Sci Med Sci: 1-9, 2009.

355. Zhao K, Luo G, Giannelli S, and Szeto HH. Mitochondriatargeted peptide prevents mitochondrial depolarization and apoptosis induced by tert-butyl hydroperoxide in neuronal cell lines. Biochem Pharmacol 70: 1796-1806, 2005.

356. Zhao K, Zhao GM, Wu D, Soong Y, Birk AV, Schiller PW, and Szeto HH. Cell-permeable peptide antioxidants targeted to inner mitochondrial membrane inhibit mitochondrial swelling, oxidative cell death, and reperfusion injury. J Biol Chem 279: 34682-34690, 2004.

357. Zhou B, Wu LJ, Li LH, Tashiro S, Onodera S, Uchiumi F, and Ikejima T. Silibinin protects against isoproterenol-induced rat cardiac myocyte injury through mitochondrial pathway after up-regulation of SIRT1. J Pharmacol Sci 102: 387-395, 2006.

358. Zhu H, Tannous $\mathrm{P}$, Johnstone JL, Kong $\mathrm{Y}$, Shelton JM, Richardson JA, Le V, Levine B, Rothermel BA, and Hill JA. Cardiac autophagy is a maladaptive response to hemodynamic stress. J Clin Invest 117: 1782-1793, 2007.

359. Zid BM, Rogers AN, Katewa SD, Vargas MA, Kolipinski MC, Lu TA, Benzer S, and Kapahi P. 4E-BP extends lifespan upon dietary restriction by enhancing mitochondrial activity in Drosophila. Cell 139: 149-160, 2009.

360. Zorov DB, Juhaszova M, and Sollott SJ. Mitochondrial ROS-induced ROS release: an update and review. Biochim Biophys Acta 1757: 509-517, 2006.

Address correspondence to: Prof. Peter S. Rabinovitch Department of Pathology University of Washington 1959 Pacific Ave. NE HSB-K081

Seattle, WA 98195

E-mail: petersr@u.washington.edu
Date of first submission to ARS Central, July 25, 2011; date of final revised submission, January 03, 2012; date of acceptance, January 04, 2012.

\section{Abbreviations Used}

AMPK = adenosine monophosphate-activated protein kinase

Ang $=$ angiotensin II

$\mathrm{ANP}=$ atrial natriuretic peptide

ATR1 $=$ angiotensin II receptor 1

$\mathrm{BNP}=$ brain natriuretic peptide

$\mathrm{CNP}=\mathrm{C}$-natriuretic peptide

$\mathrm{CVD}=$ cardiovascular diseases

$\mathrm{DR}=$ dietary restriction

$\mathrm{ECM}=$ extracellular matrix

$\mathrm{ETC}=$ electron transport chain

$\mathrm{FoxO}=$ forkhead box $\mathrm{O}$

$\mathrm{GPX}=$ glutathione peroxidase

$\mathrm{GR}=$ glutathione reductase

$\mathrm{GSH}=$ glutathione

HIF-1 = hypoxia inducible factor 1

$\mathrm{HDL}=$ high density lipoprotein

IGF $=$ insulin-like growth factor

$\mathrm{IMM}=$ inner mitochondrial membrane

$\mathrm{IR}=$ ischemia-reperfusion

$\mathrm{LDL}=$ low density lipoprotein

$\mathrm{LV}=$ left ventricular

$\mathrm{LVH}=$ left ventricular hypertrophy

$\mathrm{LVMI}=$ left ventricular mass index

$\mathrm{MAC}=$ mitral annular calcification

$\mathrm{mCAT}=$ catalase targeted to mitochondria

MitoQ $=$ ubiquinonyldecyl triphenylphosphonium

$\mathrm{MMP}=$ matrix metalloproteinase

MPI $=$ myocardial performance index

$\mathrm{mPTP}=$ mitochondrial permeability transition pore

$\mathrm{mTOR}=$ mammalian target of rapamycin

$\mathrm{NAC}=\mathrm{N}$-acetyl cysteine

$\mathrm{NADH}=$ nicotineamide adenine dinucleotide

$\mathrm{NADPH}=$ nicotineamide adenine dinucleotide phosphate

$\mathrm{NCHS}=$ National Center for Health Statistics

NHLBI $=$ National Heart Lung and Blood Institute

$\mathrm{NO}=$ nitric oxide

$\mathrm{NOX}=\mathrm{NADPH}$ oxidase

$\mathrm{OMM}=$ outer mitochondrial membrane

$\mathrm{pCAT}=$ peroxisomal catalase

PGC- $1 \alpha=$ peroxisome proliferator-activated receptor gamma coactivator-1 alpha

$\mathrm{PKC}=$ protein kinase $\mathrm{C}$

Polg $=$ mitochondrial polymerase gamma

RAAS $=$ renin angiotensin aldosterone system

ROS $=$ reactive oxygen species

SERCA2a $=$ sarcoplasmic reticulum calcium-ATPase

Sirt $=$ sirtuins

$\mathrm{SkQ}=$ plastoquinonyldecyl triphenylphosphonium

$\mathrm{SOD}=$ superoxide dismutase

$\mathrm{SS}=$ peptides szeto-schiller peptides

$\mathrm{TAC}=$ transverse aortic constriction

$\mathrm{TOR}=$ target of rapamycin

TORC $=$ target of rapamycin complex

TRX $=$ thioredoxin

$\mathrm{VEGF}=$ vascular endothelial growth factor 